$$
\begin{gathered}
\text { UnB - UNIVERSIDADE DE BRASÍLIA } \\
\text { FGA - FACULDADE GAMA } \\
\text { PROGRAMA DE PÓS-GRADUAÇÃO EM ENGENHARIA } \\
\text { BIOMÉDICA }
\end{gathered}
$$

\title{
GESTÃO DE TECNOLOGIAS EM SAÚDE \\ Desafios para o Engenheiro Biomédico
}

\author{
CLEBER DA SILVA ALVES
}

ORIENTADORA: Profa. Dra. LOURDES MATTOS BRASIL CO-ORIENTADORA: Profa. Dra. MARÍLIA M. FORTE GOMES

DISSERTAÇÃO DE MESTRADO EM ENGENHARIA BIOMÉDICA 


\section{UNIVERSIDADE DE BRASÍLIA \\ FACULDADE UNB GAMA \\ ENGENHARIA BIOMÉDICA}

\section{GESTÃO DE TECNOLOGIAS EM SAÚDE - DESAFIOS PARA O ENGENHEIRO BIOMÉDICO.}

\section{CLEBER DA SILVA ALVES}

DISSERTAÇÃO DE MESTRADO SUBMETIDA À FACULDADE UNB GAMA DA UNIVERSIDADE DE BRASÍLIA, COMO PARTE DOS REQUISITOS NECESSÁRIOS PARA A OBTENÇÃO DO TÍTULO DE MESTRE EM ENGENHARIA BIOMÉDICA.

APROVADA POR:
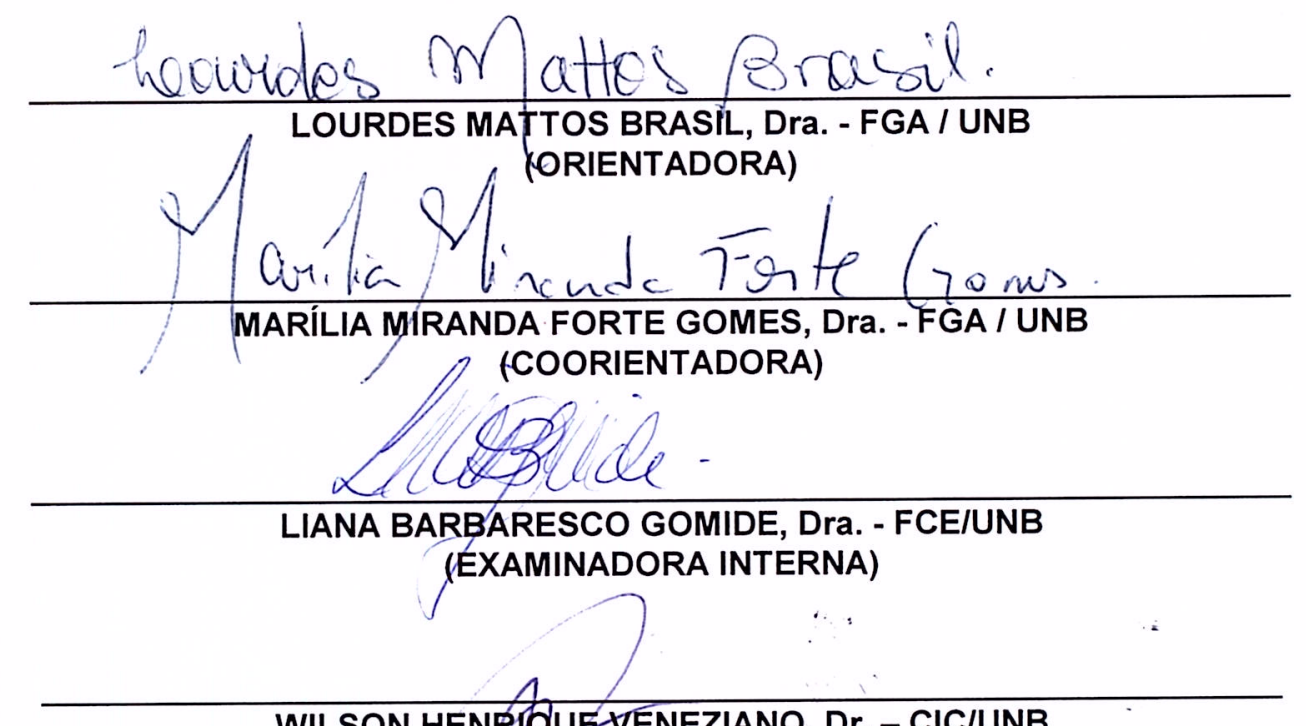

WILSON HENRIQUE VENEZIANO, Dr. - CIC/UNB

(EXAMINADOR EXTERNO)

BRASÍLIA, 06 DE JULHO DE 2015 
BRASÍLIA/DF, 06 DE JULHO DE 2015.

\section{FICHA CATALOGRÁFICA}

NOME Cleber da Silva Alves

Gestão de Tecnologias em Saúde: desafios para o engenheiro biomédico; Distrito Federal 2015.

114 p., 210 x 297 mm (FGA/UnB Gama, Mestre, Engenharia Biomédica, 2015). Dissertação de Mestrado - Universidade de Brasília. Faculdade Gama. Programa de PósGraduação em Engenharia Biomédica.

1. ENGENHARIA BIOMÉDICA

2. TECNOLOGIA BIOMÉDICA

3. AVALIAÇÃO DA TECNOLOGIA BIOMÉDICA 4. RISCO

I. FGA UnB Gama/ UnB. II. Título (série)

\section{REFERÊNCIA BIBLIOGRÁFICA}

ALVES, C. S. (2015). Gestão de Tecnologias em Saúde: desafios para o engenheiro biomédico. Dissertação de Mestrado em Engenharia Biomédica, Publicação n. ${ }^{\circ} 32 \mathrm{~A} / 2015$, Programa de Pós-Graduação em Engenharia Biomédica, Faculdade Gama, Universidade de Brasília, Brasilia, DF, 114p.

\section{CESSÃO DE DIREITOS}

AUTOR: Cleber da Silva Alves.

TÍTULO: Gestão de Tecnologias em Saúde: desafios para o engenheiro biomédico

GRAU: Mestre

ANO: 2015

É concedida à Universidade de Brasília permissão para reproduzir cópias desta dissertação de mestrado e para emprestar ou vender tais cópias somente para propósitos acadêmicos e científicos. $\mathrm{O}$ autor reserva outros direitos de publicação e nenhuma parte desta dissertação de mestrado pode ser reproduzida sem a autorização por escrito do autor.

$$
\text { Wlec da o ta peus. }
$$

Cleber da Silva Alves

SQN 406 Bloco K apartamento 106.

CEP 70847-110 Brasília, DF - Brasil. 


\section{DEDICATÓRIA}

Dedico esse trabalho à Ana Luiza e Amanda, minhas filhas. Que eu possa educá-las antes pelo exemplo que pelas palavras.

Toda caminhada começa no primeiro passo.

A natureza não tem pressa Segue seu compasso.

Inexoravelmente chega lá...

Irah Caldeira 


\section{AGRADECIMENTOS}

Agradeço o apoio e a compreensão da Profa. Dra. Marília Miranda Forte Gomes, que sempre soube levar aos alunos o conhecimento da forma com que todos pudessem recebê-lo.

À Professora Dra. Lourdes Mattos Brasil, agradeço tanto pelas diversas reuniões de orientação quanto pelo toque de humanidade dedicado às pessoas que dela se aproximam. 


\title{
RESUMO
}

\section{GESTÃO DE TECNOLOGIAS EM SAÚDE \\ Desafios para o Engenheiro Biomédico}

\author{
Autor: Cleber da Silva Alves \\ Orientadora: Profa. Dra. Lourdes Mattos Brasil \\ Co-orientadora: Profa. Dra. Marília Miranda Forte Gomes \\ Programa de Pós-Graduação em Engenharia Biomédica - Dissertação de Mestrado \\ Brasília, Julho de 2015.
}

A pesquisa teve início a partir da constatação da necessidade de gerenciar riscos inerentes a tecnologias em saúde. A partir da reflexão inicial, foi proposta a inclusão da gestão de riscos em tecnologias como forma de viabilizar o aumento da vida útil dos equipamentos eletromédicos. As análises referentes aos riscos em tecnologias em saúde envolvem todo o ciclo de vida dos equipamentos, desde os estudos técnicos preliminares, visando a incorporação da tecnologia no serviço de saúde, chegando ao seu descarte final, considerando o respeito ao meio ambiente e à sociedade. Para se alcançar os objetivos da pesquisa, foram utilizadas técnicas de gestão de projetos propostas pelo Project Management Institute, e técnicas de gestão de riscos indicadas pela Associação Brasileira de Normas Técnicas. Os resultados alcançados na pesquisa ressaltam a necessidade de se gerenciar todas as fases do ciclo de vida de uma tecnologia em serviços de saúde, implicando o uso de processos de gestão agrupados conforme a natureza das ações a serem desenvolvidas.

Palavras-chave: Engenharia Biomédica; Tecnologia Biomédica; Avaliação da Tecnologia Biomédica; Risco. 
ABSTRACT

HEALTH TECHNOLOGY MANAGEMENT:

Challenges for the Biomedical Engineer

Author: Cleber da Silva Alves

Supervisor: Profa. Dra. Lourdes Mattos Brasil

Co-supervisor: Profa. Dra. Marília Miranda Forte Gomes

Post-Graduation Program in Biomedical Engineering - Dissertation of Master Degree

Brasília, July of 2015.

The research started from the realization of the need to manage risks to health technologies. From the initial reflection, the inclusion of risk management technologies was proposed as a way to facilitate increased service life of electrical equipment. The analyzes related to risks in health technologies involve the entire equipment life cycle, from preliminary technical studies for the incorporation of technology in health care, coming to its final disposal, considering the respect for the environment and society. To achieve the research objectives, we used project management techniques proposed by the Project Management Institute, and risk management techniques given by the Brazilian Association of Technical Standards. The outcomes of the study emphasize the need to manage all phases of the life cycle of a technology in health services, implying the use of management processes grouped according to the nature of the actions to be developed.

Key words: Biomedical Engineering; Biomedical Technology; Evaluation of Biomedical Technology; Risk. 


\section{SUMÁRIO}

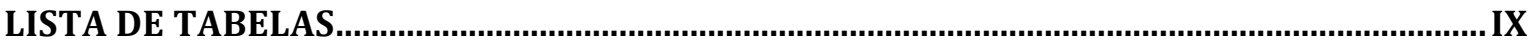

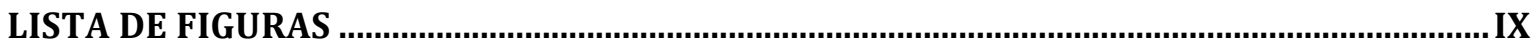

LISTA DE SÍMBOLOS, NOMENCLATURAS E ABREVIAÇõES …................................................ X

1 INTRODUÇÃO

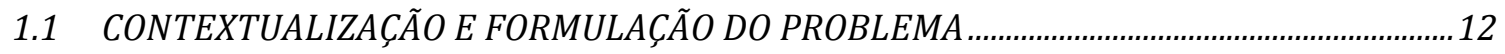

1.2 OBJETIVOS

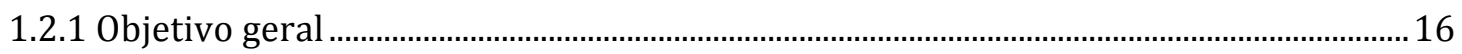

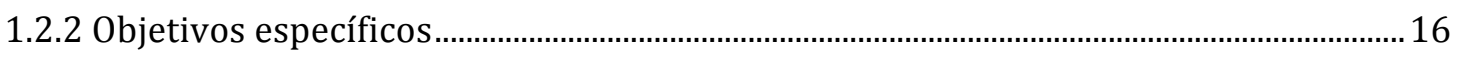

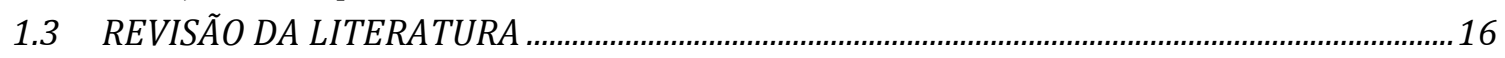

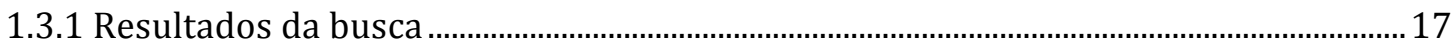

2 FUNDAMENTAÇÃO TEÓRICA

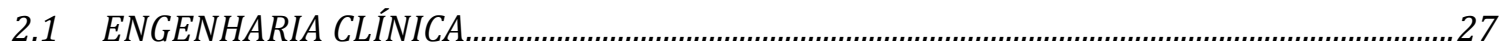

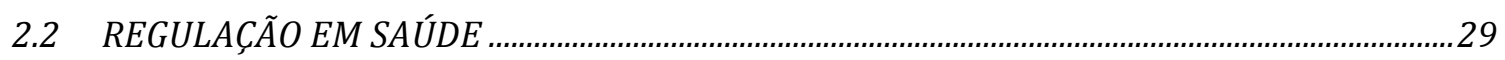

$2.3 \quad$ NORMALIZACCAOO

2.4 GESTÃO DE TECNOLOGIAS EM SAÚDE

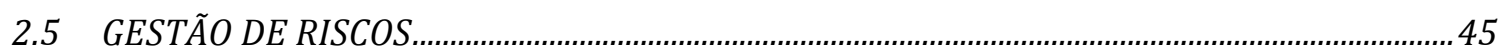

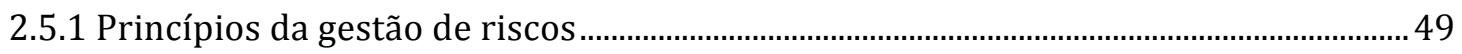

2.5.2 Estrutura da gestão de riscos ..................................................................................... 51

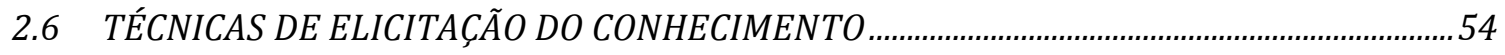

2.6.1 Seleção de técnicas para o processo de avaliação de riscos .............................................. 56

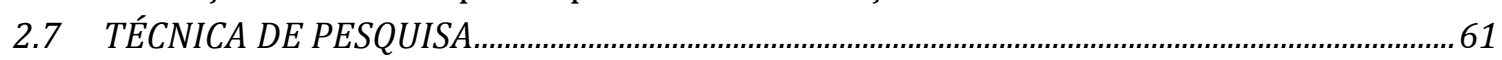

3 METODOLOGIA

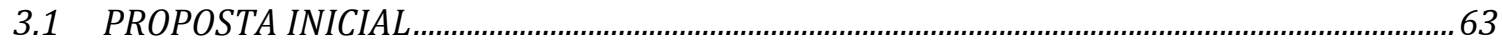

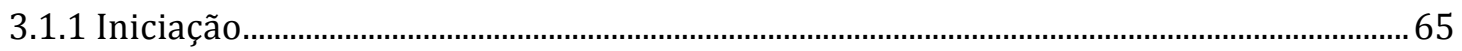

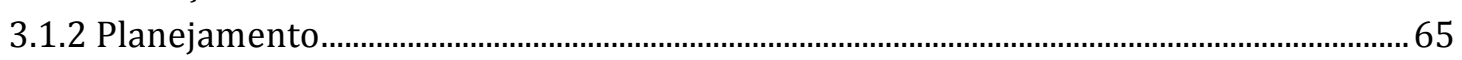

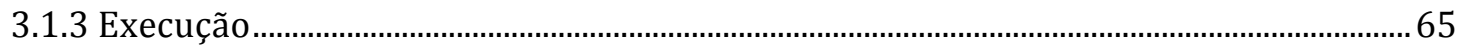

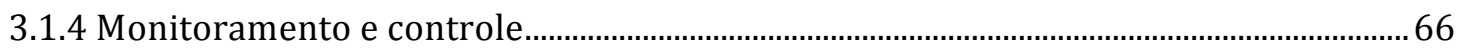

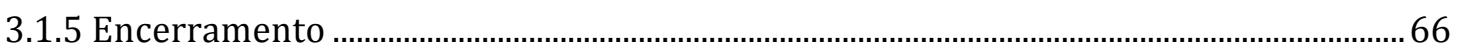

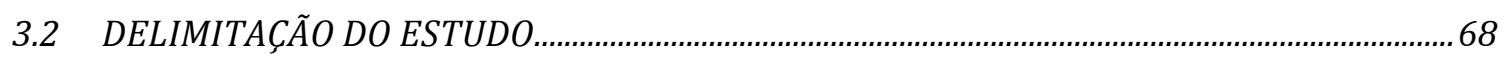

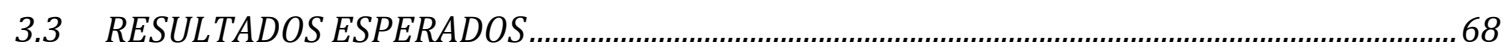

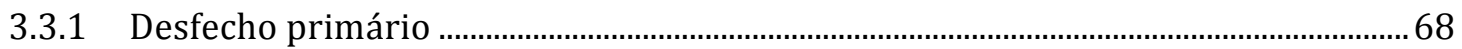

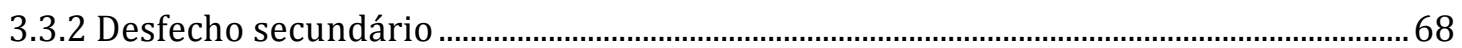

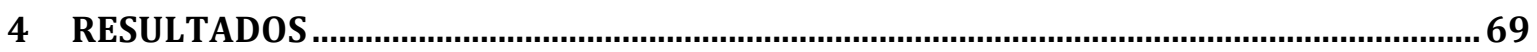

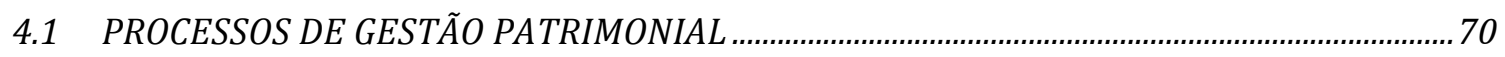

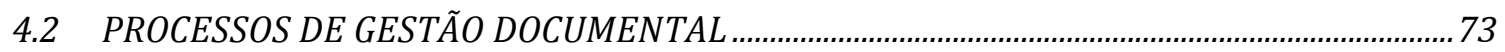

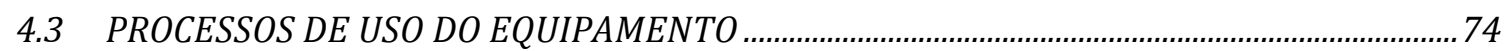

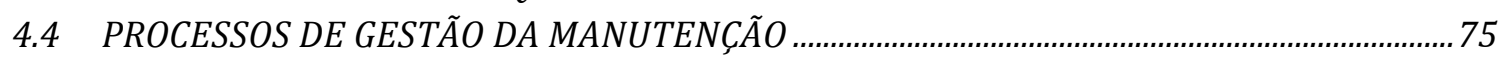

4.5 PROCESSO DE NOTIFICAÇÃO DE EVENTOS ADVERSOS ……................................................... 75

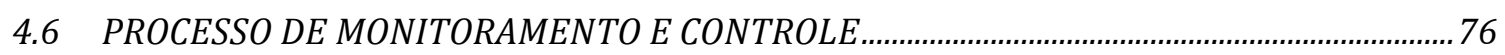

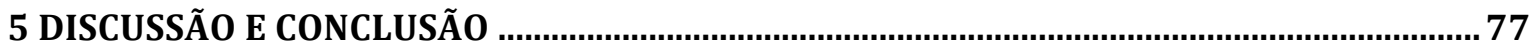

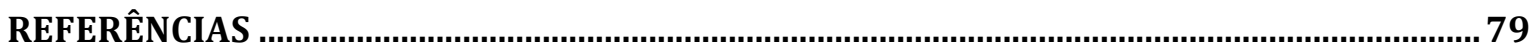




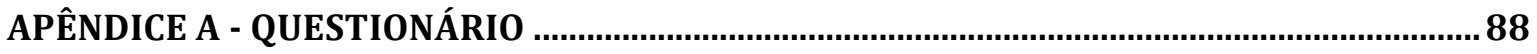

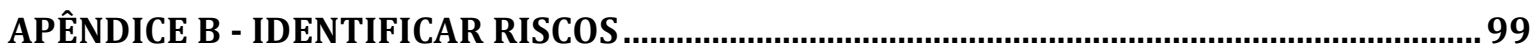

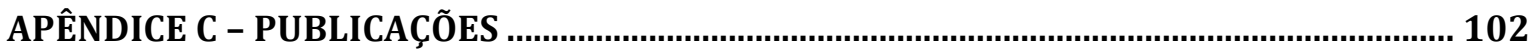

a) Publicações realizadas em eventos ……………………………………………………... 102

b) Capítulo de livro publicado..................................................................................................... 102

c) Artigo submetido para publicação em periódico....................................................................... 102

ANEXO A - ATRIBUTOS DE UMA SELEÇÃO DE FERRAMENTAS DE AVALIAÇÃO DE RISCOS

ANEXO B - PROCESSOS DE GERENCIAMENTO DE PROJETOS - ENTRADAS E SAÍDAS... 107

\section{LISTA DE TABELAS}

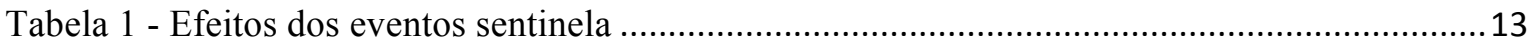

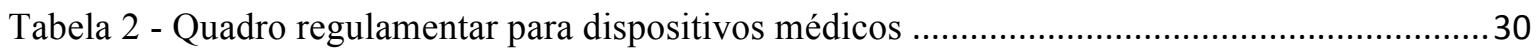
Tabela 3 - Estrutura geral da diretriz metodológica: apresentam-se de forma resumida os critérios do estudo de avaliação para EMA, conforme a abordagem. Consequentemente onde encontrada

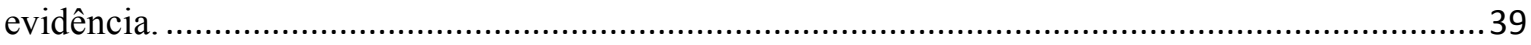

Tabela 4 - Aplicabilidade das ferramentas utilizadas para o processo de avaliação de riscos ..........55

Tabela 5 - Variáveis quantitativas para cada erro possível e seus valores atribuídos.........................60

\section{LISTA DE FIGURAS}

Figura 1 - Representação do produto - três elementos críticos ..................................................... 26

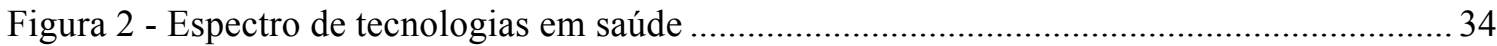

Figura 3 - Ciclo de vida das tecnologias em saúde (intensidade de uso de uma tecnologia em saúde

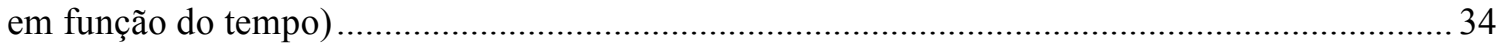

Figura 4 - Relacionamento entre os componentes da estrutura para gerenciar riscos................... 49

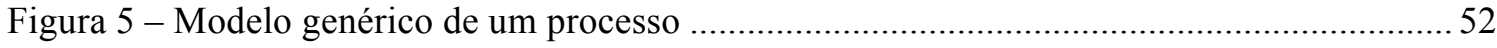

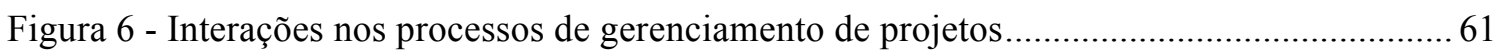

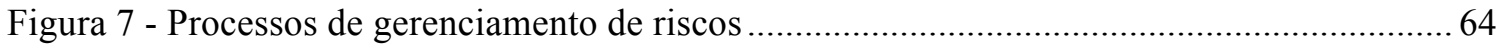




\section{LISTA DE SÍMBOLOS, NOMENCLATURAS E ABREVIAÇÕES}

ABNT

ACCE

ANS

ANSI

Anvisa

APP

APPCC

BVS

Capes

CEN

Cenelec

CEP

Conama

EB

EC

EEM

EMA

ETSI

FDA

FMEA

FMECA

HAZOP

HRA

IBGE

IEC

Inca

ISO
Associação Brasileira de Normas Técnicas

American College of Clinical Engineering

Agência Nacional de Saúde Suplementar

American National Standards Institute

Agência Nacional de Vigilância Sanitária

Análise preliminar de perigos

Análise de perigos e pontos críticos de controle

Biblioteca Virtual em Saúde

Coordenação de Aperfeiçoamento de Pessoal de Nível Superior

Comité Europeu de Normalização

Comité Europeu de Normalização Electrotécnica

Comitê de Ética em Pesquisa

Conselho Nacional do Meio Ambiente

Engenharia Biomédica

Engenharia Clínica

Equipamento Eletromédico

Equipamento Médico-Assistencial

European Telecommunications Standards Institute

Food and Drug Administration

Failure mode effect analisys (Análise de modo e efeito de falha)

Failure mode effect and criticality analisys (Análise de modo, efeito e criticidade de falha)

Hazard and operability studies (Estudos de perigo e operabilidade)

Human resource acconunting

Instituto Brasileiro de Geografia e Estatística

International Electrotechnical Commission

Instituto Nacional do Câncer

International Organization for Standardization 
JC- AHO The Joint Commission on Accreditation of Healthcare Organizations

LOPA Layer protection analisys (Análise de camadas de proteção)

MC Manutenção corretiva

MDCA Análise de decisão por multicritérios

MP Manutenção preventiva

MS Ministério da Saúde

NBR Norma Brasileira editada pela ABNT

NSP Núcleo de Segurança do Paciente

PERT/CPM Program Evaluation and Review Technique/Critical Path Method

PGEQS Plano de Gerenciamento de Equipamentos

PGTES Plano de Gerenciamento de Tecnologias em Saúde

PMI Project Management Institute

PubMed US National Library of Medicine National Institutes of Health

RDC Resolução da Diretoria Colegiada

SA Sneak analisys

SCA Sneak circuit analisys

SUS Sistema Único de Saúde

SWIFT Structured what if technique

TI

Tecnologia da informação

UCB Universidade Católica de Brasília

UFRJ Universidade Federal do Rio de Janeiro

UnB Universidade de Brasília

Unicamp Universidade Estadual de Campinas

USP Universidade de São Paulo

WHO World Health Organization 


\section{INTRODUÇÃO}

\subsection{CONTEXTUALIZAÇÃO E FORMULAÇÃO DO PROBLEMA}

A segurança do paciente é uma questão global que afeta países em todos os níveis de desenvolvimento. Não existe evidência científica suficiente para entender porquê os eventos adversos ocorrem, como e em que medida os pacientes são prejudicados e, além disso, como essas questões poderiam ser reduzidas e os danos relacionados com o paciente minimizados. As necessidades de investigações são vastas, enquanto que os recursos para custeá-las são escassos (WHO, 2014).

Em razão disso, a World Health Organization (WHO) desenvolveu um grupo de trabalho de especialistas internacionais em segurança do paciente para que se evidenciasse as grandes lacunas de conhecimento neste ramo de pesquisa. A lista de prioridades finais foi elaborada com base na gravidade do impacto e frequência de ocorrência de eventos que interferem na segurança do paciente.

Para países em desenvolvimento e em transição, foi considerado prioridade o desenvolvimento e teste de soluções eficazes e acessíveis localmente, levando em conta seu custo-efetividade e estratégias de redução de risco. Entre os temas de interesse identificados há um grupo deles relacionados à gestão de tecnologias em saúde, envolvendo custo-efetividade de soluções, competências, formação e habilidades, cultura de segurança, falhas organizacionais latentes, indicadores de segurança, tecnologia e sistemas de informação de saúde, fatores humanos em dispositivos e seus eventos adversos (WHO, 2014).

Como reforço de argumentação, tem-se ainda que em atenção à ocorrência de eventos adversos, a Joint Commission (2014), ao classificá-los em seus hospitais acreditados, segundo suas causas-raiz, evidenciou dentre tantas fontes a ocorrência de eventos relacionados a equipamentos médicos que poderiam ser atenuados ou mesmo evitados, caso se ampliasse a gestão destas tecnologias com foco em seus riscos inerentes.

A Tabela 1 relaciona as consequências da ocorrência dos eventos sentinela, segundo a Joint Commission (2014) naqueles hospitais acreditados pela instituição, observando ainda que embora seja alarmante, os eventos ali contidos não refletem o total de casos, considerando ser alta a incidência de subnotificação. 
Tabela 1 - Efeitos dos eventos sentinela

\begin{tabular}{|c|c|c|}
\hline $\begin{array}{c}\text { EFEITOS DOS EVENTOS } \\
\text { SENTINELA ENTRE } 2004 \text { - } 2014\end{array}$ & $\mathrm{~N}^{\circ}$ DE CASOS & $\%$ \\
\hline Morte do paciente & 4.984 & 58,7 \\
\hline Perda de função & 801 & 9,4 \\
\hline Outros $^{1}$ & 2.710 & 31,9 \\
\hline Total de pacientes impactados & 8.495 & 100,0 \\
\hline
\end{tabular}

Fonte: Joint Commission (2014, tradução nossa).

Ao se procurar prever a ocorrência dos eventos adversos, a Joint Commission (2010, p. 25) indica que se inicie pelos processos de alto grau de riscos. Dentre esses processos, há os próprios de unidades de assistência de alta complexidade. As unidades de assistência em alta complexidade são aquelas que possuem condições técnicas, instalações físicas, equipamentos e recursos humanos adequados à prestação de assistência qualificada a portadores de doenças que requerem atenção especializada. Envolvem assim, alta tecnologia e alto custo e requerem que se administrem essas interações de forma a manter em funcionamento um emaranhado de sistemas com o objetivo final de alcançar a saúde do indivíduo.

Nesse contexto, essas organizações de saúde administram uma série de riscos que podem afetar a realização de seus objetivos, os quais podem estar relacionados a todas as atividades da organização, desde iniciativas estratégicas até ações operacionais, processos e projetos, implicando reflexos em termos de resultados para o meio ambiente, tecnologia, impactos sociais, culturais, políticos e também na reputação.

O cenário se torna mais complexo quando se analisam as interações sob a ótica da regulação imposta por agências reguladoras sobre o setor saúde, como a Agência Nacional de Vigilância Sanitária (Anvisa), uma vez que direcionam a atenção dos profissionais de saúde aos regulamentos e normas que determinam ações e procedimentos a serem cumpridos pelas organizações e pelos profissionais que executam suas atividades nos serviços de saúde.

A respeito dos instrumentos utilizados em um hospital:

A instrumentação utilizada em um moderno hospital é extremamente variada, empregando tecnologias que passam pelas fronteiras do conhecimento atual, exigindo o que há de melhor (state of the art) do que se pode oferecer em matéria de tecnologia (CARVALHO, 2008, p. 2, grifos do autor)

No entanto, considerando que o sistema de saúde pública brasileiro é

\footnotetext{
1 Inclui: cuidados adicionais não programados, extensão do período de internação e impactos psicológicos.
} 
estabelecido sobre princípios como a integralidade e a universalidade (BRASIL, 1990), torna-se cada vez mais difícil prover aos hospitais brasileiros o que há de melhor em matéria de tecnologia, afinal, deve ser levado em consideração que as necessidades são ilimitadas enquanto que os recursos para atendê-las são limitados. Ferraz (2008, p. xix) destaca que o mundo vem assistindo a avanços decisivos na identificação precoce e no tratamento de doenças, o que sugere o fato de que a dinâmica de criação e geração de novas tecnologias se caracteriza pela celeridade e que a capacidade do sistema de saúde em absorvê-las e integralizá-las a seus processos e procedimentos não a acompanha na mesma velocidade.

Por conseguinte, o controle e o conhecimento das necessidades dos serviços de saúde aliados às tecnologias disponíveis no mercado, são fatores importantes na seleção e adoção das tecnologias mais adequadas para atender às demandas desses serviços. A Anvisa, no âmbito de suas atribuições regulamentares, publicou a Resolução da Diretoria Colegiada - RDC n ${ }^{\circ}$ 02, de 25 de janeiro de 2010 (BRASIL, 2010a), que implica a todos os estabelecimentos de saúde a obrigação de prover o gerenciamento das tecnologias em saúde utilizadas na prestação dos seus serviços, envolvendo ações que vão desde a entrada do equipamento no estabelecimento até seu destino final, incluindo o planejamento dos recursos físicos, materiais e humanos.

O gerenciamento de tecnologias em saúde proposto pela Anvisa envolve um conjunto de procedimentos de gestão, planejados e implementados a partir de bases científicas e técnicas, normativas e legais, com o objetivo de garantir a rastreabilidade, qualidade, eficácia, efetividade, segurança e em alguns casos, o desempenho das tecnologias de saúde utilizadas na prestação de serviços de saúde. Define ainda critérios mínimos para o gerenciamento de tecnologias utilizadas na prestação de serviços de saúde.

O estabelecimento de saúde deve assim, possuir uma sistemática de monitorização e gerenciamento das tecnologias disponibilizadas, gerindo os riscos relacionados ao seu uso e aos processos de trabalho, se valendo de mecanismos que permitam a rastreabilidade das tecnologias em saúde, cujo foco seja utilizar tais informações no planejamento ou seleção da tecnologia a ser adquirida. Sob esta perspectiva e a depender da tecnologia em análise e do risco a ela associado, a rastreabilidade pode ser requerida até a unidade do estabelecimento de saúde para a qual a tecnologia será distribuída ou até ao próprio paciente. 
A Política Nacional de Gestão de Tecnologias em Saúde tem como objetivo, maximizar os benefícios de saúde a serem obtidos com os recursos disponíveis, assegurando acesso da população a tecnologias efetivas e seguras, em condições de equidade (BRASIL, 2010b, p. 15). Além disso, essa política tem como fundamento de suas diretrizes a segurança, acurácia, eficácia, efetividade, custos, custo-efetividade e aspectos de equidade, impactos éticos, culturais e ambientais envolvidos na sua utilização (BRASIL, 2010b, p. 17).

Ao abordar esse tema, Fernandes (2009, p. 115) ressalta que por se considerar o perfil de morbimortalidade da população aliada à elevação dos custos nos sistemas de saúde, tem-se procurado mecanismos para mensurar e valorar a qualidade de vida, para analisar o impacto dessas tecnologias em termos de estados de saúde e de custos. Considera a autora que a escassez e finitude da disponibilidade de recursos para a saúde também tem contribuído na construção de ferramentas que auxiliem a uma melhor alocação de recursos, contemplando diferentes interesses existentes (gestores, sociedade, profissionais de saúde etc.).

Ao revisar os métodos utilizados para realização de análises de impacto orçamentário na incorporação de tecnologias em saúde, Ferreira-da-Silva (2012) concorda com o proposto por Fernandes (2009) ao destacar dentre suas recomendações que se deve analisar, pela perspectiva do gestor, a ideia de que não se pode deixar de considerar que o custo das novas tecnologias tem que ser gerenciado, sob o risco de se penalizar o próprio segmento da saúde pública e outras áreas de interesse social.

Lorenzetti (2012) destaca que as organizações de saúde são fortemente dependentes de investimentos em tecnologias como medicamentos e vacinas, próteses, órteses, exoesqueletos, máquinas e equipamentos para diagnóstico e intervenção, robôs cirúrgicos, informação e comunicação instantânea, prontuário eletrônico único nacional e integrado para acesso internacional, implantes, transplantes e, inclusive, a produção artificial de células humanas. Em função disto, a gestão dessas tecnologias, é fator primordial para que se possa prover a perfeita atenção às necessidades de saúde da população em harmonia com fatores sociais, econômicos e ambientais. 


\subsection{OBJETIVOS}

\subsubsection{Objetivo geral}

Desenhar um Plano de Gestão de Tecnologias em Saúde fundamentado na norma ABNT NBR 15943:2011, modelado sob os processos de gestão de riscos conforme prescrito pelas normas ABNT NBR ISO 31000:2009, ABNT NBR ISO IEC 31010:2012 e ABNT NBR ISO 14971:2009 para aplicação em uma organização hospitalar de alta complexidade como resposta à regulação imposta pela Anvisa, por meio das $\mathrm{RDC}^{\circ}$ 2, de 2010 e RDC no 36, de 2013.

\subsubsection{Objetivos específicos}

- Proporcionar à organização de saúde plano de gestão de equipamentos (PGEQS), a ser integrado ao Plano de Gerenciamento de Tecnologias em Saúde, possibilitando uma gestão pró-ativa dos riscos inerentes às tecnologias.

- Promover o uso do conhecimento técnico-científico atualizado no processo de gestão de tecnologias em saúde.

- Utilizar as técnicas e processos de gerenciamento de projetos para desenvolver o plano de gerenciamento.

- Desenvolver processos necessários à gerir tecnologias em saúde, agrupandoos com atenção à sua natureza.

\subsection{REVISÃO DA LITERATURA}

A pesquisa da base bibliográfica utilizada neste trabalho considerou a busca por livros, teses, monografias, normas, regulamentos, padrões e artigos nas seguintes fontes especializadas: US National Library of Medicine National Institutes of Health (PubMed), World Health Organization (WHO), U. S. Food and Drug Administration (FDA), International Electrotechnical Commission (IEC), International Organization for Standardization (ISO), Associação Brasileira de Normas Técnicas (ABNT), Universidade de Brasília (UnB), Universidade de São Paulo (USP), Universidade Católica de Brasília (UCB), Universidade Federal do Rio de Janeiro (UFRJ), Universidade Estadual de Campinas (Unicamp), Senado Federal (por meio da Biblioteca Acadêmico Luiz Viana Filho), Ministério da Saúde e órgãos subordinados como o Instituto Nacional do Câncer (Inca), Anvisa e Agência Nacional de Saúde Suplementar (ANS) e Instituto Brasileiro de 
Geografia e Estatística (IBGE).

A busca por evidências sobre o uso de processos de gestão de tecnologias em saúde com foco na gestão de riscos foi realizada como fonte primária os portais de periódicos da Coordenação de Aperfeiçoamento de Pessoal de Nível Superior (Capes) e Biblioteca Virtual em Saúde (BVS) para acesso às bases de dados. À luz dessas fontes foram sintetizados conceitos, fundamentos e princípios relevantes para a compreensão do tema estudado em algumas pesquisas.

A estratégia de busca se fundamentou na pesquisa por teses e dissertações com os seguintes critérios: risk assessment, risk management, risk, failure mode, failure, risk analisys, failure analisys, failure mode and effect analysis, e seus equivalentes em português.

Considerando o grande número de estudos encontrados, a estratégia de busca foi limitada para teses e dissertações, publicados em inglês ou português. As palavraschave utilizadas incluíram (i) risk, (ii) risk management, (iii) risk assessment, (iv) health, (v) technology management. Além de seus equivalentes em português: ( $i$ ) risco, (ii) gerenciamento do risco, (iii) avaliação do risco (iv) saúde; (v) gestão de tecnologia.

Durante a fase de levantamento de fontes de referência por meio das fontes primárias, foram identificadas pesquisas realizadas no âmbito da gestão de riscos em tecnologias em saúde e, posteriormente selecionadas aquelas que se alinhavam aos objetivos do presente estudo de modo a preencher lacunas existentes, ou ainda de subsidiar de forma teórica os conceitos abordados.

\subsubsection{Resultados da busca}

UECHI, C. A. S., 2012: Confiabilidade metrológica de ventiladores pulmonares para cuidados críticos

Ventiladores pulmonares são utilizados na assistência ventilatória mecânica, suprindo o trabalho muscular necessário para a respiração em pacientes com insuficiência respiratória aguda ou crônica. A monitoração da ventilação mecânica está baseada nos sinais de fluxo, volume, pressão das vias aéreas, frequência respiratória e fração inspirada de oxigênio. Por isso, é de suma importância que os valores apresentados sejam confiáveis, o que pode ser assegurado por meio da calibração periódica. 
A pesquisa teve como objetivo propor boas práticas para o aumento da confiabilidade metrológica dos ventiladores pulmonares. Os resultados mostraram oportunidades de melhoria no processo de comprovação metrológica, como a adequação dos erros máximos admissíveis nos estabelecimentos assistenciais de saúde (EAS) e melhorias no procedimento de calibração, incluindo o aumento do número de leituras e a automação da calibração. Além disso, na estimativa da incerteza de medição verificou-se que a avaliação da incerteza Tipo B (não estatística) não pode ser descartada. $\mathrm{O}$ estudo também mostra que a pressão positiva ao final da expiração (PEEP) pode ter influência na calibração do volume corrente e da pressão inspiratória. Por fim, uma série de eventos não esperados no funcionamento dos ventiladores pulmonares motivou a comparação entre duas marcas distintas, que evidenciou diferenças de desempenho principalmente no comportamento dinâmico. Os resultados obtidos mostram que a metrologia ainda precisa ser disseminada em abordagens distintas e em diferentes níveis de conhecimento, com consequências no controle sanitário destes produtos para segurança de seus usuários e no incremento da qualidade da assistência.

\section{LEMOS, L. A., 2012: Aplicação da metodologia de gerenciamento preditivo para implantação de projetos de engenharia biomédica}

O Gerenciamento de Projetos tem aberto oportunidades para desenvolvimento de novas metodologias a partir do seu padrão clássico de gestão. No caso da Engenharia Biomédica há especificidades, tanto pela riqueza científica aplicada nos seus projetos, quanto pelo refinamento dos requisitos que envolvem o desenvolvimento dos seus projetos e da sua implantação. As referências para o Gerenciamento de Projetos na Engenharia Biomédica, assim como na saúde de maneira geral, têm se voltado para estudos de caso onde o foco está mais no que fazer, não tanto para como fazer e menos ainda em como organizar e controlar o que dever ser realizado, para garantir o sucesso desejado.

Um estudo que foi pelo autor em 2010 apresentou um método para Gerenciamento Preditivo de Projetos - GPP e o objetivo deste trabalho foi rever os conceitos teóricos e realizar a pesquisa de campo para confirmar as hipóteses de que a metodologia proposta seja dinâmica e preditiva na prática, com eficiência e efetividade na execução, para evitar que as falhas que geralmente ocorrem, sob o gerenciamento clássico, não se transformem em fatores de insucesso. 
LIMA, E. A. N., 2008: GEM - HOS - sistema de gerenciamento de informações de equipamentos médico-hospitalares - o caso do Hospital Universitário de Brasília HUB

A pesquisa considerou o desenvolvimento de um sistema para auxiliar a gestão eficiente do parque de equipamentos médicos hospitalares, levando em conta suas interações com o trabalho finalístico hospitalar, especialmente com a maior disponibilidade e racionalidade econômica, é uma necessidade da maioria dos serviços prestadores de atenção a saúde. A pesquisa demonstrou que na sua concepção, foi possível constatar as dificuldades no desenvolvimento e na implementação dos conceitos de Engenharia de Software. O sistema desenvolvido é baseado em um software implementado na linguagem PHP, e banco de dados MYSQL, e chamado de GEM-HOS. O desempenho geral do sistema foi avaliado de acordo com os resultados em muito bom.

MUNIZ, R. P. D. 2010. Requisitos de mantenabilidade na execução dos serviços de manutenção.

Este estudo contempla um conjunto de quatro artigos que têm por finalidade identificar os requisitos de mantenabilidade a serem atendidos na execução dos serviços de manutenção. Para tanto, a partir de um estudo sistemático, identifica na literatura os principais requisitos, estruturando-os em áreas, e aplica pesquisa junto a especialistas de manutenção para classificá-los quanto à importância e aplicabilidade. Na sequência, agrupa estes requisitos em criticidade, estabelece um ranqueamento quanto à sua observação e debate a ocorrência na literatura e o operado nas organizações, bem como a possível defasagem existente entre o operado e o concebido em discussões acadêmicas. Como resultado, além de apresentar os principais requisitos de mantenabilidade na execução dos serviços de manutenção, caracteriza o impacto da adoção dos requisitos de mantenabilidade nas organizações e conclui que a mantenabilidade gerenciada é responsável pela conformidade da execução dos serviços e pelos resultados organizacionais buscados. O estudo aponta para a necessidade de construir uma sistemática capaz de diagnosticar o nível de observação dos requisitos de mantenabilidade em uma organização e de introduzir melhorias nos processos e execução de serviços de manutenção existentes.

JACOBS, G. S. 2009: Compras e manutenções de equipamentos na área da saúde pública: aperfeiçoamento de contratos e eficácia da utilização.

Este trabalho tem por objetivo identificar, e aplicar, formas de melhorar os índices de 
disponibilidade e reduzir os custos de manutenção dos equipamentos utilizados na área Biomédica do Grupo Hospitalar Conceição S. A (GHC), através da aplicação da Legislação, basicamente a Lei 8666/93 e suas modificações, no momento da compra de novos equipamentos, e da renegociação dos contratos de manutenção vigentes. Assim sendo, após uma análise preliminar dos problemas, foram identificadas formas para implementar as soluções para os mesmos, utilizando bibliografia pertinente como base referencial teórica e prática.

\section{ALEXANDRINO, J. C. 2012: Metodologia para Avaliação do Desempenho Metrológico em Equipamentos Médico-Hospitalares.}

Tecnologias trazem riscos intrínsecos, que podem resultar em danos, quando mal utilizadas ou mantidas. Os Equipamentos Médico-hospitalares (EMH) podem apresentar problemas que resultem em diagnósticos errôneos, terapias inapropriadas ou que comprometam a segurança dos usuários. A avaliação periódica, e em particular, do desempenho metrológico, constitui-se em importante meio para alcançar o uso seguro do EMH. As soluções encontradas para tal avaliação são rigidamente condicionadas às especificidades de cada tipo de EMH e dificilmente podem ser aproveitadas para outros. O trabalho apresenta uma metodologia para a avaliação do desempenho metrológico de EMHs e para tal, foi desenvolvido um sistema que reúne instrumentos de medição integrados a um software gerenciador de ensaios. Este software realiza a aquisição e monitoramento de dados de medição relativos às variáveis metrológicas do equipamento sob teste, avalia a adequação destes dados a requisitos metrológicos preestabelecidos e emite relatório de conformidade. O sistema permite a configuração de diversos parâmetros, possibilitando a execução de avaliações de desempenho metrológico em diferentes tipos de EMH. Para fins de validação, o sistema foi configurado para realizar avaliações em bisturis elétricos e incubadoras neonatais. Os resultados mostram a eficácia da metodologia desenvolvida e a eficiência da plataforma computacional para avaliação metrológica de EHM.

\section{LUCATELli, M. V. 2002: Proposta de aplicação da manutenção centrada em confiabilidade em equipamentos médico-hospitalares}

O estabelecimento de uma metodologia lógica, estruturada e custo-efetiva para a gestão da manutenção, como propõe a MCC, representa uma importante contribuição ao processo de gerenciamento de tecnologia médico-hospitalar $(\mathrm{GTMH})$, bem como à área hospitalar, que pode ser classificada como um dos ambientes mais complexos em virtude de suas 
exigências contextuais e características tecnológicas (diversificada e complexa). O autor apresenta uma proposta de MCC para EMH em estabelecimentos assistenciais de saúde (EAS), modelada por meio da revisão dos preceitos, técnicas, procedimentos e resultados da MCC característicos da indústria, do estado da arte da manutenção de EMH e do GTMH. A metodologia desenvolvida, foi sistematizada em quatro fases - planejamento, análise técnica, análise qualitativa e avaliação - compostas por etapas distinta, cuja configuração caracteriza um processo sistêmico, e aplicada a três estudos de caso, cujos resultados mais significativos apontaram: o incremento do conhecimento a respeito dos EMH, dos sistemas e dos processos envolvidos na análise; o estabelecimento de procedimentos de manutenção programada contextualizados; a identificação de deficiências quanto à confiabilidade da função cujo item é responsável e a determinação de ações corretivas acerca do projeto; a sistematização de dados para a acreditação/certificação da manutenção, bem como de evidências rastreadas para a justificação de investimentos e melhoramentos por parte da direção.

\section{AZEVEDO, G. F. C. 2004: Proposta de modelo de gerenciamento de risco aplicado ao desempenho de equipamentos eletromédicos em estabelecimentos assistenciais de saúde.}

Dentre os fatores que afetam a segurança no ambiente hospitalar estão os perigos decorrentes de problemas funcionais dos equipamentos eletromédicos (EEMs), que podem ocorrer durante sua vida útil. O gerenciamento de risco contribui para a eficiência do controle destes riscos. Através de implementação de sua etapas de gerenciamento (analise de risco, avaliação de risco e controle de risco), os problemas de segurança podem ser identificados e as ações da engenharia clinica direcionadas para a redução de riscos, eliminado, na medida do possível, as causas dos riscos existentes.

Neste sentido, foi apresentada aqui uma proposta de modelo de gerenciamento de risco aplicado ao desempenho de EEMs em estabelecimentos assistenciais de saúde (EAS), elaborado por meio da adaptação de preceitos, técnicas e procedimentos definidos pela literatura e pela norma ISO14971:2000. A sua aplicação fornece argumentos rastreados e baseados no conhecimento para a tomada de decisão acerca dos procedimentos de controle de risco. 
MESTAS VALERO, C. A. M. 2011: Metodologia para avaliar a implementação da gestão de risco em uma organização de saúde: home care que usa dispositivos médicos.

As organizações de home care já vêm gerindo seus riscos, como parte do cumprimento das normas sanitárias ou seus programas de segurança e qualidade. Esta tese tem como objetivo propor uma metodologia que mensure a implementação atual dos três elementos de gestão de risco. A metodologia proposta pondera e considera por igual à implementação de itens dos princípios, estrutura e processos de gestão de risco. Os resultados da aplicação desta metodologia em quatro simulações e num estudo de caso real, mostram que esta proposta pode ser aplicada em qualquer organização de saúde que precise acompanhar sua gestão de risco.

BATISTA, M. M. B. 2003: Contribuição ao processo de credenciamento de laboratório de ensaios de equipamentos eletromédicos

Este trabalho apresenta uma contribuição ao processo de credenciamento e habilitação de laboratórios de ensaio de equipamentos eletromédicos (EEM), que realizam ensaios de avaliação técnica de desempenho e segurança elétrica no período pós-comercialização, junto a estabelecimentos assistenciais de saúde (EAS), bem como ensaios de perícia metrológica. Laboratórios de avaliação técnica capacitados para a execução de ensaios de desempenho e segurança elétrica nos EEM utilizados pelos EAS, que forneçam resultados confiáveis, poderão auxiliar a engenharia clínica no processo de gestão da tecnologia médico-hospitalar (GTMH) permitindo, também, oferecer suporte às atividades desenvolvidas pela Tecnovigilância.

SÔNEGO, F. S. 2007: Estudo de métodos de avaliação de tecnologias em saúde aplicada a equipamentos eletromédicos.

Esta pesquisa apresenta uma metodologia de avaliação de tecnologias em saúde baseada na Portaria 1.229/GM do Ministério da Saúde e nos métodos de avaliação tecnológica existentes. Auxiliando assim, a engenharia clínica na gestão da tecnologia médicohospitalar, através da execução de atividades de avaliação de equipamentos eletromédicos. Os resultados podem, por exemplo, indicar se um equipamento deve ou não ser substituído, ou ainda, mostrar que um equipamento eletromédicos não é efetivo e/ou seguro para ser comercializado. O método proposto sugere a utilização da revisão sistemática para avaliar parâmetros tais como, eficácia, efetividade e segurança das tecnologias em saúde, por ser 
um método de investigação científica preciso e geralmente mais rápido e mais barato do que iniciar um novo estudo clínico. E também, um processo de avaliação econômica o qual auxilia na determinação da tecnologia mais eficiente.

\section{ASSIS, E. C. 2013: O papel da Avaliação de Tecnologias em Saúde (ATS) na retirada} de dispositivos médicos obsoletos no Sistema Único de Saúde (SUS).

Este trabalho discute como a Avaliação de Tecnologias em Saúde (ATS) tem sido utilizada nas decisões que envolvem a retirada de tecnologias dos sistemas públicos de saúde, em específico, dispositivos médicos. Esse estudo abrange os níveis macro e meso do serviço público de países com expertise nessa área e identifica ações de desinvestimento tanto em agências de ATS, como em hospitais que já adotam a ATS na fase da obsolescência. A principal contribuição deste trabalho é propor alguns critérios para identificação e priorização das potenciais tecnologias candidatas ao desinvestimento, com base nas experiências apresentadas por algumas agências de ATS e governos nacionais, e iniciar uma discussão sobre as possibilidades de aprimoramento da gestão de tecnologias em saúde no Brasil. Seria necessário aprofundar, por meio de estudos futuros, o conhecimento de novas formas de reembolso, critérios de valoração e uma possível política de incentivo aos serviços que desejam estudar as tecnologias que já estão em uso no SUS.

\section{SOUZA, D. B. 2012: Avaliação econômica da implantação de um serviço de} Engenharia Clínica no Hospital de Clínicas da Universidade Federal de Uberlândia.

As atividades desenvolvidas pela Engenharia Clinica nos Estabelecimentos Assistenciais de Saúde se baseiam nos conhecimentos de engenharia e de gerenciamento aplicadas às tecnologias de saúde. Nesse contexto, esta pesquisa objetivou estudar e relatar o impacto da aplicação das técnicas de gestão em Engenharia Clinica no Hospital de Clinicas da UFU, um hospital universitário de grande porte e referencia em alta complexidade. Tratase de um estudo de caso, do tipo quantitativo, considerando-se uma avaliação econômica e de qualidade, na qual foi utilizado uma pesquisa documental como procedimento técnico. Dentre os resultados encontrados, destaca-se uma redução de aproximadamente $20 \%$ nas manutenções corretivas no momento da implantação das manutenções preventivas e a estabilização das corretivas, mesmo com aumento do parque tecnológico da Instituição ao longo dos 10 anos avaliados. 


\section{AZEVEDO, F. P. B. 2004: Desenvolvimento de tecnologia de gestão para ambientes hospitalares: o caso do Instituto Fernandes Figueira - FIOCRUZ.}

Este trabalho trata da sinergia existente entre o prédio, as instalações e os equipamentos na constituição do ambiente hospitalar. Considera a complexidade deste ambiente, os riscos sanitários a ele associados, tanto na operação dos equipamentos, quanto nas suas instalações. Ao mesmo tempo reconhece a crescente importância do incremento tecnológico médico para a garantia de melhores resultados na atenção hospitalar. $\mathrm{O}$ trabalho propõe como dimensões desse ambiente hospitalar os espaços edificados, instalados e ocupados, os parques de equipamentos e sistemas funcionais prediais. A compreensão integrada destes, com suas complexidades decorrentes, possibilitam os campos para identificação das necessidades de manutenção dos equipamentos médicohospitalares e de suas necessárias infraestruturas, hoje carentes de controles dos riscos e de maiores racionalidades econômicas. Para o gerenciamento dessa massa de informações, uma metodologia de gestão integrada é proposta e experimentada num hospital específico. Com base nos instrumentos diversos identificados e utilizando-se de trabalho de campo desenvolvido no ambiente hospitalar, o trabalho apresenta o desenvolvimento de tecnologia automatizada para gestão de ambientes hospitalares, particularmente para a gestão dos equipamentos. A ferramenta proposta incorpora diversas funcionalidades. Dessa forma, uma proposta para a manutenção de equipamentos médico-hospitalares foi desenvolvida, como contribuição para o maior controle dos níveis de segurança e qualidade no atendimento aos pacientes, acompanhantes, visitantes e profissionais da saúde que transitam nas unidades de saúde, particularmente nos hospitais.

O estudo a ser desenvolvido se diferencia das pesquisas encontradas, por prover a gestão de riscos no âmbito dos processos de gestão de tecnologias em saúde (gestão de equipamentos). Dessa forma, a pesquisa acrescenta a estes trabalhos a possibilidade de incluir a análise e gestão de riscos em todos os processos relacionados à gestão de tecnologias em saúde. 


\section{FUNDAMENTAÇÃO TEÓRICA}

As tecnologias em saúde envolvem um amplo espectro de possibilidades materiais e imateriais, pois incluem desde os processos, técnicas e procedimentos adotados em ações de saúde ou mesmo nas linhas de produção de produtos para a saúde, passando por sistemas de informação, e chegando às máquinas, dispositivos e equipamentos. Pode-se compreender esse conceito, com base na definição de Brasil (2010c):

\footnotetext{
No contexto da Portaria $\mathrm{n}^{\mathrm{o}} 2.510 / \mathrm{GM}^{2}$ de 19 de dezembro de 2005, considera-se tecnologias em saúde: medicamentos, materiais, equipamentos e procedimentos, sistemas organizacionais, educacionais, de informações e de suporte, e programas e protocolos assistenciais, por meio dos quais a atenção e os cuidados com a saúde são prestados à população (BRASIL, 2010c, p. 10).
}

Importante observar que as tecnologias em saúde, assim como as demais tecnologias, têm passado por um processo de desenvolvimento acelerado, como jamais visto. Assim, não é incomum que com frequência muito grande se ter notícia da modificação e/ou evolução de uma tecnologia existente ou ainda do lançamento de uma tecnologia inovadora e algumas vezes revolucionária.

Assim, entende-se que a gestão de tecnologias em saúde é uma atividade complexa que envolve habilidades em um amplo espectro de áreas do conhecimento como engenharia, medicina, enfermagem, economia, epidemiologia, direito sanitário, ciências sociais, bioquímica, entre outras. Cada uma com sua relevância no entendimento do risco sanitário em sua complexidade atual (VECINA NETO; MARQUES; FIGUEIREDO, 2009, p. 705). Brasil (2010c) ao definir gestão de tecnologias em saúde, entende que:

Assim, define-se, lato sensu, gestão de tecnologias em saúde como o conjunto de
atividades gestoras relacionado com os processos de avaliação, incorporação,
difusão, gerenciamento da utilização e retirada de tecnologias do sistema de
saúde. Este processo deve ter como referenciais as necessidades de saúde, o
orçamento público, as responsabilidades dos três níveis de governo e do controle
social, além dos princípios de equidade, universalidade e integralidade, que
fundamentam a atenção à saúde no Brasil (BRASIL, 2010c, p. 10, grifo do
autor).

Com isso, pode-se conceber que gerenciar tecnologias em saúde envolve participar de todo o ciclo de vida da tecnologia em questão, desde sua avaliação, incorporação, difusão, utilização e na sua retirada de uso. Nesse compasso, Brasil (2010c, p. 14), destaca ainda que a ação de gerenciar tecnologias, deve ter como suporte princípios fundamentais como:

2 Gabinete do Ministro (GM) 
a) uso de evidências científicas;

b) considerar atributos de segurança, eficácia, efetividade, eficiência e impactos econômicos, éticos, sociais e ambientais da tecnologia em questão;

c) atuar de forma crítica e independente nos processos de avaliação promovidos e nas tomadas de decisões de incorporação decorrentes dessas avaliações;

d) facilitar e apoiar o envolvimento de diferentes atores no processo de incorporação de tecnologias;

e) considerar a universalidade do acesso, a equidade e a sustentabilidade das tecnologias;

f) disseminar de forma contínua e transparente o conhecimento sobre as tecnologias efetivas e seguras na atenção à saúde;

g) incorporar a ética em pesquisa envolvendo seres humanos às boas práticas no processo de avaliação de tecnologias em saúde; e

h) ampliar o acesso e participação dos atores representativos dos interesses da sociedade.

Partindo desta perspectiva, cabe destacar que nenhuma destas áreas do conhecimento isoladamente é capaz de prover todos processos e procedimentos necessários para uma completa gestão das tecnologias em saúde. Dada a importância do tema em análise, não se pode deixar de destacar que atualmente, os seguintes setores estão envolvidos nos processos de gestão de tecnologias em saúde (BRASIL, 2010c):

- Administração direta do Ministério da Saúde nas áreas de ciência, tecnologia e inovação; insumos estratégicos; atenção à saúde; vigilância em saúde; gestão participativa; gestão do trabalho e educação em saúde, entre outras;

- Agencias de Vigilância Sanitária e de Saúde Suplementar;

- Secretarias Estaduais e Municipais de Saúde;

- Universidades, hospitais de ensino e centros de pesquisa;

- Prestadores de serviço de saúde;

- Ministério Público;

- Poderes Judiciário e Legislativo;

- Entidades do controle social, como Conselhos de Saúde;

- Órgãos do Executivo envolvidos com ciência, tecnologia e produção industrial;

- Sociedades Científicas;

- Operadoras de plano de saúde; 
- Câmaras setoriais e entidades representativas da indústria; e

- Associações, conselhos e sociedades de profissionais (BRASIL, 2010c, p. 11).

De todo o exposto, pode-se afirmar que a gestão de tecnologias em saúde é um tema de relevância, que importa a toda a sociedade organizada principalmente, por considerar que no sistema de saúde público brasileiro carente de recursos, é necessário orientar o gasto segundo estudos de avaliação tecnológica e protocolos clínicos que indiquem a melhor forma de orientar e compor a gama de serviços incorporada em cada tipo e cuidado à saúde (UGÁ; PORTO, 2008, p. 503). Dessas acepções, pode-se ressaltar que a articulação de produção de saberes na área entre universidades, institutos de pesquisas, setor regulado, nas organizações da sociedade é o desafio para uma atuação mais presente e consistente desta política de proteção (VECINA NETO; MARQUES; FIGUEIREDO, 2009, p. 705).

Posto isto, deve-se considerar que há muito trabalho a ser construído no campo de gestão de tecnologias em saúde, uma vez que no país como um todo essas atividades estão em estágio prematuro quando comparados com países desenvolvidos:

[...] a gestão de tecnologias em saúde se encontra em fase de desenvolvimento inicial. Cabe salientar que, de igual modo, algumas unidades vinculadas ao SUS, como é o caso dos hospitais universitários, vêem utilizando a medicina baseada em evidências como estratégia para avaliação de tecnologias (BRASIL, 2010c, p. 13).

É importante enfatizar que sobre este assunto, WHO (2003, p. v) destaca que países em desenvolvimento possuem uma lacuna no acesso a dispositivos e equipamentos de alta qualidade, adequados para suas específicas necessidades epidemiológicas. Essa particularidade, segundo o autor, decorre da pouca ou inexistente correta avaliação das tecnologias em saúde e baixo controle regulatório por parte dos organismos governamentais.

\subsection{ENGENHARIA CLÍNICA}

A Engenharia Clínica (EC), como um ramo da Engenharia Biomédica (EB), participa de todos os processos decisórios envolvidos no ciclo de vida das tecnologias em saúde. Oshiyama et al (2012, p. 401), corroboram este pensamento ao afirmarem que a área de EC está em constante evolução para atender às novas demandas de cuidados médicos e de gestão. Asseveram os autores que uma vez que tenha ocorrido a integração de práticas de engenharia e de gestão em seus programas, tornou-se importante desenvolver indicadores objetivos e confiáveis para documentar o desempenho e permitir a melhoria dos serviços 
prestados (OSHIYAMA et al, 2012, p. 401, tradução nossa).

Com efeito, a EC é um campo interdisciplinar praticado em uma variedade de configurações e apresentando uma diversidade de desafios. O engenheiro clínico é, por meio da educação e formação, um solucionador de problemas, trabalhando com sistemas tecnológicos de alta complexidade. As responsabilidades da EC, neste cenário, incluem gestão financeira ou orçamentária, gestão de contratos de serviços, uso e desenvolvimento de sistemas de processamento de dados para a gestão do equipamento médico além de coordenação de acordos de serviços e operações in-house. O engenheiro clínico-hospitalar também pode ter a responsabilidade pela supervisão da equipe de manutenção do estabelecimento de saúde, dependendo de seu conjunto de habilidades e da estrutura do departamento (AMERICAN COLLEGE OF CLINICAL ENGINEERING, 2014, tradução nossa).

Ainda, segundo a ACCE (2014), engenheiros clínicos baseados em hospitais também ocupam funções importantes para assegurar que o equipamento médico seja seguro e eficaz. Estas funções incluem a participação no processo de planejamento e na avaliação da tecnologia, garantindo a conformidade regulatória na área de gestão da tecnologia médica, a investigação dos incidentes, e participação ativa na formação e educação do pessoal técnico e de médicos (AMERICAN COLLEGE OF CLINICAL ENGINEERING, 2014, tradução nossa).

Não é incomum, que serviços de saúde no país, possuam diversos equipamentos adquiridos e não disponibilizados à população para uso, por falta de planejamento ou, mesmo se instalados, por falta de correta gestão. Alves, Gomes e Brasil (2014), ao analisarem a quantidade de mamógrafos adquiridos no país e que se encontravam fora de uso. Ponderaram os autores que:

\begin{abstract}
A quantidade de equipamentos fora de produção, sugere planejamento inadequado e ineficiência na gestão do ciclo de vida da tecnologia. Nessa condição, os mamógrafos estão expostos ao risco de se tornarem obsoletos antes mesmo de terem prestado sua função social, representando uma degradação de recursos públicos sabidamente insuficientes para todas as demandas do SUS (ALVES; GOMES; BRASIL, 2014, p. 364).
\end{abstract}

No que diz respeito ainda à manutenção dos equipamentos parados, Malkin e Keane (2010) são categóricos ao evidenciar a carência de profissionais e técnicos de engenharia nas organizações de saúde:

Há evidências de que grande parte deste equipamento médico está fora de serviço por causa da falta de profissionais treinados, capazes de executar os 
reparos necessários ou manutenção, geralmente considerado uma falta de técnicos biomédicos de engenharia ou engenheiros biomédicos (MALKIN; KEANE, 2010, p. 721, tradução nossa).

A importância da presença do profissional de engenharia no contexto da gestão das tecnologias é evidenciada por Van Der Putten et al (1994) ao se referir ao plano de gestão de tecnologias:

O sucesso de um programa de apoio ao equipamento na organização de saúde, eficaz, depende muito do adequado treinamento e capacitação dos empregados (BARETICH, 1988). Configurações atuais consistem de um profissional com doutorado ou mestrado físico/bioengenheiro e ainda com o apoio de outros técnicos do Departamento de Engenharia (VAN DER PUTTEN et al, 1994, p. 665 , tradução nossa).

Assim, fica evidente a necessidade da inserção do engenheiro clínico nos processos decisórios de gestão de tecnologias em saúde, pois como ressalta Ponte Júnior (2014, p. 54), o engenheiro ainda é o profissional teoricamente mais adequado para prover soluções de segurança para um cenário tecnológico. Considera o autor que para alcançar esse objetivo, o engenheiro deve estar preparado para assimilar novos conhecimentos de biologia, comportamento humano, gestão tecnológica e de todos os ramos de especialidades necessários para reduzir riscos dos empreendimentos tecnológicos a níveis aceitáveis (PONTE JÚNIOR, 2014, p. 54).

\subsection{REGULAÇÃO EM SAÚDE}

A Figura 1 ilustra o conceito emitido por WHO (2003, p. 9). O autor enfatiza que a regulação de produtos para a saúde por parte do governo, envolve os três elementos críticos representados.

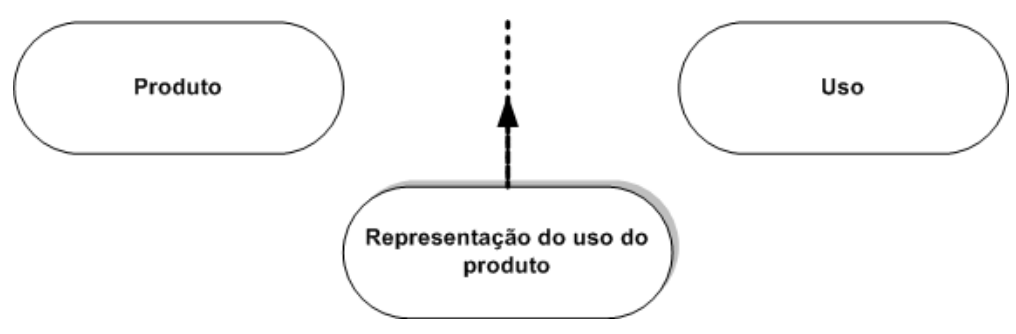

Figura 1 - Representação do produto - três elementos críticos (WHO, 2003, p. 9, tradução nossa).

Esses três elementos, segundo o autor, se relacionam de forma intrínseca, pois o produto e seu uso interrelacionam-se por meio da percepção do produto pelo usuário, que por sua vez, depende relevantemente das condições ambientais e culturais a que o usuário se submete. 
modo de intervenção do Estado para impedir possíveis danos ou riscos à saúde da população. Atua por meio da regulamentação, controle e fiscalização das relações de produção e consumo de bens e serviços relacionados à saúde. Além disso, a regulação sanitária contribui para o adequado funcionamento do mercado, suprindo suas falhas, dando cada vez mais previsibilidade, transparência e estabilidade ao processo e à atuação regulatória, a fim de propiciar um ambiente seguro para a população e favorável ao desenvolvimento social e econômico do país (BRASIL, 2014a).

Em relação às tecnologias em saúde, compete à Anvisa:

[...] a Anvisa tem a missão de regular as tecnologias, normatizando a entrada no mercado brasileiro dos produtos oriundos do complexo industrial da saúde e o seu correspondente uso público e privado nos diferentes setores de serviço, além de participar da construção do acesso a estas tecnologias (BRASIL, 2010c, p. 12).

Partindo destas premissas, Mello e Ramalho (2009, p. 241-242) inferem que no âmbito das competências regimentais da Anvisa, está inclusa a regulação de serviços de saúde, de produtos para a saúde, de laboratórios de saúde pública e da propaganda de produtos de interesse à saúde. Conciliam-se com essas reflexões Vecina Neto, Marques e Figueiredo (2009, p. 690) quando ressaltam que é neste conjunto de ações que está inscrita a prática da vigilância sanitária. Para os autores, essas ações são circunscritas em políticas, normas, técnicas, legislações, fiscalizações, planejamento, avaliação, monitoramento, entre outras naturezas de ações de campo.

Mello e Ramalho (2009, p. 241-242) complementam o raciocínio, citando como exemplos dos produtos regulados - e processos a eles relacionados - pela Anvisa, os medicamentos, os alimentos, os produtos para saúde - equipamentos, produtos médicos e kits diagnósticos; sangue, outros tecidos, células e órgãos; saneantes; cosméticos; produtos tóxicos - com destaque para os agrotóxicos; e produtos derivados do tabaco. Por fim, relatam que a Anvisa mantém controle também sobre os ambientes, os processos, os insumos e as tecnologias a eles relacionados além de realizar o monitoramento de preços de medicamentos.

Para Vecina Neto, Marques e Figueiredo (2009, p. 705) a ação da vigilância sanitária deve sempre ser balizada pela regra (lei, portaria, resolução, ou outra hierarquia legislativa). No campo da gestão de tecnologias em saúde, a Anvisa comumente se instrumentaliza com resoluções colegiadas para regulamentar a forma como os serviços de saúde devem executar suas ações.

Os atos regulatórios cujo contexto se referem à gestão de tecnologias em saúde e gestão de riscos em saúde são os seguintes: 
a) Resolução da Diretoria Colegiada $n^{0} 2$, de 25 de janeiro de 2010. Esta resolução dispõe sobre o gerenciamento de tecnologias em saúde em estabelecimentos de saúde (BRASIL, 2010a).

b) Resolução da Diretoria Colegiada no 36, de 25 de julho de 2013. Esta resolução institui ações para a segurança do paciente em serviços de saúde (BRASIL, 2013a).

c) Resolução da Diretoria Colegiada no 63, de 25 de novembro de 2011. Esta resolução dispõe sobre os requisitos de Boas Práticas de Funcionamento para os Serviços de Saúde (BRASIL, 2011).

\subsection{NORMALIZAÇÃO}

Segundo a ABNT (2014), normalização é uma atividade que estabelece, em relação a problemas existentes ou potenciais, prescrições destinadas à utilização comum e repetitiva com vistas à obtenção do grau ótimo de ordem em um dado contexto. A ABNT (2014) infere ainda que na prática, a normalização está presente na fabricação dos produtos, na transferência de tecnologia, na melhoria da qualidade de vida através de normas relativas à saúde, à segurança e à preservação do meio ambiente.

Para países como o Brasil, o uso de normas e padrões reconhecidos internacionalmente contribui para sua inserção no mercado mundial (tanto como importador quanto como exportador). Mais ainda, no contexto dos serviços de saúde:

\footnotetext{
Para os países em desenvolvimento, a referência a um sistema de normas, não só ajuda a administração de dispositivos médicos, também é importante para outros desenvolvimentos industriais e econômicos. Agências de desenvolvimento internacionais percebem cada vez mais que uma infraestrutura padronizada é um requisito básico para o sucesso das políticas econômicas que irão melhorar a produtividade, a competitividade no mercado e capacidade de exportação (LEOTSAKOS et al, 2014, p . 111, tradução nossa).
}

Atividades de engenharia são, em sua essência, normalizadas a fim de que se obtenha uma forma padronizada de execução dos seus processos. Outro fator relevante no que diz respeito à normalização em engenharia é o fato de que com o uso de normas, se pode comparar resultados alcançados uma vez que com a padronização dos processos, se espera atingir resultados semelhantes, se preservadas todas as condições ambientais. Da mesma forma, os serviços de saúde também estão sujeitos a se alinharem às prescrições normalizadas: 
equipamentos e dispositivos médicos é dada pela ISO:

As normas são acordos que contêm especificações técnicas ou outros critérios precisos para serem usados constantemente como regras, diretrizes ou definições de características, documentado para assegurar que materiais, produtos, processos e serviços são adequados para os seus fins (WHO, 2003, p. 18, tradução nossa).

As normas possuem características distintas e se destinam para diferentes propósitos:

Tipos de especificações em normas:

As normas podem estabelecer uma ampla gama de especificações para produtos, processos e serviços (ver www.iso.org para definições).

1. As especificações prescritivas obrigam as características do produto, como por exemplo dimensões do dispositivo, biomateriais, procedimentos de ensaio ou calibração, bem como definições de termos e terminologias.

2. As especificações do projeto estabelem características do projeto específico ou características técnicas de um produto, por exemplo, instalações da sala de cirurgia ou sistemas de gás medicinal.

3. As especificações de desempenho asseguram que um produto satisfaça um teste prescrito, por exemplo, requisitos de resistência, precisão de medição, a capacidade da bateria ou energia máxima desfibrilador.

4. Especificações de gestão estabelecem requisitos para os processos e procedimentos de empresas colocados em prática, por exemplo, sistemas de qualidade para a fabricação ou de sistemas de gestão ambiental (WHO, 2003, p. 18 , tradução nossa).

Ainda sobre os tipos de normas, existem também aquelas de características mistas:

Uma norma pode conter uma combinação de especificações. Prescritiva, projeto e especificações de desempenho têm sido comuns em padrões. Especificações de gerenciamento também estão rapidamente ganhando destaque (WHO, 2003, p. 18, tradução nossa).

Decorre de fatos como a globalização da economia, da produção e do consequente consumo de bens e serviços, a necessidade de padronização em escala global. No âmbito dos serviços de saúde é muito comum o uso de dispositivos médicos produzidos em diversas partes do mundo que atendem a padrões e normas internacionais de especificações prescritivas, de projeto, de desempenho e performance e ainda de gestão.

Outro aspecto relevante em relação à padronização em escala global diz respeito ao fato de diferentes fabricantes produzirem peças e partes que compõem os equipamentos e máquinas que devem ser compatíveis entre si, de forma a manter a performance, segurança e demais características técnicas do equipamento:

Os profissionais de saúde estão bem conscientes de consumo incompatíveis ou peças de reposição em dispositivos médicos de função similar que são produzidas por fabricantes diferentes. A falta de materiais de consumo e peças de reposição disponíveis é uma importante causa de problemas de equipamentos médicos que são constantemente encontrados em países em desenvolvimento.

A maioria dos dispositivos médicos são utilizados em todo o mundo. A 
segurança, desempenho e qualidade consistente de dispositivos médicos é, portanto, um interesse de saúde pública internacional. Assim, a harmonização global das normas e regulamentações de dispositivos médicos é crítica (WHO, 2003, p. 19, tradução nossa).

É importante destacar que em contexto mundial, existem diversos organismos normalizadores, cada qual com seu âmbito específico de atuação. Nos Estados Unidos, o American National Standards Institute (ANSI), uma organização privada sem fins lucrativos, é uma organização nacional oficial. No Canadá, é o Standards Council of Canada (SCC), uma corporação governamental. Na Europa, há um comitê composto pela Comité Européen de Normalisation (CEN) pelo European Committee for Electrotechnical Standardization (CENELEC) e pelo European Telecommunication Standards Institute (ETSI), que substitui os vários organismos europeus de normalização nacionais que estavam em vigor anteriormente.

Para WHO (2003, p. 19), as três principais organizações internacionais de normalização são a International Organization for Standardization (ISO), a International Electrotechnical Commission (IEC) e a International Telecommunication Union (ITU). Geralmente, ITU abrange telecomunicações, IEC abrange engenharia elétrica e eletrônica, e ISO cobre o restante. Para tecnologia da informação, gestão de riscos, sistemas de qualidade e muitas outras áreas, comitês técnicos da ISO / IEC em conjunto gerenciam a padronização. Para o presente estudo, são consideradas de relevância, sob o aspecto internacional, as normas editadas pela ISO e IEC.

Em consonância com a normalização internacional, cada país pode ter internamente, um ou mais organismos normalizadores. Para Leotsakos et al (2014, p. 111), não obstante à possibilidade de existência de diversos organismos normalizadores, normalmente há uma organização oficial nacional que coordena e credencia os organismos de desenvolvimento de normas no país. Ressaltam os autores que esta organização nacional oficial teria a autoridade para aprovar um documento como um padrão nacional, em conformidade com os critérios oficiais, e também representa o país nas diversas organizações internacionais de normalização.

No Brasil, a Associação Brasileira de Normas Técnicas (ABNT) cumpre o papel de organização normalizadora. Segundo informações veiculadas no corpo das normas elaboradas pela ABNT, as Normas Brasileiras, cujo conteúdo é de responsabilidade dos Comitês Brasileiros (ABNT/CB) e dos Organismos de Normalização Setorial (ABNT/ONS), são elaboradas por Comissões de Estudo (CE), formadas por 
representantes dos setores envolvidos, delas fazendo parte: produtores, consumidores e neutros (universidades, laboratórios e outros).

No entendimento de ABNT (2011b, 2014), normas de segurança para produtos para a saúde e processos possuem um papel significativo tanto no seu gerenciamento adequado, quanto no gerenciamento de risco intrínseco. Em princípio, estas normas são desenvolvidas utilizando um tipo de gerenciamento de risco que pode incluir a identificação de perigos e situações perigosas, a análise de risco, a determinação de risco e as medidas de controle de risco específicas. $\mathrm{O}$ gerenciamento adequado dos equipamentos para a saúde é vital para garantir que eles permaneçam seguros ao uso pretendido e para que sua vida útil seja maximizada (ASSOCIAÇÃO BRASILEIRA DE NORMAS TÉCNICAS, 2011b, 2014).

ABNT $(2014$, p. 1) considera que para os produtos para a saúde que satisfazem os requisitos e estão em conformidade com os critérios destas normas, o risco relacionado aos perigos/situações perigosas identificadas pode ser considerado aceitável, a não ser que exista uma evidência objetiva contrária. Algumas fontes de evidência objetiva contrária podem incluir relatórios de eventos adversos, reclamações e recolhimentos de produtos para a saúde.

As referências normativas para a gestão de riscos e gestão de tecnologias em saúde em contexto mundial e nacional a serem utilizadas no presente estudo são as seguintes:

a) ISO 31000:2009 - Risk management - principles and guidelines. Esta ISO 31000:2009 foi traduzida para o português pela ABNT (Comissão de Estudo Especial de Gestão de Riscos - ABNT/CEE-63) e nomeada ABNT NBR ISO 31000:2009 - Gestão de riscos - princípios e diretrizes (ASSOCIAÇÃO BRASILEIRA DE NORMAS TÉCNICAS, 2009b);

b) IEC 60300-3-9 (1995-12) - Dependability management-Part3: Application guide - Section 9: Risk analysis of technological systems. Esta norma foi substituída pela norma ISO/IEC 31010:2009 - Risk management - Risk assessment techniques. Esta ISO/IEC 31010:2009, por sua vez, foi traduzida para o português pela ABNT (Comissão de Estudo Especial de Gestão de Riscos - ABNT/CEE-63) e nomeada ABNT NBR ISO/IEC 31010:2012 - Gestão de riscos - técnicas para o processo de avaliação de 
riscos (ASSOCIAÇÃO BRASILEIRA DE NORMAS TÉCNICAS, 2012c);

c) ISO 14971:2007 - Medical devices - Application of risk management to medical devices. Esta ISO 14971:2007 foi traduzida para o português pela ABNT (Comitê Brasileiro Odonto-Médico-Hospitalar - ABNT/CB-26) e nomeada ABNT NBR ISO 14971:2009 - Produtos para a saúde aplicação de gerenciamento de risco a produtos para a saúde (ASSOCIAÇÃO BRASILEIRA DE NORMAS TÉCNICAS, 2009a);

d) ISO 24971:2013 - Medical devices - Guidance on the application of ISO 14971. Esta ISO 24971:2013 foi traduzida para o português pela ABNT (Comitê Brasileiro Odonto-Médico-Hospitalar - ABNT/CB-26) e nomeada ABNT ISO/TR 24971:2014 - Produtos para a saúde Orientações para a aplicação da ABNT NBR ISO 14971 (ASSOCIAÇÃO BRASILEIRA DE NORMAS TÉCNICAS, 2014);

e) ISO Guide 73:2009 - Risk management - vocabulary. Esta ISO Guide 73:2009 foi traduzida para o português pela ABNT (Comissão de Estudo Especial de Gestão de Riscos - ABNT/CEE-63) e nomeada ABNT ISO GUIA 73:2009 - Gestão de riscos - Vocabulário (ASSOCIAÇÃO BRASILEIRA DE NORMAS TÉCNICAS, 2009c); e

f) ABNT NBR 15943:2011 - Diretrizes para um programa de gerenciamento de equipamentos de infraestrutura de serviços de saúde e de equipamentos para a saúde (ASSOCIAÇÃO BRASILEIRA DE NORMAS TÉCNICAS, 2011b).

\subsection{GESTÃO DE TECNOLOGIAS EM SAÚDE}

Para efeito da discussão a respeito da gestão de tecnologias em saúde, foram considerados essencialmente os seguintes dispositivos:

- Regulação: Brasil (2010a, 2011 e 2013a);

- Normalização: ABNT (2009d e 2011b); e

- Padrões (standards): Brasil (2013b).

A Figura 2 ilustra o modo como os equipamentos médico-assistenciais (EMA) 
estão inseridos no contexto das tecnologias em saúde, da forma como proposta por Brasil (2009, p. 19).

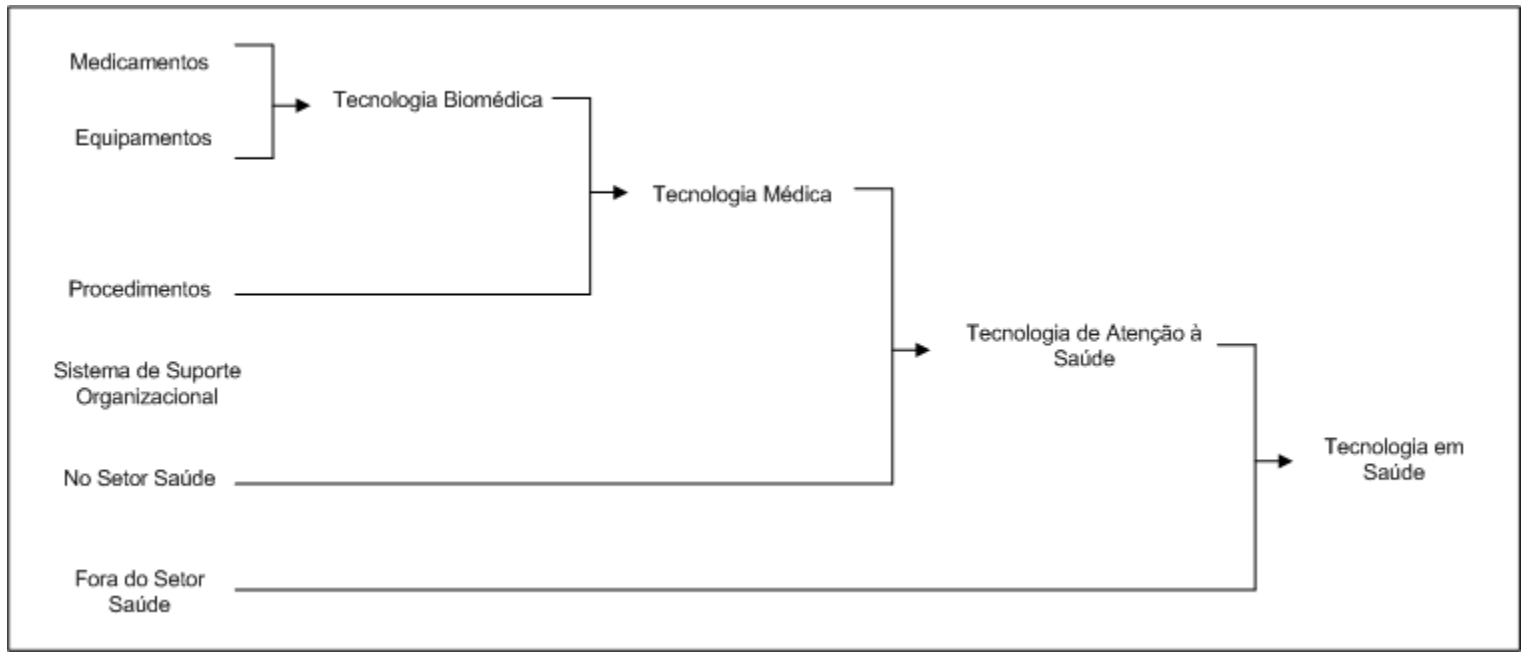

Figura 2 - Espectro de tecnologias em saúde (BRASIL, 2009, p. 19).

Assim, estes EMAs, compõem o espectro das tecnologias em saúde, sendo classificados como tecnologia biomédica. Para Brasil (2009) a tecnologia biomédica (equipamentos e medicamentos) são aquelas que interagem diretamente com os pacientes. O ciclo de vida destas tecnologias, composto pelas fases de desenvolvimento e utilização no mercado é ilustrado graficamente (Figura 3) por Brasil (2013b).

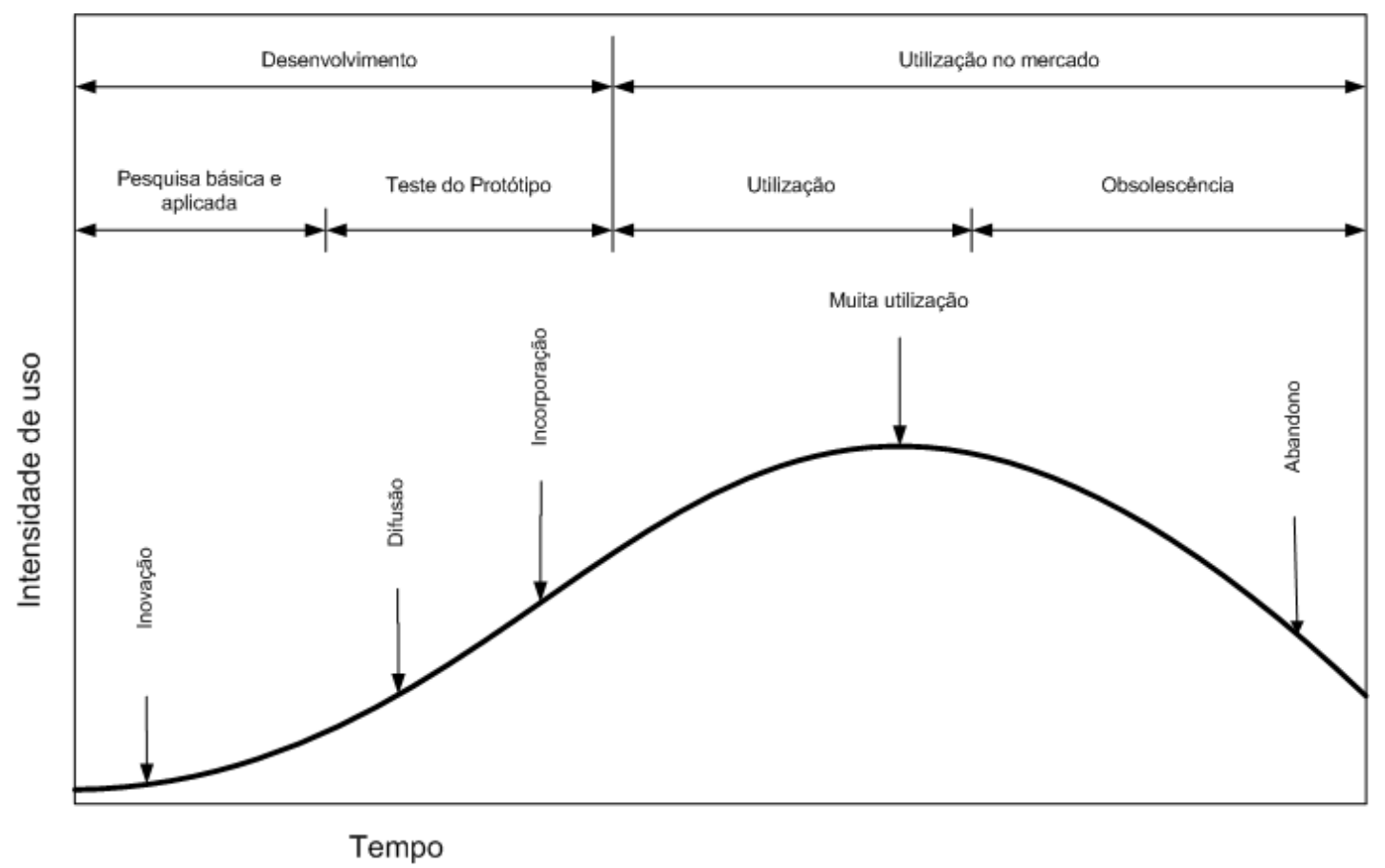

Figura 3 - Ciclo de vida das tecnologias em saúde (intensidade de uso de uma tecnologia em saúde em função do tempo) (Brasil, 2013b, p. 16). 
Durante a fase de utilização no mercado, a tecnologia em saúde, passa pelos seguintes estágios (ASSOCIAÇÃO BRASILEIRA DE NORMAS TÉCNICAS, 2011b), considerando o contexto interno do estabelecimento de saúde: (i) planejamento e seleção, (ii) aquisição, (iii) recebimento e verificação, (iv) armazenamento, (v) instalação, (vi) ensaios de aceitação, (vii) treinamento, (viii) uso, (ix) intervenção técnica, $(x)$ inventário, (xi) transferência interna, (xii) desativação e (xiii) descarte.

Todos os processos e procedimentos a serem executados nestes estágios devem ser documentados, gerando assim, (i) um registro histório e o seu (ii) arquivo de registro. Para Brasil (2010a), todos os processos e procedimentos que geram esses documentos compõem o Plano de Gerenciamento de Tecnologias em Saúde e devem sofrer revisão com periodicidade mínima anual.

Para Augustoviski, Pichon-Riviere e Rubinstein (2010, p. 493), as decisões sobre incorporação, aquisição, reembolso ou cobertura de novas tecnologias e a determinação de como utilizá-las estão entre as decisões mais importantes que devem tomar um sistema de saúde em geral e os administradores de serviços de saúde em particular. Considerando a importância desta decisão e extrapolando o modelo proposto por Brasil (2014b) que estabelece que o planejamento de uma contratação de Soluções de Tecnologia da Informação (TI) deve ser composto pelas etapas de:

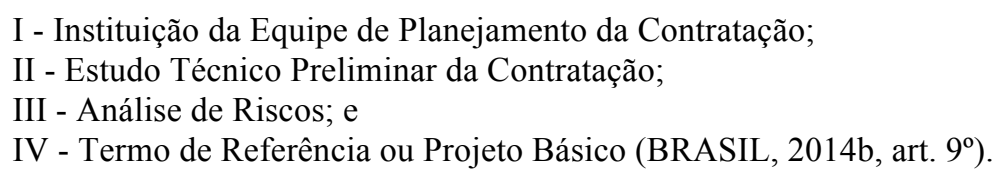

Este modelo proposto para aquisição de soluções de TI, quando adaptado à aquisição de EMAs se mostra adequado, pois há a necessidade de instalação de uma equipe multidisciplinar para subsidiar a tomada de decisão de incorporação de uma determinada tecnologia, sendo determinado a esta equipe a confecção dos estudos técnicos preliminares à aquisição.

Brasil (2013b) alerta para a importância desta fase que precede a aquisição de EMA:

Para a adequada avaliação de EMA, principalmente no SUS, é necessário conhecer os processos nos quais serão inseridas essas tecnologias. O processo de avaliação, quando pautado no momento de aquisição dos EAS consta das seguintes etapas: planejamento, especificação, aquisição, recebimento, instalação e treinamento. Ressalta-se que, na etapa de planejamento, as necessidades, os impactos, custos e benefícios dos EMAs devem ser avaliados com o auxílio da 
$\mathrm{ATS}^{3}$ (WANG, 2009). Além disso, conhecer o ciclo de vida das tecnologias se faz necessário para melhor planejar os recursos requeridos durante as diferentes etapas das fases de seu ciclo de vida. Tecnologias pouco investigadas durante o processo de avaliação poderão ser propensas à variação do seu efeito ou poderiam ser aderidas tecnologias que já estejam obsoletas (BRASIL, 2013b, p. $15)$.

A Tabela 3 contém, de forma resumida, a estrutura geral da diretriz metodológica estabelecida por Brasil (2013) no que diz respeito aos critérios para estudo de avaliação de EMA.

Tabela 3 - Estrutura geral da diretriz metodológica: apresentam-se de forma resumida os critérios do estudo de avaliação para EMA, conforme a abordagem. Consequentemente onde encontrada evidência.

\begin{tabular}{|c|c|c|}
\hline Domínio & Critérios & Fontes de informação \\
\hline \multirow{3}{*}{ Clínico } & $\begin{array}{l}\text { Revisões sistemáticas e } \\
\text { estudos com qualidade } \\
\text { metodológica, buscando } \\
\text { evidências de segurança } \\
\text { e eficácia/efetividade }\end{array}$ & CoCHrane; PubMed; LILACS; CRD; NHSCEP \\
\hline & $\begin{array}{l}\text { Demais estudos que } \\
\text { contenham evidências de } \\
\text { segurança, } \\
\text { eficácia/efetividade }\end{array}$ & $\begin{array}{l}\text { ECRI; EMBASE. CENETEC; FDA; MS; Web of Science; CEP (Centre for } \\
\text { Evidence based Purchasing); AAMI (Association for the Advencedment of } \\
\text { Medical Instrumentation) }\end{array}$ \\
\hline & Fase do ciclo de vida & FDA; ECRI \\
\hline \multirow{4}{*}{ Admissibilidade } & $\begin{array}{l}\text { Registro Sanitário do } \\
\text { Produto }\end{array}$ & Anvisa RDC n² 260: 2002; RDC Nº 185:2001 e atualizações \\
\hline & Recall & \\
\hline & $\begin{array}{l}\text { Cobertura Populacional } \\
\text { Recomendada }\end{array}$ & ECRI; Notivisa; FDA; Anvisa; Portaria n. ${ }^{\circ} 1101: 2002$ e Atualizações \\
\hline & $\begin{array}{l}\text { Parâmetros Assistenciais } \\
\text { do SUS }\end{array}$ & \\
\hline Técnico & $\begin{array}{l}\text { Modelos } \\
\text { Caracteristica Técnica do } \\
\text { Equipamento }\end{array}$ & $\begin{array}{l}\text { Anvisa; ECRI; Cenetec; Notivisa; Cnes; OMS; RDC nº 59: } 2000 \text { e No } \\
\text { 56:2001; RDC Nº 185:2001 e atualizações }\end{array}$ \\
\hline \multirow{7}{*}{ Operacional } & $\begin{array}{l}\text { Ergonomia } \\
\text { Segurança no Trabalho }\end{array}$ & $\begin{array}{l}\text { Normas Regulamentadoras (NR), Ministério do Trabalho e Emprego; NBR } \\
\text { IEC 60601:2010 }\end{array}$ \\
\hline & Usabilidade & ISO 9241-11; IEC 60601-1-6; Anvisa \\
\hline & Treinamento & RDC Nº 2:2010 e Nº 20:2012 e atualizações \\
\hline & $\begin{array}{l}\text { Infraestrutura, Espaço } \\
\text { Físico e Instalações }\end{array}$ & $\begin{array}{l}\text { RDC n50:2002;e atualizações; Somasus (Portaria 2.481:2007) } \\
\text { NBR's; Cnen n 112:2011; Cnen NE 6.02:1998; Código, Leis e Normas; } \\
\text { Municipais, Estaduais e Federais }\end{array}$ \\
\hline & $\begin{array}{l}\text { Acessórios, Insumos e } \\
\text { Armazenamento }\end{array}$ & IN nº 13 de 2009; NBR 15943:2011 \\
\hline & Manutenção e Calibração & MS; RDC n²:2010; NBR 15943:2011; NBR 5462:94 \\
\hline & Fatores de Risco & ISO14971; RDC n56 /2001; RDC n 59/2000; IEC 60601-1-4; Anvisa \\
\hline \multirow{2}{*}{ Econômico } & $\begin{array}{l}\text { Estudos de Avaliação } \\
\text { Econômica D }\end{array}$ & Diretriz Metodológica: Pareceres Técnico-Científicos, 3ª ed. 2011 \\
\hline & $\begin{array}{l}\text { Custo Total de } \\
\text { Propriedade }\end{array}$ & $\begin{array}{l}\text { Anvisa; Diretriz Metodológica: Estudos de Avaliação Econômica de } \\
\text { Tecnologia em Saúde, 2009; Portaria № 448: } 2002 .\end{array}$ \\
\hline Inovação & $\begin{array}{l}\text { Capacidade industrial } \\
\text { instalada } \\
\text { Patentes registradas } \\
\text { Volume de produtos }\end{array}$ & $\begin{array}{l}\text { CNPq - <www.cnpq.br>; CAPES - <www.capes.gov.br>; IBGE } \\
<w w w . i b g e . g o v . b r>; \text { Pesquisa Industrial de Inovação Tecnológica } \\
\text { <www.pintec.ibge.gov.br>; INPI <www.inpi.gov.br>; ABDI } \\
\text { <www.abdi.com.br>; Banco de teses das Universidades, ABIMO }\end{array}$ \\
\hline
\end{tabular}

3 Avaliação de Tecnologias em Saúde. 


\begin{tabular}{|c|c|c|}
\hline Domínio & Critérios & Fontes de informação \\
\hline & $\begin{array}{l}\text { industrializados } \\
\text { Pesquisas desenvolvidas }\end{array}$ & $\begin{array}{l}\text { <www.abimo.org.br>; IPEA <www.ipea.gov.br>; MDIC <ww.mdic.gov.br>; } \\
\text { Sistema de Análise das Informações de Comércio Exterior } \\
\text { <http://aliceweb2.mdic.gov.br>; Agência Brasileira de Promoção de } \\
\text { Exportação e Investimento <www.apexbrasil.com.br>; BNDES } \\
\text { <www.bndes.gov.br> }\end{array}$ \\
\hline
\end{tabular}

Fonte: Brasil (2013, p. 72-74).

Importa destacar que a ABNT (2011b) entende que a organização de saúde deve estabelecer fluxo para incorporação tecnológica, considerando: $(i)$ critérios para seleção de equipamentos, (ii) regularização dos equipamentos e dos seus fornecedores junto à autoridade sanitária competente, (iii) a demanda, (iv) a infraestrutura física ou tempo necessário para sua adequação e, $(v)$ os recursos e materiais necessários à utilização do equipamento. Enfatiza o autor que o planejamento e a seleção devem ser documentados e atender aos procedimentos escritos.

O estágio de aquisição dos EMAs compreende qualificar fornecedores (tanto de equipamentos quando de serviços) envolvendo regularização junto ao órgão sanitário e registro no conselho de classe, quando aplicável. A qualificação consiste em um modo de avaliação da conformidade de empresas, realizada por meio de auditorias de certificação para verificar o atendimento a requisitos estabelecidos. Barbieri e Machline (2006) enfatizam que a seleção de fornecedores deve ser fundamentada em uma análise multicritério, mesmo nos casos de compras com base no menor preço. Para os autores a relação de critérios deve envolver análises quanto a:

- assistência técnica;

- atendimento às compras de emergência;

- atendimento às normas trabalhistas;

- capacidade de inovação;

- certificações de segunda e terceira partes;

- consumo de energia;

- devoluções de produtos vencidos;

- disponibilidade de estoques para pronta entrega;

- divergências anteriores;

- especificações do produto;

- facilidade de manutenção;

- flexibilidade para incorporar mudanças nas condições iniciais do pedido;

- nível de atendimento;

- pontualidade nas entregas anteriores;

- prazo de entrega;

- prazo de pagamento;

- preço;

- prestação de informações durante o processo de compra;

- qualidade;

- reputação do fornecedor;

- saúde financeira;

- sistema de gestão da qualidade;

- sistema de gestão ambiental;

- sistemas de segurança e saúde do trabalho; 
- status da conformidade com a legislação de defesa do consumidor;

- status dos licenciamentos e das demais exigências ambientais (BARBIERI; MACHLINE, 2006, p. 212-213).

O para ABNT (2011b) o serviço de saúde somente deve receber o equipamento acompanhado de: (i) especificações técnicas do equipamento; (ii) comprovação da regularização do equipamento no órgão sanitário competente; (iii) número de série; (iv) documento fiscal, e $(v)$ documentos acompanhantes. Para o autor, o recebimento inicia com a chegada do equipamento ao serviço de saúde e finaliza com a emissão do laudo de ensaio de aceitação.

Esse processo deve ser composto por:

a) inspeção de recebimento: técnica designada para recebimento do equipamento. A equipe deverá realizar uma inspeção visual do equipamento entregue pelo fornecedor, para assegurar que: $(i)$ o equipamento corresponde àquele especificado no edital; (ii) o equipamento está completo, com todos acessórios e documentação técnica especificados no edital; (iii) não existem partes do equipamento e seus acessórios danificados, e (iv) o equipamento está compatível com os requisitos de pré-instalação aprovados pelo fornecedor;

b) formalização do recebimento: a equipe técnica comunicará à unidade competente da instituição, o recebimento formal do equipamento, para a adoção das providências necessárias ao cumprimento das condições e prazos previstos no contrato firmado entre o fornecedor e a instituição;

c) identificação do equipamento: após seu recebimento formal, o equipamento deve receber um código de identificação apropriado, a fim de inclui-lo no patrimônio e no sistema de gerência e manutenção da instituição; e

d) formalização da aceitação: a equipe técnica comunicará à unidade competente da instituição, o aceite final do equipamento, para adoção das providências necessárias ao cumprimento das condições e prazos previstos no contrato firmado entre o fornecedor e a instituição (BRASIL, 2014c).

No que diz respeito ao armazenamento dos equipamentos após o seu recebimento, ABNT (2011) enfatiza determinados cuidados a serem tomados com o enquipamento no período de tempo entre sua recepção no estabelecimento de saúde e a sua devida instalação, pelo responsável:

a) os equipamentos devem ser armazenados conforme especificação do fornecedor;

b) quando as especificações do fornecedor exigirem controle ambiental contínuo, deve haver registros que comprovem o atendimento a estas exigências;

c) devem ser estabelecidos e implementados critérios para impedir o uso de equipamentos que ainda não tenham sido aprovados no recebimento, estejam sob manutenção, impedidos de uso, indicados para descarte ou devolução, devendo estar identificados quando à sua situação e destino, além de devidamente segregados;

d) os equipamentos devem ser armazenados isoladamente de produtos e substâncias que possam afetar a sua identidade, integridade, segurança e desempenho, tais como: produtos radioativos, substancias químicas voláteis, inflamáveis, explosivas, altamente reativas, toxicas ou corrosivas; 
e) o armazenamento deve ser feito em local específico, não podendo ocorrer em área de circulação, mesmo que temporariamente; e

f) o armazenamento de fontes radioativas ou de equipamentos que possuam fontes radioativas incorporadas deve estar de acordo com o plano de proteção radiológica aprovado para o serviço de saúde, conforme legislação vigente (ABNT, 2011).

A instalação dos equipamentos deve atender às prescrições do fabricante no que diz respeito à infraestrutura e conformidade com normalização e regulação específicas. Neste sentido a Anvisa publicou a RDC 50, de 2002 (além de outras RDCs que a alteram/complementam) que se destina a regular o planejamento, programação, elaboração, avaliação e aprovação de projetos físicos de estabelecimentos assistenciais de saúde, tratando inclusive das condições de infraestrutura desses estabelecimentos, para atender às diversas necessidades. Compete, assim, ao departamento de infraestrura da organização de saúde, manter as condições alí prescritas, para que o equipamento seja instalado.

No que diz respeito à EC, esta deve ser provida de espaço destinado à intervenção técnica de equipamentos, mantidas em bom estado de conservação, higiene e limpeza. Este espaço deve possuir instalações elétricas, iluminação e sistemas de climatização necessários à conservação dos equipamentos para saúde e às atividades desenvolvidas, de acordo com a recomendação do fabricante e demais regulamentações pertinentes, além de estar protegida contra a entrada de insetos, roedores e outros animais (ASSOCIAÇÃO BRASILEIRA DE NORMAS TÉCNICAS, 2011).

O serviço de saúde deve desenvolver e manter um procedimento que assegure que todos os equipamentos sejam avaliados antes do seu primeiro uso (após a instalação), por meio de ensaios de aceitação, sendo recomendável que a empresa fornecedora do equipamento participe da realização desses ensaios (ASSOCIAÇÃO BRASILEIRA DE NORMAS TÉCNICAS, 2011).

Os ensaios de aceitação devem seguir atividades estabelecidas entre o fabricante, o fornecedor e o serviço de saúde, com base nas normas técnicas aplicáveis ao equipamento e a regulação pertinente. Neste contexto, não se pode deixar de ter atenção especial às atividades que garantam a segurança e o desempenho essencial do equipamento (ASSOCIAÇÃO BRASILEIRA DE NORMAS TÉCNICAS, 2011).

Compõem etapas do ensaio de aceitação: ( $i)$ emissão de parecer técnico que evidencie a segurança e o desempenho essencial do equipamento, e (ii) comissionamento 
da infraestrutura, quando necessário ao funcionamento seguro do equipamento.

Atendidos todos os requisitos referentes aos ensaios e aceitação do equipamento, o estabelecimento de saúde estará em condições a iniciar a etapa de treinamento necessário para garantir que cada agente de serviços esteja apto a realizar as suas atividades. O conteúdo do treinamento deve incluir capacitação em: $(i)$ normas de segurança previstas em atos legais e normativos; (ii) novos equipamentos e ferramentas; e (iii) novos processos de trabalho.

A ABNT (2010) estabelece ainda que, caso o treinamento a ser oferecido seja um requisito para o uso seguro e efetivo do equipamento, em uma função de operação primária, o fabricante deve realizar pelo menos um dos itens a seguir:

a) fornecer os materiais necessários para o treinamento;

b) assegurar que os materiais necessários para o treinamento sejam disponíveis; $\mathrm{ou}$

c) fornecer o treinamento (ASSOCIAÇÃO BRASILEIRA DE NORMAS TÉCNICAS, 2010, p. 14).

Especifica ainda a $\mathrm{ABNT}$ (2010, p. 14) que caso o treinamento seja requerido, o uso pretendido e o perfil de usuário devem ser sua base assim como o material utilizado. Com isso se procura vencer uma barreira cultural, caso exista, ao se planejar acapacitação no uso do em EMA, utilizando-a para fornecer conhecimentos e habilidades requeridas para o uso seguro e efetivo do produto para a saúde, além daqueles conhecimentos e habilidades definidos pelo perfil do usuário.

Devem ser documentadas as partes que compõem o treinamento, incluindo: $(i)$ seu conteúdo programático; (ii) os critérios da avaliação de suas necessidades; (iii) participação e avaliação do treinado; e (iv) avalição da sua eficácia (ASSOCIAÇÃO BRASILEIRA DE NORMAS TÉCNICAS, 2011).

A ABNT (2010) alerta para a possibilidade do uso inadequado de EMAs decorrente de falhas no projeto do equipamento:

[...] Erros de utilização causados por inadequada usabilidade dos produtos para a saúde têm se tornado uma causa crescente de preocupação. Muitos produtos para a saúde são desenvolvidos sem a aplicação de processos de engenharia de usabilidade, tornando-se, portanto, não intuitivos, de difícil aprendizado e utilização. Com a evolução dos cuidados à saúde, usuários menos habilitados, incluindo os próprios pacientes, estão utilizando produtos para a saúde e estes estão tornando-se mais complexos. Assim, o usuário de produtos para a saúde deveria estar apto a lidar com uma interface de usuário ambígua e de difícil utilização (ASSOCIAÇÃO BRASILEIRA DE NORMAS TÉCNICAS, 2010, p. vii). 
Partindo dessa premissa, o equipamento somente deve ser utilizado por profissional comprovadamente treinado, para que se possa garantir a segurança e efetividade. Além do mais, o EMA deve ser mantido em condições adequadas de segurança durante o uso.

Para uso de equipamento emissor de radiações ionizantes, devem ser observados ainda os requisitos de proteção radiológica contidos em legislação específica vigente.

Passado o estágio de treinamento, com posterior início do uso dos EMAs, tem então o início do estágio em que devem ocorrer as intervenções técnicas. Ao tratar do assunto, Holsbach e Calil (2005) categorizam as intervenções:

a) manutenção corretiva (MC): manutenção feita para restabelecer um bem ou um serviço, cujo desempenho tenha sofrido uma queda depor de ter saído de um estado específico. Para equipamentos, podemos dizer que a manutenção corretiva é o conjunto de ações aplicadas para adequar o equipamento, de forma que ele possa voltar a desempenhar suas funções.

b) manutenção preventiva (MP): manutenção feita nos sistemas técnicos, bens ou servicoes para assegurar o seu funcionamento dentro de um estado específico. No caso de equipamentos, pode-se dizer que a manutenção preventiva representa todas as acoes necessárias para manter o equipamento em boas condições de operações e reduzir falhas (HOLSBACH; CALIL, 2005, p. 13).

Para atingir os objetivos deste estágio, o serviço de saúde deve ainda estabelecer e implementar procedimentos para assegurar a rastreabilidade metrológica do equipamento, assim como desenvolver e implementar procedimentos para inserção, ensaio, manutenção, ajuste e calibração no equipamento. Todas as intervenções (independente da categoria) devem ser documentadas no registro histórico do equipamento, indicando inclusive o nome do executor e, obrigatoriamente ser executados somente por profissional comprovadamente treinado (ASSOCIAÇÃO BRASILEIRA DE NORMAS TÉCNICAS, 2011).

A desativação de um EMA pode se dar por diversos motivos: $(i)$ obsolescência tecnológica, (ii) carência e/ou inexistência de peças e mão de obra no mercado, (iii) mudança dos objetivos de uma organização de saúde, (iv) ausência de recursos financeiros que custeiem o correto funcionamento do EMA. Para tanto, o serviço de saúde deve possuir documentados, os critérios utilizados para desativação dos equipamentos para a saúde, gerando um laudo de desativação para cada EMA.

Esses equipamentos deve ser mantidos segregados até que atinjam a condição 
de descarte ou qualquer outra destinação indicada. Deve ser observado pelo estabelecimento de saúde os cuidados relativos ao descarte ambientalmente correto, evitando que sejam despejados no meio ambiente partes de EMA que possam trazer riscos à saúde do meio ambiente e da população.

Dessa forma, o descarte de EMAs deve atender à legislação ambiental e sanitária, importando que seja documentado por meio do Plano de Gerenciamento de Resíduos de Saúde (PGRSS), da forma como estabelecido pela RDC n 36, de 2004 e resoluções do Conselho Nacional do Meio Ambiente (Conama) que tratam sobre os resíduos tecnológicos. Neste aspecto, devem ser levados em consideração os preceitos da logística reversa, onde o EMA desativado, pode ser devolvido à cadeia de produção, tendo suas partes recicladas ou reaproveitadas de forma ambientalmente responsável.

Todas as informações relativas à vida do equipamento no âmbito do serviço de saúde devem ser registrados e mantidos arquivados durante o prazo estabelecido em lei para cada tipo de EMA. Dessa forma, devem ser mantidos os registros de informações como: (i) a identificação da unidade no serviço de saúde onde está alocado o equipamento, incluindo suas informações de transferência, quando houver; (ii) profissional designado pelo serviço de saúde responsável pelo uso do equipamento em cada unidade; (iii) histórico de falhas do equipamento; (iv) histórico documentado dos problemas e incidentes relacionados a eventos adversos causados, ou potencialmente causados, por falhas do equipamento; e $(v)$ documentação de intervenções técnicas no equipamento.

Compete ao serviço de saúde estabelecer e implementar um plano de gerenciamento de equipamentos que atenda aos requisitos legais e regulatórios, devendo $(i)$ prever e prover os recursos necessários ao seu cumprimento. Assim, os recursos humanos e materiais devem estar prontamente disponíveis para a realização das atividades descritas nos procedimentos de inspeção e manutenção, equipamentos de proteção exigidos em legislação especifica voltada à segurança e saúde do trabalhador, entre outros (ASSOCIAÇÃO BRASILEIRA DE NORMAS TÉCNICAS, 2011).

\subsection{GESTÃO DE RISCOS}

Para efeito da discussão a respeito da gestão de riscos em tecnologias em saúde, foram considerados essencialmente os seguintes dispositivos:

- Regulação: Brasil (2010a, 2011 e 2013a); 
- Normalização: ABNT (2009a, 2009b, 2009c, 2009d, 2012c e 2014), e

- Padrões (standards): PMI (2009 e 2014).

Esses dispositivos reguladores, normalizadores e padrões tratam da gestão de tecnologias em saúde e de riscos. Os dispositivos que tratam de riscos o fazem de maneira genérica, sendo que apenas ABNT $(2009 \mathrm{a}, 2014)$ tratam de riscos em dispositivos médicos. No entanto, foi necessário fazer adequações para o contexto de serviços de saúde, pois mesmo estas duas últimas normas se destinam especificamente aos fabricantes de produtos para a saúde/sistemas de produtos para a saúde não havendo na normalização normas específicas para os estabelecimentos que prestam serviços de saúde, tampouco para a EC.

No que diz respeito ao risco, há diversas formas de defini-lo: (i) para ABNT (2009c, p. 1) risco é o efeito da incerteza nos objetivos; (ii) para PMI (2014, p. 310) risco é o efeito da incerteza nos projetos e objetivos organizacionais; (iii) Brasil (2002) o define como a probabilidade de ocorrer um evento bem definido no espaço e no tempo, que causa dano à saúde, às unidades operacionais, ou dano econômico/financeiro. Explica este último autor, que na presença de um perigo não existe risco zero, porém existe a possibilidade de minimizá-lo ou alterá-lo para níveis aceitáveis. Nesta linha de raciocínio, Brasil (2002) infere que avaliar riscos:

Corresponde ao início dos procedimentos que conduzirão a implementação de ações no sentido de minimizar as consequências danosas dos riscos. Para que isso ocorra é importante a percepção e o conhecimento dos possíveis prejuízos que a exposição ao risco proporciona (BRASIL, 2002).

Lewis (1990, p. 69) entende que existem duas estratégias básicas para gerenciar riscos: prevenir e mitigar. Relata o autor que a primeira diz respeito à capacidade de minimizar a probabilidade de ocorrência do risco, enquanto que a segunda se refere a absorver as menores consequências do risco quando ele ocorre. Divergindo, de certa forma, de Lewis (1990), a ABNT (2009b, p. 2) destaca que gerir riscos é um processo que tem como fundamentos a aplicação sistemática de políticas, procedimentos e práticas de gestão para as atividades de comunicação, consulta, estabelecimento do contexto, e na identificação, análise, avaliação, tratamento, monitoramento e análise crítica dos riscos.

Para WHO (2003), avaliar riscos é um processo sistemático:

[...] A avaliação de risco começa com a análise do perigo para identificar todos possíveis eventos adversos, seguido da avaliação de risco para estimar a 
probabilidade de cada evento adverso ocorrer. Em geral, a avaliação de risco é baseado na experiência, provas, cálculo, ou mesmo adivinhação. A avaliação de risco é complexa, uma vez que pode ser influenciada pela percepção pessoal e outros fatores como formação cultural, condições econômicas, e climas políticos (WHO, 2003, p. 3, tradução nossa).

Ampliando este conceito, o PMI (2009, p. 4) ressalta que gerenciar riscos é uma forma de aumentar o impacto dos riscos positivos e minimizar o impacto dos riscos negativos. Assim PMI (2009) parte do pressuposto da existência de riscos positivos e negativos, sendo que os primeiros se confundem com oportunidades, enquanto os segundos, com ameaças. Gerenciar riscos pode, então, ser entendido como uma possibilidade de aproveitar as oportunidades e evitar as ameaças.

Todas as atividades de uma organização envolvem riscos. Como um conceito geral, atividades que envolvem um indivíduo, organização ou governo, podem expor ao perigo tanto as partes citadas quanto outras interessadas. As organizações gerenciam o risco, identificando-o, analisando-o e, em seguida, avaliando se ele deve ser modificado a fim de atender a seus critérios de risco (ASSOCIAÇÃO BRASILEIRA DE NORMAS TÉCNICAS, 2009a, 2009b). No entanto, para ABNT (2009a) a aceitabilidade de um risco por uma parte interessada é influenciada pela percepção que esta tem do risco.

Os conceitos de gerenciamento de risco são particularmente importantes em relação aos produtos para a saúde, devido à variedade de partes interessadas, incluindo profissionais de saúde, organizações que prestam serviços de assistência médica, governos, indústrias, pacientes e o público em geral (ASSOCIAÇÃO BRASILEIRA DE NORMAS TÉCNICAS, 2009a). No contexto do ambiente de saúde, não se pode desconsiderar também que eventos (incidentes ou acidentes) implicam na ocorrência dos riscos que podem culminar com danos à saúde das pessoas.

Não bastassem todas essas circunstâncias, para ABNT (2009a) a percepção do risco por cada parte interessada pode variar muito, dependendo de sua formação cultural, da formação socioeconômica e educacional da sociedade em questão, do estado de saúde real e percebido do paciente e muitos outros fatores. Assim, partindo do pressuposto de que cada parte interessada possui distintas percepções a respeito do risco e, consequente distintos graus de aceitabilidade pode-se inferir que cada parte interessada pondera diferentes critérios de riscos.

Não obstante, a decisão de adotar um procedimento clínico utilizando um produto para a saúde requer um balanceamento entre os riscos residuais e os benefícios 
associados ao procedimento clínico ou às circunstâncias de uso. Alguns desses julgamentos somente podem ser feitos por médicos qualificados que conheçam o estado de saúde de um paciente, em particular, sem desconsiderar a opinião do próprio paciente (ASSOCIAÇÃO BRASILEIRA DE NORMAS TÉCNICAS, 2009a). Este fato é relevante, pois contribui com o aumento da complexidade da gestão de riscos no contexto de uma organização de saúde.

A gestão de riscos pode ser aplicada a toda uma organização, em suas várias áreas e níveis, a qualquer momento, bem como a funções, atividades e projetos específicos. Ao longo de todo esse processo, as organizações comunicam e consultam as partes interessadas e ainda monitoram e analisam criticamente o risco e os controles que o modificam, a fim de assegurar que nenhum tratamento de risco adicional seja requerido (ASSOCIAÇÃO BRASILEIRA DE NORMAS TÉCNICAS, 2009b, p. v).

Considerando que cada setor específico ou aplicação da gestão de riscos traz consigo necessidades particulares, vários públicos, percepções e critérios, uma característica-chave na gestão de riscos é o estabelecimento de contexto, entendido como uma atividade inicial do processo de gestão de riscos. Para ABNT (2009b), o contexto externo se relaciona a fatores afetos ao ambiente externo à organização: (a) ambiente cultural, social político, regulatório, financeiro, tecnológico, econômico, natural e competitivo, seja internacional, nacional, regional ou local; (b) fatores-chave e as tendências que tenham impacto sobre os objetivos da organização, e (c) as relações com as partes interessadas externas e suas percepções de valores.

Da mesma forma, o contexto interno se refere ao ambiente interno da organização, incluindo: (a) a governança, estrutura organizacional, funções e responsabilidades; (b) políticas, objetivos e estratégias implementadas para atingi-los; (c) capacidades compreendidas em termos de recursos e conhecimento (capital, tempo, pessoas, processos, sistemas e tecnologias); (d) sistemas de informação, fluxos de informação, e processos de tomada de decisão (tanto formais quanto informais); (e) relações com partes interessadas internas, e suas percepções e valores; (f) cultura da organização; (g) normas, diretrizes e modelos adotados pela organização, e (g) forma e extensão das relações contratuais (ASSOCIAÇÃO BRASILEIRA DE NORMAS TÉCNICAS, 2009b).

Vale ressaltar que o PMI (2014, p. 29) ao abordar a questão do gerenciamento de projetos no âmbito de uma empresa, trata os contextos interno e externo como fatores 
ambientais da empresa. Para o autor, esses fatores ambientais se referem a condições fora de controle da equipe do projeto que influenciam, restringem ou direcionam o projeto. Podem variar em tipo e natureza. Para o autor, incluem, mas não se restringem a:

- Cultura, estrutura e governança organizacional;

- Distribuição geográfica de instalações e recursos;

- Normas governamentais ou do setor (p. ex. regulamentos de agências reguladoras, códigos de conduta, padrões de produto, padrões de qualidade e padrões de mão de obra);

- Infraestrutura (p. ex. equipamentos e instalações existentes);

- Recursos humanos existentes (p. ex. habilidades, disciplinas e conhecimento, como projeto, desenvolvimento, jurídico, contratação e compras);

- Administração de pessoal (p. ex. diretrizes de recrutamento e seleção de pessoal, análises de desempenho de empregados e registros de treinamento, política de compensação e horas extras, e controle de tempo);

- Sistemas de autorização de trabalho na empresa;

- Condições de mercado;

- Tolerância a risco das partes interessadas;

- Clima político;

- Canais de comunicação estabelecidos na organização;

- Bancos de dados comerciais (p. ex. dados padronizados de estimativas de custos, informações sobre estudos de risco do setor e banco de dados de riscos), e

- Sistemas de informações de gerenciamento de projetos (p. ex. uma ferramenta automatizada, como um software de cronograma, um sistema de gerenciamento de configuração, um sistema de coleta e distribuição de informações, ou interfaces web para outros sistemas automatizados online) (PROJECT MANAGEMENT INSTITUTE, 2014, p. 29, grifos do autor).

\subsubsection{Princípios da gestão de riscos}

Os princípios de gestão de risco têm sido propostos, discutidos e tratados por diferentes organizações de normas internacionais (MESTAS VALERO, 2011, p. 11). Para efeito do presente estudo, foram adotados os princípios elencados por ABNT (2009b, p. 7-8), por terem aplicabilidade ao contexto de gestão de tecnologias em saúde:

a) A gestão de riscos cria e protege valor. Para o autor, a gestão de riscos contribui para a realização demonstrável dos objetivos e para a melhoria do desempenho referente, por exemplo, à segurança e saúde das pessoas, à segurança, à conformidade legal e regulatória, à aceitação pública, à proteção do meio ambiente, à qualidade do produto, ao gerenciamento de projetos, à eficiência nas operações, à governança e à reputação.

b) A gestão de riscos é parte integrante de todos os processos organizacionais. Com isso, infere o autor que a gestão de riscos não é uma atividade autônoma separada das principais atividades e processos da organização. Importa o destaque referente ao fato de que a gestão de riscos compõe as responsabilidades da administração, sendo parte integrante de todos os processos organizacionais, incluindo o planejamento estratégico e 
todos os processos de gestão de projetos e gestão de mudanças.

c) A gestão de riscos é parte da tomada de decisões. A partir dessa reflexão, o autor informa que a gestão de riscos auxilia os tomadores de decisão a fazer escolhas conscientes, priorizar ações e distinguir entre formas alternativas de ação. Assim, o processo de tomada de decisão dentro da organização, seja qual for o nível de sua importância e significância, envolve explicitamente a consideração dos riscos e aplicação da gestão de riscos em algum grau apropriado.

d) A gestão de riscos aborda explicitamente a incerteza. Nesta linha argmentativa, o autor destaca que a gestão de riscos é vista como central nos processos de gestão da organização, de forma que os riscos sejam considerados em termos do efeito da incerteza sobre os objetivos, ou seja a gestão de riscos explicitamente leva em consideração a incerteza, a natureza dessa incerteza, e como ela pode ser tratada.

e) A gestão de riscos é sistemática, estruturada e oportuna. Em função disso, uma abordagem sistemática, oportuna e estruturada para a gestão de riscos contribui para a eficiência e para os resultados consistentes, comparáveis e confiáveis.

f) A gestão de riscos baseia-se nas melhores informações disponíveis. As entradas para o processo de gerenciar riscos são baseadas em fontes de informação confiáveis, tais como dados históricos, experiências, realimentação das partes interessadas, observações, previsões, e opiniões de especialistas. Por este motivo (forte dependência de informações confiáveis), convém que os tomadores de decisão se informem e levem em consideração quaisquer limitações dos dados ou modelagem utilizados, ou a possibilidade de divergências entre especialistas.

g) A gestão de riscos é feita sob medida e está alinhada com o contexto interno e externo da organização e com seu perfil do risco. Contextos diferentes levam a análises distintas a respeito do risco, impondo posturas até antagônicas frente ao risco, suas causas e efeitos.

h) A gestão de riscos considera fatores humanos e culturais. A propósito dos fatores humanos, a gestão de riscos reconhece as capacidades, percepções e intenções do pessoal interno e externo que podem facilitar ou dificultar a realização dos objetivos da organização. Neste sentido, Ponte Júnior (2014, p. 22) destaca que não se pode desconsiderar que indivíduos possuem capacidades e limitações diferentes, o que resulta em implicações importantes para os projetos de engenharia. 
i) A gestão de riscos é transparente e inclusiva. O envolvimento apropriado e oportuno de partes interessadas e, em particular, dos tomadores de decisão em todos os níveis da organização, assegura que a gestão de riscos permaneça pertinente e atualizada. Com efeito, o envolvimento também permite que as partes interessadas sejam devidamente representadas e tenham suas opiniões levadas em consideração na determinação dos critérios de risco.

j) A gestão de riscos é dinâmica, interativa e capaz de reagir a mudanças. $\mathrm{Na}$ medida em que acontecem eventos externos e internos, o contexto e o conhecimento modificam-se, o monitoramento e a análise crítica de riscos são realizados, novos riscos surgem, alguns se modificam e outros desaparecem.

k) A gestão de riscos facilita a melhoria contínua da organização. Convém que as organizações desenvolvam e implementem estratégias para melhorar a sua maturidade na gestão de riscos, juntamente com todos os demais aspectos da sua organização.

Importa destacar que, conforme a visão que se tenha da gestão de riscos, os princípios podem ser ampliados ou ainda reduzidos, cabendo ao gestor a tarefa de harmonizar esses princípios em função do contexto organizacional. Ponte Júnior (2014, p. 55-66) relaciona tantos outros princípios da gestão de riscos que se considerados no todo, ampliam as considerações de ABNT (2009b). Para Ponte Júnior (2014) os princípios se sintetizam em:

Princípios de fatores humanos: (a) centralização de objetivos nas pessoas; (b) adaptação do projeto ao homem, e (c) controle da interação homem x sistema;

Princípios de cultura de segurança: (a) multidisciplinaridade; (b) subjetividade; (c) priorização; (d) atenção certa; (e) tempo certo; (f) inclusão de projeto de fatores humanos, e $(\mathrm{g})$ inteligência técnica;

Princípios de eficiência: (a) descarte de riscos desnecessários; (b) respeito às leis naturais; (c) simplicidade; (d) concisão de regras; (e) combate ao legalismo; (f) combate ao heroísmo, e (g) humildade (PONTE JÚNIOR, 2014, p. 55-66, grifos nossos).

\subsubsection{Estrutura da gestão de riscos}

ABNT (2009b) esclarece que para obter sucesso na gestão de riscos deve ser considerado o grau de dependência existente entre a estrutura de gestão e os arranjos. A primeira fornece os fundamentos, enquanto os segundos irão incorporá-la através de toda organização, em todos os níveis. Como reforço de argumentação, o autor propõe uma estrutura modelo 
(Figura 4) a ser utilizada pelas organizações ao gerenciar os riscos aplicando e adaptando ao caso em análise.

É necessário, pois, analisar em separado os aspectos relacionados, tendo em conta sempre as características do serviço que é prestado pela instituição hospitalar a ser estudada. Desta forma, no que concerne ao mandato e comprometimento, a ABNT (2009b) é enfática ao afirmar que a garantia de sua contínua eficácia (da gestão de riscos) requer comprometimento forte e sustentação a ser assumido pela administração da organização, bem como um planejamento rigoroso e estratégico para que se obtenha esse comprometimento em todos os níveis.

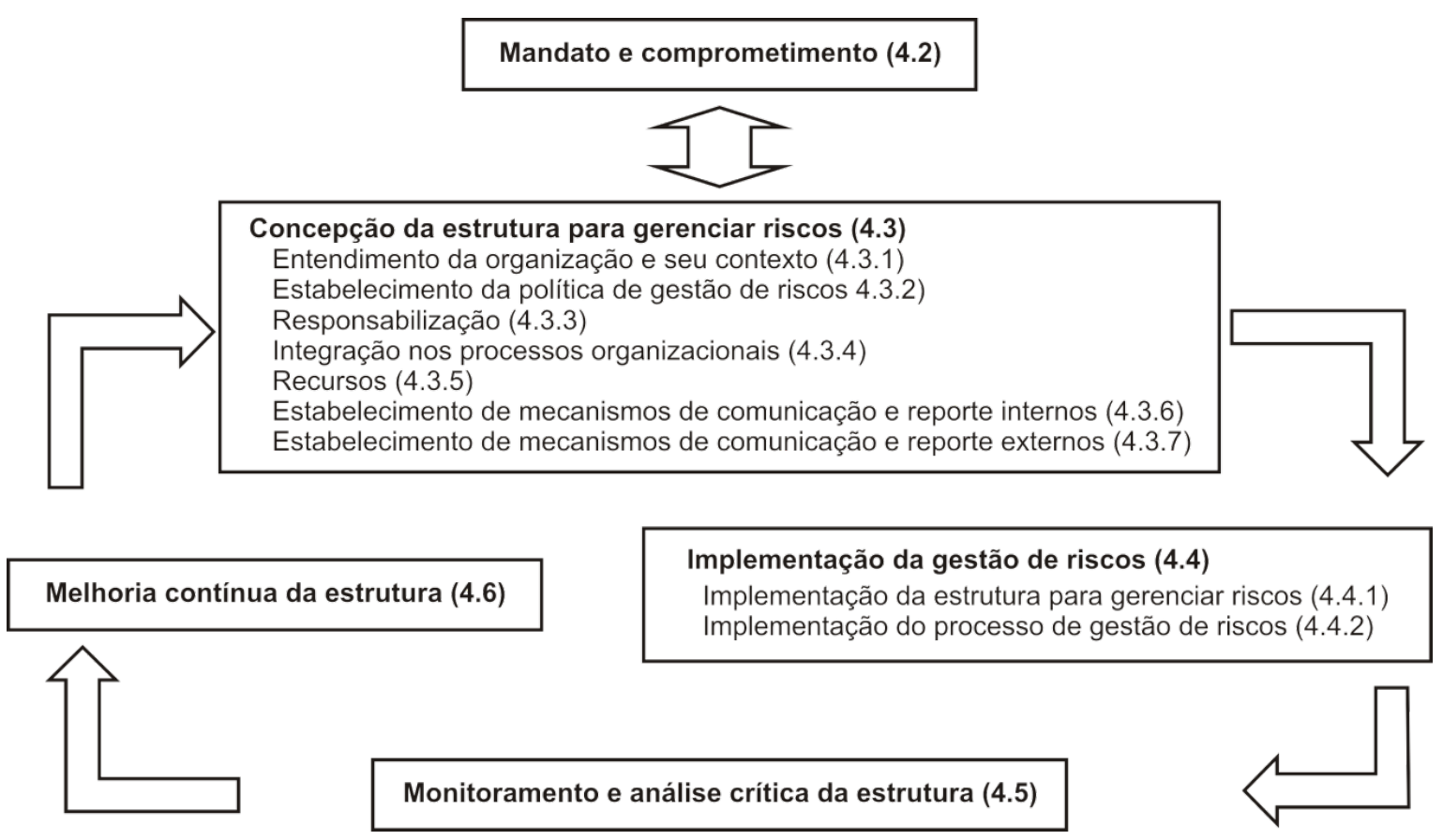

Figura 4 - Relacionamento entre os componentes da estrutura para gerenciar riscos. Adaptado de ABNT (2009b, p. 9).

Nesta mesma direção, Brasil (2013a) estabelece em seu art. $4^{\circ}$ que:

A direção do serviço de saúde deve constituir o Núcleo de Segurança do Paciente (NSP) e nomear a sua composição, conferindo aos membros autoridade, responsabilidade e poder para executar as ações do Plano de Segurança do Paciente em Serviços de Saúde (BRASIL, 2013a).

Ao citado Núcleo de Segurança do Paciente (NSP) compete, dentre outras atribuições, promover ações para a gestão de risco no serviço de saúde (Brasil, 2013a). O Plano de Segurança do Paciente, elaborado pelo NSP é o documento que, no âmbito do serviço de saúde, aponta as situações de risco e descreve as estratégias e ações definidas 
pelo serviço de saúde para a gestão e risco visando a prevenção e mitigação dos incidentes.

De forma mais abrangente, a ABNT (2009a) se refere ao Plano de

Gerenciamento de Riscos que deve incluir ao menos o seguinte:

a) o escopo das atividades de gerenciamento de risco, identificando e descrevendo os produtos para a saúde e as fases do ciclo de vida às quais cada elemento do plano se aplica;

b) atribuição de responsabilidade e autoridade;

c) requisitos para análise crítica das atividades de gerenciamento de risco;

d) critério para aceitabilidade de risco, com base na política da organização de saúde para determinação de aceitabilidade de risco, incluindo o critério para aceitar riscos quando a probabilidade de ocorrência do dano não puder ser estimada;

e) atividades de verificação; e

f) atividades relacionadas à coleta e análise crítica de informações de produção e pós-produção relevantes (ABNT, 2009a, p. 8-9, adaptado).

Dessa forma, ABNT (2009b) explicita que a administração deve:

a) definir e aprovar a política de gestão de riscos;

b) assegurar que a cultura da organização e a política de gestão de riscos estejam alinhadas;

c) definir indicadores de desempenho para a gestão de riscos alinhados com os indicadores de desempenho da organização;

d) alinhar os objetivos da gestão de riscos com os objetivos e estratégias da organização;

e) assegurar conformidade legal e regulatória;

f) atribuir responsabilidades nos níveis apropriados dentro da organização;

g) assegurar que os recursos necessários sejam alocados para a gestão de riscos;

h) comunicar os benefícios da gestão de riscos a todas as partes interessadas, e

i) assegurar que a estrutura para gerenciar riscos continue a ser apropriada (ASSOCIAÇÃO BRASILEIRA DE NORMAS TÉCNICAS, 2009b, p. 9-10).

Em respeito específico à alta direção da organização, ABNT (2009a, p. 8) impõe que esta deve fornecer evidência de seu comprometimento com o processo de gerenciamento de risco, garantindo a provisão de recursos adequados e designando pessoal qualificado para o gerenciamento de risco. Para o autor, a alta direção deve ainda:

a) definir e documentar a política para determinação do critério de aceitabilidade de risco. Esta política deve garantir que o critério seja baseado em regulamentos aplicáveis nacionais ou regionais e Normas relevantes, e deve levar em consideração informações disponíveis, como o estado-da-arte geralmente aceito e preocupações conhecidas das partes interessadas.

b) analisar criticamente a adequação do processo de gerenciamento de risco em intervalos planejados para garantir a eficácia contínua do processo de gerenciamento de risco e documentar as decisões e ações tomadas (ASSOCIAÇÃO BRASILEIRA DE NORMAS TÉCNICAS, 2009a, p. 8, grifos nossos). 


\subsection{TÉCNICAS DE ELICITAÇÃO DO CONHECIMENTO}

Ao longo da fase de desenvolvimento do plano de gestão de tecnologias em saúde, uma quantidade significativa de informações é coletada, analisada, transformada e distribuída em vários formatos para as partes interessadas. Os dados referentes às tecnologias são coletados, como resultados de vários processos de execução e compartilhados no âmbito da organização de saúde. Estes dados coletados são analisados no contexto da organização, agregados e transformados tornando-se informações durante os vários processos de controle. As informações podem então ser comunicadas, ou armazenadas e distribuídas como relatórios em vários formatos (PROJECT MANAGEMENT INSTITUTE, 2014, p.58).

Com o objetivo de selecionar um conjunto de técnicas para os processos de: $(i)$ coleta de dados; (ii) processamento e (iii) transformação em informação, são consideradas o uso de adequadas técnicas voltadas para o contexto de gestão de tecnologias em saúde. Para tanto, foram analisadas as técnicas propostas por ABNT (2012c) como as referências para a aquisição ou elicitação do conhecimento da forma como relatada por Rosário, Kipper e Frozza (2014):

[...] as fontes de aquisição de conhecimento se tornam a parte crítica do processo de aquisição de conhecimento.

Segundo Kim et al. (2011), há três formas de fontes de conhecimento: fontes diádica, publicações e conhecimento de um grupo. Uma fonte de conhecimento diádica trata-se de aquisição do conhecimento através do contato direto entre o receptor e o provedor do conhecimento. Uma fonte de conhecimento publicada se enquadra como documentos, livros, apostilas, catálogos e postadas em comunidade virtual. Uma fonte de conhecimento de um grupo refere-se à troca de conhecimentos entre os múltiplos provedores de conhecimento, onde os receptores de conhecimento podem acessar e obter o conhecimento através de fontes de conhecimento do grupo, como uma conversa aberta ou pública entre os envolvidos, através de sistemas de perguntas e respostas, ou equipes de trabalho (ROSÁRIO; KIPPER; FROZZA, 2014, p. 120-121).

A técnica apresentada, foi documentada por ABNT (2012c) e modelada da forma como proposta por PMI (2014), onde são evidenciados os relacionamentos entre os dados coletados (entradas), as ferramentas e técnicas de análise (processo) e as informações transformadas (saídas). A Figura 5 evidecia o relacionamento entre esses processos.

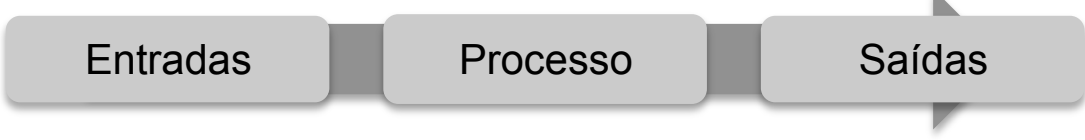

Figura 5 - Modelo genérico de um processo. Adaptado de PMI (2014). 
No que diz respeito aos métodos para avaliação dos riscos em tecnologias em saúde, foram selecionadas aqueles que possibilitem uma saída quantitativa, possibilitando assim, a comparação de resultados em avaliações posteriores. A Tabela 4, proposta por ABNT (2012c), correlaciona as ferramentas utilizadas na identificação de riscos sua melhor aplicabilidade para cada fase desta avaliação. Os aributos da seleção de ferramentas de avaliação de riscos foram dispibilizados no Apêndice A.

\section{Tabela 4 - Aplicabilidade das ferramentas utilizadas para o processo de avaliação de riscos}

\begin{tabular}{|c|c|c|c|c|c|}
\hline \multirow{3}{*}{ Ferramentas e técnicas } & \multicolumn{5}{|c|}{ Processo de avaliação de riscos } \\
\hline & \multirow{2}{*}{$\begin{array}{l}\text { Identificação } \\
\text { de riscos }\end{array}$} & \multicolumn{3}{|c|}{ Análise de riscos } & \multirow{2}{*}{$\begin{array}{c}\text { Avaliação de } \\
\text { riscos }\end{array}$} \\
\hline & & Consequência & Probabilidade & Nível de risco & \\
\hline Brainstorming & $F A^{4}$ & $N A^{5}$ & NA & NA & NA \\
\hline $\begin{array}{l}\text { Entrevistas estruturadas ou } \\
\text { semi-estruturadas }\end{array}$ & FA & NA & NA & NA & NA \\
\hline Delphi & FA & NA & NA & NA & NA \\
\hline Lista de verificação & FA & NA & NA & NA & NA \\
\hline $\begin{array}{l}\text { Análise preliminar de perigos } \\
\text { (APP) }\end{array}$ & FA & NA & NA & NA & NA \\
\hline $\begin{array}{l}\text { Estudos de Perigo e } \\
\text { operabilidade (HAZOP) }\end{array}$ & FA & FA & $A^{6}$ & A & A \\
\hline $\begin{array}{l}\text { Análise de perigos e pontos } \\
\text { críticos de controle (APPCC) }\end{array}$ & FA & FA & NA & NA & NA \\
\hline Avaliação de risco ambiental & FA & FA & FA & FA & FA \\
\hline $\begin{array}{l}\text { Técnica estruturada "E se" } \\
\text { (SWIFT) }\end{array}$ & FA & FA & FA & FA & FA \\
\hline Análise de cenários & FA & FA & A & A & A \\
\hline $\begin{array}{l}\text { Análise de impacto nos } \\
\text { negócios }\end{array}$ & $A$ & FA & A & A & A \\
\hline Análise de causa-raiz & NA & FA & FA & FA & FA \\
\hline $\begin{array}{l}\text { Análise de modos de falha e } \\
\text { efeito }\end{array}$ & FA & FA & FA & FA & FA \\
\hline Análise de árvores de falha & $A$ & $\mathrm{Na}$ & FA & A & A \\
\hline Análise de árvore de eventos & $A$ & FA & $A$ & A & NA \\
\hline $\begin{array}{l}\text { Análise de causa e } \\
\text { consequência }\end{array}$ & $A$ & FA & FA & A & A \\
\hline Análise de causa e efeito & FA & FA & NA & NA & NA \\
\hline $\begin{array}{l}\text { Análise de camadas de } \\
\text { proteção (LOPA) }\end{array}$ & A & FA & $A$ & $A$ & NA \\
\hline Árvore de decisões & NA & FA & FA & A & A \\
\hline $\begin{array}{l}\text { Análise da confiabilidade } \\
\text { humana }\end{array}$ & FA & FA & FA & FA & A \\
\hline Análise Bow tie & NA & A & FA & FA & $A$ \\
\hline $\begin{array}{l}\text { Manutenção centrada em } \\
\text { confiabilidade }\end{array}$ & FA & FA & FA & FA & FA \\
\hline $\begin{array}{l}\text { Sneak analisys (SA) e sneak } \\
\text { circuit analisys (SCA) }\end{array}$ & A & NA & NA & NA & NA \\
\hline Análise de Markov & $A$ & FA & NA & NA & NA \\
\hline Simulação de Monte Carlo & NA & NA & NA & NA & FA \\
\hline $\begin{array}{l}\text { Estatística Bayesuana e Redes } \\
\text { de Bayes }\end{array}$ & NA & FA & NA & NA & FA \\
\hline Curvas FN & $A$ & FA & FA & $A$ & FA \\
\hline Índices de risco & A & FA & FA & A & FA \\
\hline
\end{tabular}

\footnotetext{
Fortemente aplicável.

Não aplicável.

Aplicável.
} 


\begin{tabular}{|c|c|c|c|c|c|}
\hline \multirow{3}{*}{ Ferramentas e técnicas } & \multicolumn{5}{|c|}{ Processo de avaliação de riscos } \\
\hline & \multirow{2}{*}{$\begin{array}{l}\text { Identificação } \\
\text { de riscos }\end{array}$} & \multicolumn{3}{|c|}{ Análise de riscos } & \multirow{2}{*}{$\begin{array}{l}\text { Avaliação de } \\
\text { riscos }\end{array}$} \\
\hline & & Consequência & Probabilidade & Nível de risco & \\
\hline $\begin{array}{l}\text { Matriz de probabilidade / } \\
\text { consequência }\end{array}$ & FA & FA & FA & FA & A \\
\hline Análise de custo/benefício & $A$ & FA & $A$ & $A$ & $A$ \\
\hline $\begin{array}{l}\text { Análise de decisão por } \\
\text { multicritérios (MCDA) }\end{array}$ & A & FA & A & $\mathrm{FA}$ & A \\
\hline
\end{tabular}

Fonte: ABNT (2012c, p. 18-19).

\subsubsection{Seleção de técnicas para o processo de avaliação de riscos}

A eleição das ferramentas a serem utilizadas no presente estudo foi fundamentada no cruzamento entre sua maior aplicabilidade no processo de avaliação de riscos e maior impacto quanto à pertinência da influência de fatores (complexidade; recursos e capacidade; natureza e grau de incerteza) da ferramenta aliada à possibilidade de fornecer resultados quantitativos.

Todas essas implicações impactaram na seleção da ferramenta Failure Mode and Effect Analisys (FMEA) conjugada com a sua variante Failures Mode, Effect and Criticality Analisys (FMECA). Esta ferramenta combina o fato de ser fortemente aplicável a todos os processos de avaliação de riscos, além de possuir atributos graduados como de alta ou média relevância sobre os fatores de complexidade, recursos e capacidade, natureza e grau de incerteza, fornecendo inclusive resultados quantitativos.

A FMEA é uma técnica utilizada para identificar as formas em que componentes, sistemas ou processos podem falhar em atender o intuito de seu projeto. A FMEA identifica:

- todos os modos de falha potenciais das várias partes de um sistema (um modo de falha é aquilo que é observado ao falhar ou ao desempenhar incorretamente);

- os efeitos que estas falhas podem ter no sistema;

- os mecanismos de falha;

- como evitar as falhas e/ou mitigar os efeitos das falhas no sistema. A análise de modo, efeito e criticidade de falha FMECA estende uma FMEA de modo que cada modo de falha identificado seja classificado de acordo com a sua importância ou criticidade. Esta análise de criticidade é normalmente qualitativa ou semiquantitativa, porém pode ser quantificada utilizando taxas reais de falha. 
A relevância do uso de FMEA para avaliar riscos em tecnologias é referenciado por Manrique-Rodríguez et al (2014):

[...] quando novas tecnologias são implementadas, elas frequentemente introduzem novos riscos nos processos, eles podem levar a novos erros caso eles não sejam detectados e interceptados em tempo. Análise de Modos de Falha e Efeitos (FMEA) pode ser utilizado para prevenir alguns erros e seus resultados decorrentes da implementação de novas tecnologias. Esta técnica visa a prover processos e é utilizada para identificar pontos onde hajam riscos no novo produto antes e depois de sua produção (MANRIQUE-RODRÍGUEZ et al, 2014, p. 210, tradução nossa).

Conclui o autor inferindo a respeito da forma como se pode usar a técnica:

Possíveis erros ou modos de falhas podem ser classificados de acordo com: (a) sua probabilidade de ocorrência; (b) sua probabilidade de ser detectado, e (c) a gravidade ou severidade de quaisquer efeitos que possa ter sobre o paciente. $\mathrm{O}$ método FMEA é usado atualmente por um grande número de instituições, relacionadas com cuidados de saúde assim como pela The Joint Commission on Accreditation of Healthcare Organizations (JC-AHO) que o utiliza para identificar o que são conhecidos como eventos sentinela em cada um de seus processos (MANRIQUE-RODRÍGUEZ et al, 2014, p. 211, tradução nossa).

A FMEA/FMECA pode fornecer entradas para outras técnicas de análises, como análise de árvore de falhas em um nível qualitativo ou quantitativo. Para tanto, FMEA e FMECA necessitam de informações sobre os elementos do sistema em detalhes suficientes para análise do significado das formas em que cada elemento pode falhar. Para uma FMEA de Projeto detalhada, o elemento pode estar no nível de componente individual detalhado, enquanto que, para FMEA de Sistemas de alto nível, os elementos podem ser definidos em um nível superior.

As informações podem incluir:

- desenhos ou um fluxograma do sistema que está sendo analisado e seus componentes, ou as etapas de um processo;

- uma compreensão da função de cada etapa de um processo ou componente de um sistema;

- detalhes dos parâmetros ambientais e outros parâmetros que podem afetar a operação;

- uma compreensão dos resultados de falhas específicas;

- informações históricas sobre falhas, incluindo dados da taxa de falha, quando disponíveis.

O processo de FMEA é o seguinte: 
a) definir o escopo e objetivos do estudo;

b) montar a equipe;

c) entender o sistema/processo a ser submetido ao FMEA;

d) desdobrar o sistema em seus componentes ou etapas;

e) definir a função de cada etapa ou componente;

f) para cada componente ou etapa listado, identificar:

- como pode ser concebível cada parte falhar?

- quais mecanismos podem produzir estes modos de falha?

- quais podem ser os efeitos se as falhas ocorrerem?

- a falha é inofensiva ou prejudicial?

- como a falha é detectada?

g) identificar as medidas inerentes ao projeto para compensar a falha.

Para a FMECA, a equipe de estudo prossegue na classificação de cada um dos modos de falha identificados, de acordo com sua criticidade

Existem diversas maneiras de como isto pode ser feito. Os métodos comuns incluem

- indice de criticidade de modo

- nivel de risco

- número de prioridade de risco

O modelo de criticidade é uma medida da probabilidade de que o modo a ser considerado resultará em falha do sistema como um todo; é definido como:

\section{Probabilidade do efeito de falha *Taxa do modo de falha *Tempo de operação do sistema}

É mais frequentemente aplicado a falhas em equipamentos onde cada um desses termos pode ser definido quantitativamente e todos os modos de falha têm a mesma consequência.

O nível de risco é obtido pela combinação das consequências da ocorrência de um modo de falha com a probabilidade de falha. É utilizado quando as consequências de diferentes modos de falha diferem e pode ser aplicado a sistemas de equipamentos ou 
processos. O nível de risco pode ser expresso qualitativa, semiquantitativa ou quantitativamente.

$\mathrm{O}$ número de prioridade de risco (NPR) é uma medida semiquantitativa da criticidade, obtido pela multiplicação de números em escalas de classificação (normalmente entre 1 e 10) para consequência de falha, probabilidade de falha e capacidade de detectar o problema (à falha é dada uma maior prioridade, se ela for difícil de detectar). Este método é utilizado frequentemente em aplicações de garantia da qualidade.

Uma vez que os modos e os mecanismos de falha são identificados, ações corretivas podem ser definidas e implementadas para os modos de falha mais significativos.

A FMEA é documentada em um relatório que contém:

- detalhes do sistema que foi analisado;

- a forma como o exercício foi conduzido;

- premissas feitas na análise;

- fontes de dados;

- os resultados, incluindo as planilhas preenchidas;

- a criticidade (se finalizada) e a metodologia utilizada para defini-la;

- quaisquer recomendações para análises adicionais, alterações de projeto ou características a serem incorporadas em planos de teste.

O sistema pode ser reavaliado por um outro ciclo de FMEA após as ações terem sido completadas.

A saída principal da FMEA é uma lista de modos de falha, os mecanismos de falha e os efeitos para cada componente ou etapa de um sistema ou processo (que podem incluir informações sobre a probabilidade de falha). Também são dadas informações sobre as causas da falha e as consequências ao sistema como um todo. A saída da FMECA inclui uma classificação de importância com base na probabilidade de que o sistema irá falhar, o nível de risco resultante do modo de falha ou uma combinação do nível de risco e a detectabilidade do modo de falha. 
Tabela 5 - Variáveis quantitativas para cada erro possível e seus valores atribuídos

\begin{tabular}{|c|c|c|c|}
\hline $\begin{array}{l}\text { Valor } \\
\text { atribuído }\end{array}$ & $\begin{array}{l}\text { Probabilidade de ocorrência } \\
\qquad(\mathrm{O})\end{array}$ & $\begin{array}{l}\text { Probabilidade de detecção } \\
\text { (D) }\end{array}$ & $\begin{array}{l}\text { Severidade de possíveis } \\
\text { resultados }(\mathrm{S})\end{array}$ \\
\hline 1 & $\begin{array}{l}\text { Remota: Probabilidade de } 1 \\
\text { em } 10 \text { mil } \\
\text { Sem ocorrências conhecidas }\end{array}$ & $\begin{array}{l}\text { Muito alta: Probabilidade de } 9 \\
\text { em } 10 \\
\text { Erros sempre ocorrem }\end{array}$ & $\begin{array}{l}\text { Incômodo leve: pode afetar o } \\
\text { sistema }\end{array}$ \\
\hline 2 & \multirow{2}{*}{$\begin{array}{l}\text { Baixa: Probabilidade de } 1 \text { em } \\
5 \text { mil. } \\
\text { Possível mas não há dados } \\
\text { conhecidos }\end{array}$} & \multirow{2}{*}{$\begin{array}{l}\text { Alta: Probabilidade de } 1 \text { em } \\
10 \\
\text { Erro propenso a ser } \\
\text { detectado }\end{array}$} & $\begin{array}{l}\text { Problema moderado no } \\
\text { sistema: pode afetar o } \\
\text { paciente }\end{array}$ \\
\hline 4 & & & \multirow{2}{*}{$\begin{array}{l}\text { Problema grave no sistema: } \\
\text { pode afetar o paciente }\end{array}$} \\
\hline 5 & \multirow{2}{*}{$\begin{array}{l}\text { Moderada: Probabilidade de } 1 \\
\text { em } 200 \\
\text { Documentada mas pouca } \\
\text { frequência. }\end{array}$} & \multirow[b]{2}{*}{$\begin{array}{l}\text { Moderada: Probabilidade de } 5 \\
\text { em } 10\end{array}$} & \\
\hline 6 & & & Ferimentos leves \\
\hline 7 & \multirow{2}{*}{$\begin{array}{l}\text { Alta: Probabilidade de } 1 \text { em } \\
100 \\
\text { Documentada e frequente }\end{array}$} & \multirow{2}{*}{$\begin{array}{l}\text { Baixa: Probabilidade de } 2 \text { em } \\
10\end{array}$} & Ferimentos graves \\
\hline 8 & & & \multirow{3}{*}{ Lesão terminal ou morte } \\
\hline 9 & \multirow{2}{*}{$\begin{array}{l}\text { Muito alta: Probabilidade de } 1 \\
\text { em } 20 \\
\text { Documentada, quase certo }\end{array}$} & $\begin{array}{l}\text { Remota: Probabilidade de } 0 \\
\text { em } 10\end{array}$ & \\
\hline 10 & & $\begin{array}{l}\text { Detecção não é possível a } \\
\text { qualquer momento }\end{array}$ & \\
\hline
\end{tabular}

Fonte: Manrique-Rodríguez et al (2014, p. 211, tradução nossa).

A FMECA pode dar uma saída quantitativa se dados adequados da taxa de falha e consequências quantitativas forem utilizados. Os pontos fortes da FMEA/FMECA são os seguintes:

- amplamente aplicável a modos de falha humana, de equipamentos, e de sistemas, e para hardware, software e procedimentos;

- identificar modos de falha de componentes, suas causas e seus efeitos sobre o sistema, e apresentá-los em um formato facilmente legível;

- evitar a necessidade de modificações muito dispendiosas no equipamento em serviço por meio da identificação antecipada de problemas no processo de projeto;

- identificar os modos de falha pontuais e requisitos para sistemas redundantes ou de segurança;

- fornecer entrada para o desenvolvimento de programas de monitoramento, destacando as características chave a serem monitoradas.

As limitações incluem:

- só poder ser utilizada para identificar modos de falha singulares e não as combinações de modos de falha; 
- a menos que sejam adequadamente controlados e tocados, os estudos podem ser demorados e onerosos;

O número de falhas reais pode ser muito reduzida com adequado uso da técnica FMEA e manutenção preemptiva em todos os componentes (PATEL, et al, 2005, p. 15-16, tradução nossa).

\subsection{TÉCNICA DE PESQUISA}

A proposta metodológica para a pesquisa em questão tem embasamento no que se define como um estudo de caso, tratado por Shi (2008, p. 444) como uma investigação empírica que utiliza múltiplas fontes de evidência para investigar uma entidade social da vida real ou fenômeno. Para o autor, este delineamento é particularmente útil quando a pesquisa tem como objetivo capturar as diferenças individuais ou variações originais de uma configuração de um programa para outro, ou para uma experiência de um programa para outro. O autor evidencia que um caso pode ser uma organização, em que se procura descrever essa unidade no contexto em profundidade e detalhe e de forma integral.

O estudo de caso, de caso único, da forma como está sendo proposto, já é descrita por Yin:

[...] encontra-se um fundamento lógico para um caso único quando ele representa um caso decisivo ao testar uma teoria bem formulada. A teoria deve especificar um conjunto claro de proposições, assim como as circunstâncias nas quais se acredita que as proposições sejam verdadeiras. (YIN, 2005, p. 61).

Ainda segundo o autor, ao se confirmar, contestar, ou estender a teoria, deve existir um caso único que satisfaça todas as condiçõs para testar a teoria. O caso único pode, então, ser utilizado para determinar se as proposições de uma teoria são corretas ou se algum outro conjunto alternativo de explanações possa ser mais relevante.

Considerando a necessidade de coleta de dados diretamente na unidade de saúde em análise, a pesquisa tem as características de estudo de campo, envolvendo aspectos quantitativo-descritivos e exploratórios. Dessa forma, as técnicas de pesquisa a serem empregadas alinham-se tanto ao método quantitativo-descritivo, como ao exploratório, definidos por Marconi e Lakatos:

Quantitativos-descritivas: consistem em investigações de pesquisa empírica cuja principal finalidade é o delineamento ou análise das características de fatos ou fenômenos, avaliação de programas, ou o isolamento de variáveis principais ou chave. 
Exploratórias: são investigações de pesquisa empírica cujo objetivo é a formulação de questões ou de um problema, com tripla finalidade: desenvolvimento de hipóteses, aumentar a familiaridade do pesquisador com o ambiente, fato ou fenômeno para a realização de uma pesquisa futura mais precisa ou modificar e clarificar conceitos. Empregam-se geralmente procedimentos sistemáticos para a obtenção de observações empíricas ou para as análises de dados (ou ambas, simultaneamente). Obtêm-se frequentemente descrições tanto quantitativas quanto qualitativas do objeto estudado, e o investigador deve conceituar as inter-relações entre as propriedades do fenômeno, fato ou ambiente estudado. (MARCONI e LAKATOS, 2011, pp. 7071).

As características do estudo podem assim ser descritas como um estudo exploratório-descritivo combinado, tal como as autoras descrevem:

Estudo exploratório que tem por objetivo descrever completamente determinado fenômeno, como o estudo de caso para o qual são realizadas análise empíricas e teóricas. Podem ser encontradas tanto descrições quantitativas e/ou qualitativas quanto acumulação de informações detalhadas como as obtidas por intermédio da observação participante. Dá-se precedência ao caráter representativo sistemático e, em consequência, os procedimentos de amostragem são flexíveis. (MARCONE e LAKATOS, 2011, p. 71).

Essa metodologia de estudo se revela adequada para a pesquisa, pois ao descrever as possíveis subdivisões do método, as autoras enfatizam ainda que os estudos de avaliação de programas consistem nos estudos quantitativos-descritivos que dizem respeito à procura dos efeitos e resultados de todo um programa ou método específico de atividades de serviços, que podem dizer respeito a grande variedade de objetivos, relativos a educação, saúde e outros. 


\section{METODOLOGIA}

\subsection{PROPOSTA INICIAL}

A proposta metodológica, envolve a aplicação do conhecimento, habilidades, ferramentas e técnicas às atividades do desenvolvimento do projeto da forma como documentada por PMI (2014), com as adaptações necessárias, relacionadas na Figura 6, para atender aos propósitos da pesquisa, a fim de gerar como produto um PGEQS. O desenvolvimento da pesquisa envolveu assim, a aplicação e integração apropriada dos 47 processos de gerenciamento de projetos, logicamente agrupados em cinco grupos de processos: (i) iniciação; (ii) planejamento; (iii) execução; (iv) monitoramento e controle, e (v) encerramento.

A fase que precedeu a pesquisa foi composta por pesquisa a respeito do objeto de estudo onde foram analisados, investigados, documentados e compreendidos os aspectos centrais da gestão de tecnologias em saúde.

Para o desenvolvimento da pesquisa, foram necessárias reuniões com diversas partes interessadas no âmbito de serviços de saúde. Para o levantamento de dados e informações iniciais, foram realizadas entrevistas estruturadas, com tempo de execução variando entre 20 minutos a uma hora, dependendo do objeto de avaliação. As entrevistas e reuniões foram agendadas previamente, com a possibilidade do entrevistado informar datas e horários mais favoráveis para que se execute a entrevista.

Os questionários incluídos nos Apêndices A e B, foram elaborados fundamentados em ABNT (2011b) e ABNT (2009), respectivamente, sendo suficientes para subsidiar as fases de iniciação e planejamento, onde parte dos documentos necessários como entradas dos processos foram fornecidos pelos serviços de saúde. As fazes de execução, monitoramento e controle e encerramento foram executadas, conforme os documentos apresentados pelo serviços de saúde foram analisados e que forneciam as informações necessárias.

Os processos de gerenciamento do tempo foram executados na fase de planejamento, porém não forneceram o tempo das atividades, devido à limitação tanto do tempo de pesquisa quanto do conhecimento prévio do tempo que cada atividade devia levar para ser concluída. Não obstante, esses processos forneceram valiosas informações referentes ao planejamento de execução de atividades e a forma como elas se relacionam. 


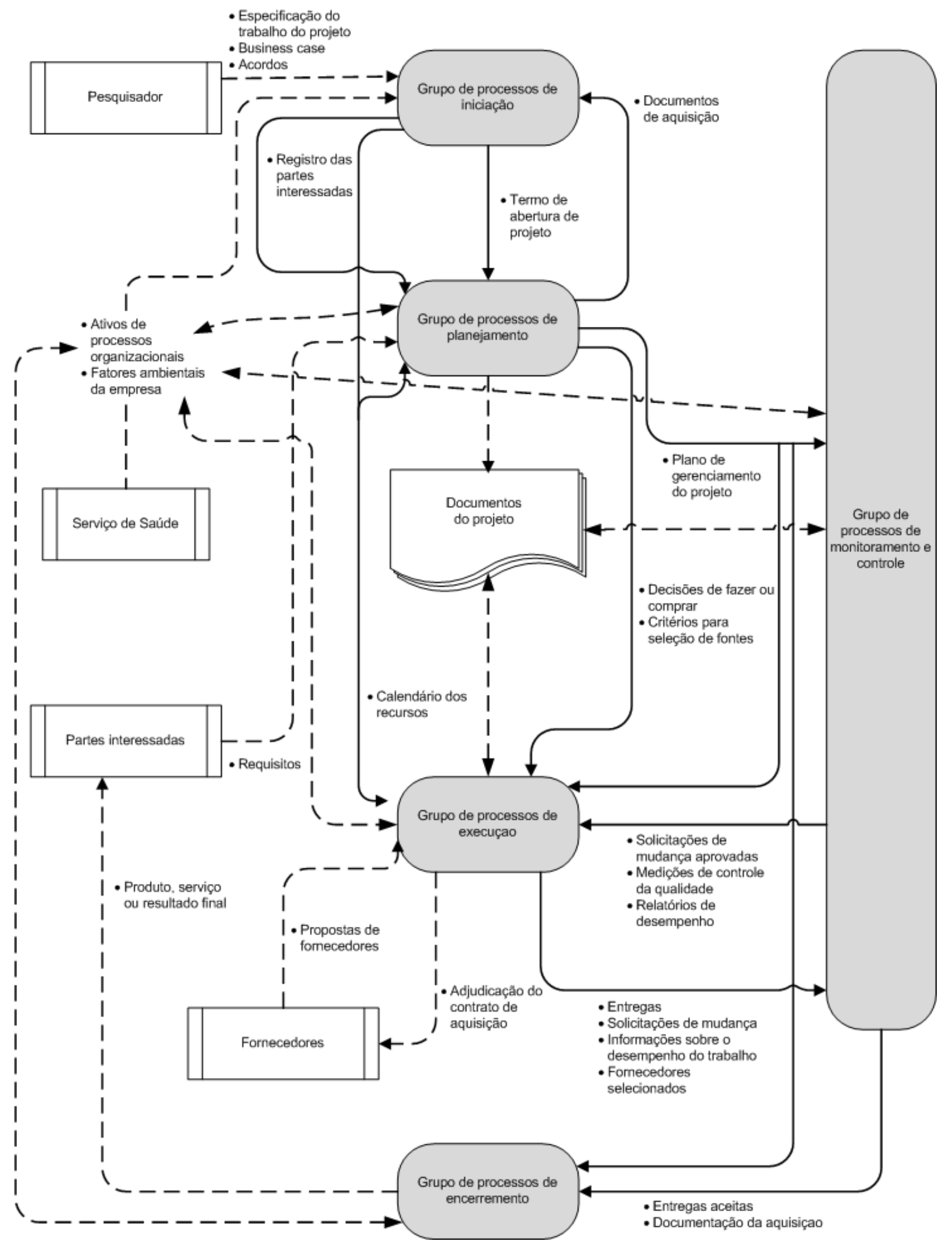

Figura 6 - interações nos processos de gerenciamento de projetos. Adaptado de PMI (2014). 
Prioritariamente foram empregadas as técnicas de Program Evaluation and Review Technique / Critical Path Method (PERT/CPM) para determinação do cronograma e os custos do projeto.

\subsubsection{Iniciação}
a) integração: desenvolver o termo de abertura; e
b) partes interessadas: identificar as partes interessadas;

\subsubsection{Planejamento}

a) integração: desenvolver o plano de gerenciamento do projeto.

b) escopo: ( $i$ ) planejar o gerenciamento do escopo; (ii) coletar requisitos; (iii) definir escopo, e (iv) criar a estrutura analítica de projeto.

c) custos: (i) planejar o gerenciamento dos custos; (ii) estimar os custos, e (iii) determinar o orçamento;

d) tempo: (i) planejar o gerenciamento do cronograma; (ii) definir as atividades; (iii) sequenciar as atividades; (iv) estimar os recursos das atividades; ( $v$ ) estimar as durações das atividades, e (vi) desenvolver o cronograma;

e) qualidade: planejar o gerenciamento da qualidade;

f) recursos humanos: planejar o gerenciamento dos recursos humanos;

g) comunicações: planejar o gerenciamento das comunicações;

h) riscos: (i) planejar o gerenciamento dos riscos; (ii) identificar os riscos; (iii) realizar a análise qualitativa dos riscos; (iv) realizar a análise quantitativa dos riscos, e (v) planejar a resposta aos riscos;

i) aquisições: planejar o gerenciamento das aquisições; e

j) partes interessadas: planejar o gerenciamento das partes interessadas.

\subsubsection{Execução}
a) integração: planejar e orientar o trabalho do projeto;
b) qualidade: realizar a garantia da qualidade;
c) recursos humanos: (i) mobilizar a equipe do projeto; (ii) desenvolver a 
equipe do projeto, e (iii) gerenciar a equipe do projeto;

d) comunicações: gerenciar as comunicações;

e) aquisições: conduzir as aquisições;

f) partes interessadas: gerenciar o engajamento das partes interessadas.

\subsubsection{Monitoramento e controle}

a) integração: (i) monitorar e controlar o trabalho do projeto, e (ii) realizar o controle integrado de mudanças;

b) escopo: (i) validar o escopo, e (ii) controlar o escopo;

c) tempo: controlar o cronograma;

d) custos: controlar os custos;

e) qualidade: controlar a qualidade;

f) comunicações: controlar as comunicações;

g) riscos: controlar os riscos;

h) aquisições: controlar as aquisições; e

i) partes interessadas: controlar o engajamento das partes interessadas.

\subsubsection{Encerramento}

a) integração: encerrar o projeto ou fase.

b) aquisições: encerrar as aquisições.

O Anexo B correlaciona as entradas e saídas de cada processo, relativo à elaboração do PGEQS.

Para cada fase do Plano de Gerenciamento de Equipamentos (planejamento e seleção, aquisição, recebimento e verificação, armazenamento, instalação, ensaios de aceitação, treinamento, uso, intervenção técnica, registro histórico, inventário, transferência interna, desativação, descarte, arquivo de registro, avaliação do plano), foram executados os processos aplicáveis.

A Figura 7, adaptada de ABNT (2009a) representa o processo de gerenciamento de riscos utilizado, em todas as fases do ciclo de vida das tecnologias em estudo. 


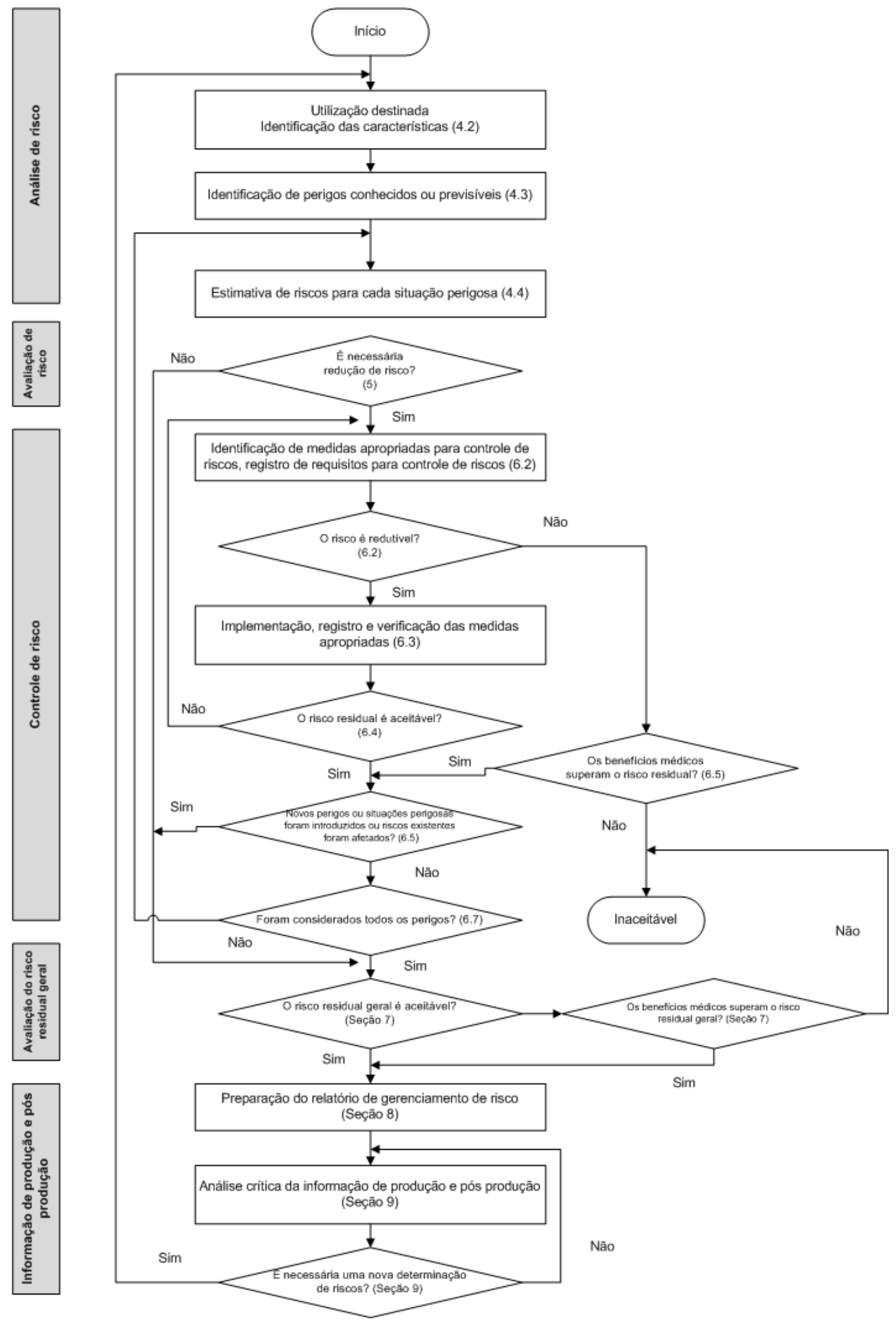

Figura 7 - Processos de gerenciamento de riscos. Adaptado de ABNT (2009a, p. 25). 


\subsection{DELIMITAÇÃO DO ESTUDO}

O escopo do plano de gestão em tecnologias ora desenvolvido envolve a fase de utilização do equipamento, iniciada após os testes de aceitação, sendo considerada até o momento da desativação, alienação dos equipamentos em função de sua obsolescência ou ainda de seu abandono em função da incorporação de alguma outra tecnologia emergente, que atenda a critérios técnicos já previamente estabelecidos pelos gestores dos serviços de saúde (econômicos, qualidade, segurança, eficácia, efetividade, disponibilidade, carga de doença, equidade).

\subsection{RESULTADOS ESPERADOS}

\subsubsection{Desfecho primário}

Proporcionar à instituição de saúde a possibilidade de ampliar a capacidade de identificar os riscos inerentes às tecnologias em saúde.

\subsubsection{Desfecho secundário}

- Proporcionar à organização de saúde plano de gestão de equipamentos (PGEQS), a ser integrado ao Plano de Gerenciamento de Tecnologias em Saúde, possibilitando uma gestão pró-ativa dos riscos inerentes às tecnologias:

- Ampliar a segurança do paciente;

- Atentar para que a necessidade de identificar e tratar riscos perpassa por toda a organização;

- Identificar oportunidades e ameaças;

- Atender às normas nacionais $\mathrm{e}$ internacionais $\mathrm{e}$ requisitos legais $\mathrm{e}$ regulatórios afetos aos riscos;

- Estabelecer uma base confiável para tomada de decisões e planejamento;

- Alocar de forma eficaz recursos para tratar riscos;

- Melhorar eficácia e eficiência operacional;

- Melhorar o desempenho em saúde e segurança ocupacional e proteção ao meio ambiente. 


\section{RESULTADOS}

O ciclo de vida dos equipamentos eletromédicos, da forma como relatada por Brasil (2013), se inicia na fase de pesquisa básica e aplicada e passa pela de teste do protótipo. A partir de então são difundidos e, em consequência são incorporados pelos estabelecimentos de saúde, onde se tem a fase de utilização, seguida pela de obsolescência.

Para efeito do presente estudo, a gestão de tecnologias em saúde, foi subdividida em sete grupos de processos, onde as atividades foram agrupadas em camadas por grupos de afinidade. Assim, o resultado do agrupamento levou em consideração os processos relacionados na ABNT NBR 15943:2011 que tinham maior afinidade entre suas funções:

\section{Grupo I: Processos de avaliação de tecnologia.}

Subprocesso de incorporação de tecnologias: (i) planejamento e seleção; (ii) aquisição; (iii) recebimento, verificação e aceitação; (iv) ensaios de aceitação do equipamento; e (v) instalação.

Subprocesso de desincorporação de tecnologias: (i) desativação; e (ii) descarte.

\section{Grupo II: Processos de gestão patrimonial.}

Envolvem os seguintes processos: (i) inventário; (ii) armazenamento; e (iii) transferência interna do equipamento.

\section{Grupo III: Processos de gestão documental.}

Envolvem os seguintes processos: (i) arquivo de registros; e (ii) registro histórico do equipamento.

\section{Grupo IV: Processos de uso do equipamento.}

Envolvem os seguintes processos: (i) treinamento; e (ii) uso.

Grupo V: Processo de gestão manutenção.

Envolvem o seguinte processo: (i) intervenção técnica.

Grupo VI: Processo de notificação de eventos adversos.

Envolve o seguinte processo: (i) evento adverso relacionado ao equipamento.

Grupo VII: Processo de monitoramento e controle. 
Envolve o seguinte processo: (i) avaliação do plano de gerenciamento do equipamento.

O escopo do plano de gestão em tecnologias ora desenvolvido envolve a fase de utilização do equipamento (Grupos de processos de II a VII), iniciada após os testes de aceitação, sendo considerada até o momento da desativação, alienação dos equipamentos em função de sua obsolescência ou ainda de seu abandono em função da incorporação de alguma outra tecnologia emergente, que atenda a critérios técnicos já previamente estabelecidos pelos gestores dos serviços de saúde (econômicos, qualidade, segurança, eficácia, efetividade, disponibilidade, carga de doença, equidade). Para os processos de gestão da tecnologia são considerados os aspectos relativos aos riscos de cada etapa relativa à fase de utilização.

\subsection{PROCESSOS DE GESTÃO PATRIMONIAL}

Os equipamentos devem ser armazenados em conformidade com as especificações do fabricante, incluindo as condições ambientais prescritas (temperatura, humidade, pressão, incidência de radiação solar). Devem ainda ser observadas as prescrições de segurança contidas no Plano de Proteção Radiológica relativas a fontes de radiação ionizante ou equipamentos que contenham essas fontes incorporadas.

Equipamentos sob análise em processos de validação e aceite devem ser segregados de forma a impedir seu uso antes de todas as etapas de avaliação.

O serviço de saúde deve documentar os procedimentos relativos à transferência interna dos equipamentos, levando em consideração que durante a realização do procedimento, deve-se manter a integridade, segurança, rastreabilidade, desempenho e a adequada utilização do equipamento.

Objetivos:

I - zelar pela segurança e integridade do patrimônio;

II - manter a exatidão dos registros físico-financeiros;

III - estabelecer a responsabilidade pela guarda, uso, conservação, administração e devolução de bens patrimoniais;

IV - definir as competências dos utilizadores e gestores;

V - fixar as obrigações dos utilizadores e gestores. 
Para que se alcance os objetivos do planejamento, nenhum material permanente será distribuído sem o devido termo de responsabilidade atestado pelo responsável por sua guarda e conservação, vedada, ainda, a sua movimentação sem o prévio tombamento. Para efeito de registro e controle do tombamento, o material permanente receberá número sequencial de registro patrimonial, aposto pelo departamento de gestão patrimonial, mediante gravação, fixação de plaqueta, etiqueta, ou qualquer outro método adequado às características do bem.

A movimentação do material permanente, entre unidades administrativas ou dentro do mesmo serviço de saúde, somente será efetivada com o registro da transferência no sistema informatizado de controle patrimonial e atesto do termo de transferência pelo responsável.

Quando a movimentação de material permanente exigir a circulação fora das dependências do serviço de saúde, o responsável por sua guarda solicitará, por escrito, autorização de saída ao departamento de gestão patrimonial. No caso de autorizado, a autorização de saída será dada em formulário próprio, do qual constará a identificação do portador, a descrição do material, o seu destino e motivo.

O departamento de gestão patrimonial exercerá o controle sobre os equipamentos eletromédicos através do inventário, cujos objetivos básicos são, dentre outros:

I - verificar a existência física do bem e seu estado de conservação;

II - conferir a atualização dos registros e lançamentos efetivados pelos setores competentes;

III - confirmar a responsabilidade dos agentes;

IV - instruir a tomada de contas anual do serviço de saúde;

V - identificar e afixar etiquetas gerenciadas pelo sistema informatizado de controle patrimonial;

VI - permitir a emissão de relatórios atualizados dos bens.

O departamento de gestão patrimonial promoverá inventário:

I - anual, destinado a comprovar a quantidade e o valor dos bens patrimoniais, constituído do inventário anterior e das variações patrimoniais ocorridas durante o 
exercício;

II - inicial, quando da criação de uma unidade administrativa, para identificação e registro do material permanente existente e efetivação da carga patrimonial do responsável;

III - de transferência de responsabilidade, quando da mudança do responsável pelo material permanente de uma unidade administrativa;

IV - de Extinção ou Transformação, quando da extinção ou transformação de uma unidade administrativa;

V - eventual, em qualquer época, sempre que provocado pelo titular de Unidade Administrativa, aleatoriamente para controle estatístico do departamento de gestão patrimonial, ou por qualquer outra necessidade.

Após a realização do inventátio, o departamento de gestão patrimonial deverá emitir relatório final, do qual constará:

I - lista de cargas patrimoniais de todas as unidades inventariadas;

II - os respectivos termos de responsabilidade devidamente atestados;

III - lista de bens encontrados sem registro ou outro elemento que os identifiquem;

IV - lista de bens com descrição errada;

V - lista de bens não localizados.

Deverá ser criado um mecanismo para que no período de realização do inventário geral seja vedada a movimentação de bens, salvo em situações excepcionais previamente justificadas pelo interessado e autorizadas pelo departamento de gestão patrimonial.

Compete ao responsável pelos equipamentos:

a) fiscalizar a integridade, o uso, a conservação e a movimentação dos bens móveis do serviço de saúde, sob sua responsabilidade, através de ações sistemáticas;

b) manter o controle dos bens de terceiros instalados ou em trânsito nas dependências do serviço de saúde, autorizando a utilização dos referidos bens, por intermédio do sistema de controle patrimonial; 
c) solicitar a movimentação de material permanente por intermédio de sistema de controle patrimonial informatizado (caso exista na unidade de saúde);

d) comunicar por escrito departamento de gestão patrimonial qualquer irregularidade relacionada aos bens sob sua responsabilidade;

e) solicitar abertura de procedimento de apuração em casos de extravio ou danos ao patrimônio.

\subsection{PROCESSOS DE GESTÃO DOCUMENTAL}

O registro histórico envolve as anotações referentes a eventos e ocorrências que dizem respeito a cada equipamento. A ABNT NBR 15943:2011 estabelece que tal registro deve conter, minimamente:

a) a identificação da unidade no serviço de saúde onde está alocado o equipamento, incluindo as informações de transferência quando houver;

b) profissional designado pelo serviço de saúde responsável pelo uso do equipamento em cada unidade;

c) histórico de falhas do equipamento;

d) histórico documentado dos problemas e incidentes relacionados a eventos adversos causados, ou potencialmente causados, por falhas do equipamento. Deve existir evidência da ação tomada pelo serviço de saúde e da notificação ao órgão sanitário competente e fornecedor, quando pertinente.

e) documentação de intervenções técnicas no equipamento.

O serviço de saúde deve arquivar os registros históricos dos equipamentos e indicar formalmente o responsável pelo seu gerenciamento. O registro histórico deve ser arquivado pelo tempo que o equipamento estiver em utilização pelo serviço de saúde acrescido de pelo menos dois anos.

O serviço de saúde deve dispor de local específico para a guarda, arquivamento e manutenção dos registros históricos do equipamento; o registro deve ser legível, assinado pelo responsável pela execução dos serviços e anotações, sendo redigido em uma sequência lógica e contínua com: registro dos estudos técnicos preliminares que subsidiaram a aquisição do equipamento, registros dos procedimentos de aquisição, histórico do equipamento, envolvendo as intervenções, substituição de peças e 
componentes, registro das manutenções corretivas e preventivas, registro de eventos adversos relacionados ao equipamento.

\subsection{PROCESSOS DE USO DO EQUIPAMENTO}

$\mathrm{O}$ ato normativo estabelece que o prestador de serviços (fornecedor dos equipamentos e materiais) deve prover treinamento permanente necessário para garantir que cada agente dos serviços esteja apto a realizar as suas atividades.

O conteúdo do treinamento deve abranger capacitação em:

a) normas de segurança previstos em atos legais ou normativos;

b) novos equipamentos e ferramentas; e

c) novos processos de trabalho.

Devem ser documentados em relação ao treinamento:

a) seu conteúdo programático;

b) critérios de avaliação das necessidades do treinamento;

c) participação e avaliação do treinando; e

d) avaliação da eficácia do treinamento.

Neste contexto, deve ser claramente estabelecidas quais as responsabilidades do prestador de serviços assim como as responsabilidades do contratante, em particular no que diz respeito à qualificação técnica do facilitador de aprendizagem, experiência prévia na área de atuação, formação acadêmica.

Para a execução do treinamento, devem ser consideradas as condições das instalações, que devem ser apropriadas para a realização das aulas e palestras. Aspectos pedagógicos de relevância como carga horária do treinamento, uso de material didático adequado devem também ser considerados.

Durante a fase de uso do equipamento, deve ser assegurado que o equipamento deve ser operado por profissional capacitado para tanto (comprovado por meio dos registros de treinamento). As condições de funcionamento devem ser atestadas pela equipe de engenharia responsável pelos procedimentos de validação do equipamento ao longo do seu ciclo de vida. 


\subsection{PROCESSOS DE GESTÃO DA MANUTENÇÃO}

O serviço de saúde deve:

a) estabelecer e implementar procedimentos para assegurar a rastreabilidade metrológica do equipamento;

b) desenvolver e implementar procedimentos para inspeção, ensaio, manutenção, ajuste e calibração no equipamento.

As intervenções técnicas devem;

a) ser documentadas no registro histórico do equipamento, indicando inclusive o nome do executor;

b) ser efetuadas por profissional comprovadamente treinado.

O serviço de saúde deve elencar os procedimentos a serem executados pela equipe interna ou contratada para executar os serviços, levendo em consideração:

a) Procedimentos para manutenção corretiva

b) Procedimentos para manutenção preventiva

c) Critérios para análise de risco para a priorização da Manutenção Preventiva

\subsection{PROCESSO DE NOTIFICAÇÃO DE EVENTOS ADVERSOS}

O normativo estabelece que o estabelecimento de saúde deve manter registro dos eventos adversos relacionados ao equipamento. As etapas relativas ao gerenciamento da tecnologia devem conter informações necessárias para uma investigação de possível evento adverso, para notificação ao Sistema Nacional de Vigilância Sanitária e comunicação ao fabricante.

Assim, os procedimentos de notificação de eventos adversos relacionados ao equipamento devem ser reportados ao Sistema Nacional de Vigilância Sanitária em conformidade com o que é estabelecido na RDC Anvisa no 36/2012, onde fica estabelecido que os serviços de saúde devem constituir Núcleos de Segurança do Paciente (NSP), criados para promover e apoiar a implementação de ações voltadas à segurança do paciente, incluindo a notificação de incidentes/eventos adversos ocorridos no serviço de saúde. 


\subsection{PROCESSO DE MONITORAMENTO E CONTROLE}

No que diz respeito à avaliação do plano de gerenciamento, o normativo indica a necessidade de revisões anuais quanto ao teor do documento, sua eficiência e eficácia, mensurada por meio de indicadores. 


\section{DISCUSSÃO E CONCLUSÃO}

O plano de gestão de tecnologias em saúde propicia que o serviço de saúde integre todas as ações necessárias para proporcionar um aumento de disponibilidade dos equipamentos eletromédicos, devido à tomada de decisões de maneira pró-ativa. Além disso, propicia à equipe que atua no âmbito da gestão das tecnologias (incluindo o engenheiro biomédico) condições de analisar e inserir tal tecnologia no contexto do ciclo de vida, como proposto por Brasil (2013b, p.16).

Os benefícios desta contextualização, incluem a maior disponibilidade do equipamento, decorrente da execução dos processos: de uso; de manutenção; de gestão patrimonial, e de gestão documental.

Os processos de gestão dos riscos inerentes às tecnologias, quando executados concomitantemente com a execução do plano, possibilitam o aumento da segurança provida ao paciente, à medida em que se permitem que a unidade de saúde se utilize de um equipamento submetido às análises prévias implicando ações preventivas quanto a possíveis danos tanto ao equipamento quanto ao paciente.

Esses processos se alinham às determinações de Brasil (2013a) à medica em que trocam informações a respeito do gerenciamento de risco do estabelecimento de saúde e, importam o aumento da segurança do paciente uma vez que permitem não apenas a identificação dos riscos como uma análise sistemática de suas ocorrência no contexto interno da organização.

A divisão das atividades de gestão das tecnologias em grupos de processos em nível macro com características similares, permite a melhor alocação de recursos para execução das atividades pertinentes além de possibilitar a melhor comunicação entre esses processos.

O plano de gerenciamento de tecnologias em saúde adere às normas nacionais e internacionais e requisitos legais e regulatórios em relação aos equipamentos médicos, sendo ainda fonte de informações para análises e estudos que possam ser necessários para a pesquisa e documentação de eventos adversos proporcionados pelo uso do equipamento fato que alinha as ações tomadas pelo estabelecimento de saúde aos preceitos determinados por Brasil (2010a).

As ações de monitoramento e controle desses eventos aproximam os usuários 
dos fabricantes e provedores de ações de vigilância sanitária, considerando que os procedimentos de notificação envonlvem não apenas a comunicação de fato como ainda a interação entre as partes interessadas.

As vantagens de se trabalhar com foco na gestão das tecnologias de maneira estruturada se alinham ao estabelecimento de uma base confiável para tomada de decisões e planejamento, de forma que os gestores possam alocar de forma eficaz recursos para tratar riscos identificados, melhorando assim a eficácia e eficiência operacional.

A fim de dar continuidade à pesquisa em curso é necessário validar o processo elaborado em uma unidade de saúde, aplicando as técnicas adequadas a cada tecnologia em uso. Nesse mesmo contexto, os processos de avaliação de tecnologias devem ser implementados e alinhados ao plano de gerenciamento de tecnologias, de forma a se trabalhar integralmente em todo o ciclo de vida dos equiopamentos, desde os estudos preliminares até o seu descarte após ter sido utilizado em sua plenitude. 


\section{REFERÊNCIAS}

ALEXANDRINO, J. C. Metodologia para avaliação do desempenho metrológico em equipamentos médico-hospitalares. (Tese) Universidade Federal da Bahia. Salvador, 2012.

ALVES, C. S.; GOMES, M. M. F.; BRASIL, L. M. Disponibilidade de mamógrafos no Brasil: desempenho na produção de exames de mamografia de rasreamento. In: CONGRESSO BRASILEIRO DE ENGENHARIA BIOMÉDICA, XXIV, 2014, Uberlândia. Anais... . Uberlândia: Sbeb, 2014. p. 361-364.

AMERICAN COLLEGE OF CLINICAL ENGINEERING. What's a clinical engineer. Disponível em <www.acce.org>. Acesso em 14 nov. 2014.

ASSOCIAÇÃO BRASILEIRA DE NORMAS TÉCNICAS. ABNT ISO/TR 24971:

Produtos para a saúde - Orientações para a aplicação da ABNT NBR ISO 14971. Rio de Janeiro, 2014. 15p.

ASSOCIAÇÃO BRASILEIRA DE NORMAS TÉCNICAS. ABNT NBR 15287:

Informação e documentação - Projeto de pesquisa - Apresentação. Rio de Janeiro, 2011c. $8 \mathrm{p}$.

ASSOCIAÇÃO BRASILEIRA DE NORMAS TÉCNICAS. ABNT NBR 5462: Confiabilidade e mantenabilidade. Rio de Janeiro, 1994. 37p.

ASSOCIAÇÃO BRASILEIRA DE NORMAS TÉCNICAS. ABNT NBR IEC 62366: Produtos para a saúde - aplicação da engenharia de usabilidade a produtos para a saúde. Rio de Janeiro, 2010. 109p.

ASSOCIAÇÃO BRASILEIRA DE NORMAS TÉCNICAS. ABNT NBR ISO 10993-1: Avaliação biológica de produtos para a saúde - Parte 1: avaliação e ensaio dentro de um processo de gerenciamento de risco. Rio de Janeiro, 2013. 23p.

ASSOCIAÇÃO BRASILEIRA DE NORMAS TÉCNICAS. ABNT NBR ISO 14040: Gestão ambiental - Avaliação de ciclo de vida - Princípios e estrutura. Rio de Janeiro, 2009d. 21p.

ASSOCIAÇÃO BRASILEIRA DE NORMAS TÉCNICAS. ABNT NBR ISO 14155-1: Pesquisas clínicas envolvendo seres humanos. Parte 1: Requisitos gerais. Rio de Janeiro, 2004a. 24p.

ASSOCIAÇÃO BRASILEIRA DE NORMAS TÉCNICAS. ABNT NBR ISO 14155-2:

Pesquisas clínicas envolvendo seres humanos. Parte 2: Projetos de pesquisa clínica. Rio de Janeiro, 2004b. 9p.

ASSOCIAÇÃO BRASILEIRA DE NORMAS TÉCNICAS. NBR 10520: Informação e documentação - Citações em documentos - Apresentação. Rio de Janeiro, 2002a. 7p.

ASSOCIAÇÃO BRASILEIRA DE NORMAS TÉCNICAS. NBR 14724: Informação e documentação - Trabalhos acadêmicos - Apresentação. Rio de Janeiro, 2011a. 11p. 
ASSOCIAÇÃO BRASILEIRA DE NORMAS TÉCNICAS. NBR 14971: Produtos para a saúde - Aplicação de gerenciamento de risco a produtos para a saúde. Rio de Janeiro, 2009a. 88p.

ASSOCIAÇÃO BRASILEIRA DE NORMAS TÉCNICAS. ABNT NBR ISO 13485:

Produtos para a saúde - sistemas de gestão da qualidade - requisitos para fins regulamentares. Rio de Janeiro, 2004. 57p.

ASSOCIAÇÃO BRASILEIRA DE NORMAS TÉCNICAS. NBR 15943: diretrizes para um programa de gerenciamento de equipamentos de infraestrutura de serviços de saúde e de equipamentos para a saúde. Rio de Janeiro, 2011b. 21 p.

ASSOCIAÇÃO BRASILEIRA DE NORMAS TÉCNICAS. NBR 6023: Informação e documentação - Referências - Elaboração. Rio de Janeiro, 2002. 24p.

ASSOCIAÇÃO BRASILEIRA DE NORMAS TÉCNICAS. NBR 6024: Informação e documentação - Numeração progressiva das seções de um documento - Apresentação. Rio de Janeiro, 2012a. 4p.

ASSOCIAÇÃO BRASILEIRA DE NORMAS TÉCNICAS. NBR 6027: Informação e documentação - Sumário - Apresentação. Rio de Janeiro, 2012b. 3p.

ASSOCIAÇÃO BRASILEIRA DE NORMAS TÉCNICAS. NBR 6028: Informação e documentação - Resumo - Apresentação. Rio de Janeiro, 2003. 2p.

ASSOCIAÇÃO BRASILEIRA DE NORMAS TÉCNICAS. NBR 6032: Abreviação de periódicos e publicações seriadas. Rio de Janeiro, 1989. 14p.

ASSOCIAÇÃO BRASILEIRA DE NORMAS TÉCNICAS. NBR 6034: Informação e documentação - Índice - Apresentação. Rio de Janeiro, 2005. 4p.

ASSOCIAÇÃO BRASILEIRA DE NORMAS TÉCNICAS. NBR ISO 31000: Gestão de riscos - Princípios e diretrizes. Rio de Janeiro, 2009b. 24p.

ASSOCIAÇÃO BRASILEIRA DE NORMAS TÉCNICAS. NBR ISO GUIA 73: Gestão de riscos - Vocabulário. Rio de Janeiro, 2009c. 12p.

ASSOCIAÇÃO BRASILEIRA DE NORMAS TÉCNICAS. NBR ISO IEC 31010: gestão de riscos — técnicas para o processo de avaliação de riscos. Rio de Janeiro, 2012c. 96p.

AUGUSTOVISKI, F.; PICHON-RIVIERE, A.; RUBINSTEIN, A. Critérios utilizados pelos sistemas de saúde para a incorporação de tecnologias. In: NITA, M. E. et al. Avaliação de tecnologias em saúde: evidência clínica, análise econômica e análise de decisão. Porto Alegre: Artmed, 2010. p. 493-505.

AZEVEDO, G. F.C. Proposta de modelo de gerenciamento de risco aplicado ao desempenho de equipamentos eletromédicos em estabelecimentos assistenciais de saúde. 2004. 145 f. Dissertação (Mestrado) Curso de Engenharia Biomédica, UNICAMP, Campinas, 2004.

BARBIERI, J. C.; MACHLINE, C. Logística hospitalar: teoria e prática. São Paulo: Saraiva, 2006. 
BATES, D. W. et al. Global priorities for patient safety research BMJ 2009; 338:b1775.

BRASIL. Agência Nacional de Vigilância Sanitária. RDC 2, de 25 de janeiro de 2010. Dispõe sobre o gerenciamento de tecnologias em saúde em estabelecimentos de saúde. Brasília, 2010a.

BRASIL. Agência Nacional de Vigilância Sanitária. Manual de boas práticas de aquisição de equipamentos médicos-hospitalares. 2014c. Disponível em:

$<$ http://www.anvisa.gov.br/produtosaude/auto/boas.htm>. Acesso em: 27 nov. 2014.

BRASIL. Ministério da Saúde. Secretaria-Executiva. Área de Economia da Saúde e Desenvolvimento. Avaliação de tecnologias em saúde: ferramentas para a gestão do SUS. Brasília: Editora do Ministério da Saúde, 2009. 110 p.

BRASIL. Agência Nacional de Vigilância Sanitária. RDC 36, de 25 de julho de 2013. Institui ações para a segurança do paciente em serviços de saúde e dá outras providências. Brasília, 2013a.

BRASIL. Secretária de Logística e Tecnologia da Informação. Instrução normativa $\mathbf{n}^{\circ} \mathbf{4}$, de 11 de setembro de 2014. Dispõe sobre o processo de contratação de soluções de tecnologia da informação pelos órgãos integrantes do Sistema de Administração de Recursos de Tecnologia da Informação e Informática (SISP) do Poder Executivo Federal. Brasília, 2014b.

BRASIL. Agencia Nacional de Vigilância Sanitária. RDC n. ${ }^{\circ}$ 63, de 25 de novembro de 2011. Dispõe sobre os requisitos de boas práticas de funcionamento para os serviços de saúde. Brasília, 2011.

BRASIL. Agência Nacional de Vigilância Sanitária. Regulação Sanitária. Disponível em $<$ http://portal.anvisa.gov.br/wps/content/Anvisa+Portal/Anvisa/regulacao+sanitaria $>$. Acesso em 15 nov. 2014. Brasília, 2014a.

BRASIL. Congresso. Senado. Lei no 8080, de 19 de setembro de 1990. Lei Orgânica da Saúde.

BRASIL. Ministério da Saúde. Política Nacional de Gestão de Tecnologias em Saúde / Ministério da Saúde, Secretaria de Ciência, Tecnologia e Insumos Estratégicos, Departamento de Ciência e Tecnologia. - Brasília : Ministério da Saúde, 2010c. 48 p. (Série B. Textos Básicos em Saúde).

BRASIL. Ministério da Saúde. Portaria MS n 210, de 2004. Define unidades de assistência em alta complexidade cardiovascular e os centros de referência em alta complexidade cardiovascular e suas aptidões e qualidades. Brasília, 2004.

BRASIL. Ministério da Saúde. Secretaria de Ciência, Tecnologia e Insumos Estratégicos. Departamento de Ciência e Tecnologia. Diretrizes metodológicas: elaboração de estudos para avaliação de equipamentos médicos assistenciais. Brasília : Ministério da Saúde, 2013b. 96 p.

BRASIL. Ministério da Saúde. Secretaria de Ciência, Tecnologia e Insumos Estratégicos. Departamento de Ciência e Tecnologia. Política Nacional de Gestão de Tecnologias de 
Saúde. Brasília, 2010b.

BRASIL. Tribunal de Contas da União. Manual de auditoria de natureza operacional Brasília: TCU, Coordenadoria de Fiscalização e Controle, 2000. 114 p.

CARVALHO, L. C. Instrumentação médico-hospitalar. - Barueri, SP: Manole, 2008.

CNI. COMPI. Avaliação da conformidade: conhecendo e aplicando na sua empresa. 2. ed. rev. Brasília, 2002.

FERRAZ, M. B. Dilemas e escolhas do sistema de saúde: economia da saúde ou saúde da economia? Rio de Janeiro: MEDBOOK, 2008.

FERREIRA-DA-SILVA, A. L. et al . Diretriz para análises de impacto orçamentário de tecnologias em saúde no Brasil. Cad. Saúde Pública, Rio de Janeiro, v. 28, n. 7, July 2012. Disponível em $<$ http://www.scielosp.org/scielo.php?script=sci_arttext\&pid=S0102311 X2012000700002\&lng=en\&nrm=iso>. Acesso em 1 jul. 2013.

FUNDAÇÃO INSTITUTO BRASILEIRO DE GEOGRAFIA E ESTATÍSTICA - IBGE. Centro de Documentação e Disseminação de Informações. Normas de apresentação tabular. 3. ed. Rio de Janeiro: IBGE, 1993. 62 p.

HOLSBACH, L. R.; CALIL, S. J. Implantação de um programa de manutenção preventiva em equipamentos médicos-hospitalares. In: BRASIL. Anvisa. Léria Rosane Holsbach; Ministério da Saúde (Org.). Manutenção preventiva em equipamentos médicohospitalares. Brasília: Ministério da Saúde, 2005. Cap. 1. p. 11-25.

INTERNATIONAL ELECTROTECHNICAL COMMISSION. About the IEC. Disponível em <http://www.iec.ch>. Acesso em 20 nov. 2014.

INTERNATIONAL ORGANIZATION FOR STANDARDIZATION. About ISO. Disponível em <http://www.iso.org>. Acesso em 20 nov. 2014.

JOINT COMMISSION. Failure Mode and Effect Analisys in Health Care: proactive risk reduction. The Joint Commission Resources: Illinois, 2010.

JOINT COMMISSION. Summary Data of Sentinel Events Reviewed by The Joint Commission. Disponível em $<\mathrm{http}$ ://www.jointcommission.org/>. Acesso em 28 out. 2014.

LEOTSAKOS, A. et al. Standardization in patient safety: the WHO High 5s Project. International Journal for Quality in Health Care 2014; Volume 26, Number 2: pp. 109116.

LEWIS, H. W. Technological risk. W. W. Norton: New York, 1990.

LORENZETTI, J. et al. Tecnologia, inovação tecnológica e saúde: uma reflexão necessária. Texto contexto - enferm., Florianópolis, v. 21, n. 2, June 2012 . Disponível em $<$ http://www.scielo.br/scielo.php?script=sci_arttext\&pid=S0104$07072012000200023 \& \operatorname{lng}=$ en\&nrm=iso $>$. Acesso em 1 jul. 2013.

LUCATELLI, M. V. Proposta de aplicação da manutenção centrada em confiabilidade 
em equipamentos médico-hospitalares. 2002. (Tese) Curso de Engenharia Elétrica, Universidade Federal de Santa Catarina, Florianópolis: 2002.

MALKIN, R. e KEANE, A. Evidence-based approach to the maintenance of laboratory and medical equipment in resource-poor settings. Med Biol Eng Comput (2010) 48:721-726.

MANRIQUE-RODRÍGUEZ, S. et al. Risks in the implementation and use of smart pumps in a pediatric intensive care unit: application of the failure mode and effects analysis. International Journal of Technology Assessment in Health Care, 30:2 (2014), 210-217. Cambridge University Press, 2014.

MARCONI, M. A. e LAKATOS, E. M. Técnicas de pesquisa: planejamento e execução de pesquisas, amostragens e técnicas de pesquisa, elaboração, análise e interpretação de dados. 7. ed. 4. reimpr. São Paulo: Atlas, 2011.

MELLO, D. R. e RAMALHO, P. I. S. Boas práticas regulatórias: previsibilidade e transparência na Agência Nacional de Vigilância Sanitária. In: BRASIL, Agência Nacional de Vigilância Sanitária. Regulação e Agências Reguladoras: governança e análise de impacto regulatório. RAMALHO, P. I. S. (Org.) - Brasília: Anvisa, 2009.

MESTAS VALERO, C. A. Metodologia para avaliar a implementação da gestão de risco em uma organização de saúde: home care que usa dispositivos médicos. (Tese). UNICAMP. Campinas, SP: 2011.

OSHIYAMA, N. F. et al. Medical equipment classification: method and decisionmaking support based on paraconsistent annotated logic. Med Biol Eng Comput (2012) 50:395-402.

PATEL, S. M. et al. Methods of failure and reliability assessment for mechanical heart pumps. Artificial Organs. 29(1):15-25, Blackwell Publishing, Inc. International Center for Artificial Organs and Transplantation, 2005.

PONTE JÚNIOR, G. P. Gerenciamento de risco baseado em fatores humanos e cultura de segurança: estudo de caso de simulação computacional do comportamento humano durantes a operação de escape e abandono em instalações offshore. Rio de Janeiro: Elsevier, 2014.

PROJECT MANAGEMENT INSTITUTE. Practice standard for project risk management. Pennsylvania: PMI, 2009.

PROJECT MANAGEMENT INSTITUTE. Um guia do conhecimento de gerenciamento de projetos (Guia PMBOK). 5. ed. Pennsylvania: PMI, 2014.

ROSÁRIO, C. R.; KIPPER, L. M. e FROZZA, R. Técnicas de elicitação de conhecimento tácito: um estudo de caso aplicado a uma empresa do ramo metalúrgico. Inf. \& Soc.:Est., João Pessoa, v.24, n.1, p. 117-134, jan./abr. 2014

RUBINSTEIN, R. Y. e KROESE, D. P. Simulation and the monte carlo method. 2. ed. New Jersey: John Wiley \& Sons, 2008. 
SHI, L. Health services research methods. 2. ed. New York: Delmar Cengage Learning, 2008.

UGÁ, M. A. D. e PORTO, S. M. Financiamento e alocação de recursos em saúde no Brasil. in GIOVANELlA, Lígia et al. (org.) Políticas e sistema de saúde no Brasil. Rio de Janeiro: Fiocruz, 2008.

VAN DER PUTTEN, W. J. M. et al. In-house management of diagnostic imaging equipment. Med Biol Eng Comput (1994) 32:664-669.

VECINA NETO, G.; MARQUES, M. C. C.; FIGUEIREDO, A. M. Vigilância Sanitária no Brasil. In: CAMPOS, Gastão W. S. et al. Tratado de Saúde Coletiva. 2. ed. Rio de Janeiro: Hucitec - Fiocruz, 2009. p. 689-713.

WORLD HEALTH ORGANIZATION. Global priority areas for Patient Safety research. Disponível em < http://www.who.int/patientsafety/research/priority_setting/en>. Acesso em 27 out. 2014.

WORLD HEALTH ORGANIZATION. Medical device regulations: global overview and guiding principles. WHO: Geneva, 2003.

YIN, R. K. Estudo de caso: planejamento e métodos. Tradução Daniel Grassi. 3. ed. Porto Alegre: Bookman, 2005. 


\section{GLOSSÁRIO}

Ciclo de vida [1]: todas as fases da vida de um produto para a saúde, desde a concepção inicial até a retirada de serviço e descarte (ABNT NBR ISO 14971:2009).

Ciclo de vida [2]: estágios consecutivos e encadeados de um sistema de produto, desde a aquisição da metéria-prima ou de sua geração a partir de recursos naturais até a disposição final (ABNT NBR ISO 14040:2009).

Ciclo de vida de tecnologias: corresponde às diferentes fases de evolução de uma tecnologia, que vai do seu processo de desenvolvimento, inovação, difusão, incorporação e uso até a sua obsolescência (BRASIL, 2010c).

Ensaio: operação técnica que consiste na determinação de uma ou mais características de um dado produto, processo ou serviço, de acordo com um procedimento especificado (CNI, 2002).

Evento adverso: incidente que resulta em dano à saúde (Brasil, 2013).

Frequência: número de eventos ou resultados por uma unidade de tempo definida (ABNT ISO GUIA 73:2009).

Gerenciamento de tecnologias: procedimentos de gestão, planejados e implementados a partir de bases científicas e técnicas, normativas e legais, com o objetivo de garantir a rastreabilidade, qualidade, eficácia, efetividade, segurança e em alguns casos o desempenho das tecnologias de saúde utilizadas na prestação de serviços de saúde, abrangendo cada etapa do gerenciamento, desde o planejamento e entrada das tecnologias no estabelecimento de saúde até seu descarte, visando à proteção dos trabalhadores, a preservação da saúde pública e do meio ambiente e a segurança do paciente (Brasil, 2011b).

Gestão de risco: aplicação sistêmica e contínua de políticas, procedimentos, condutas e recursos na identificação, análise, avaliação, comunicação e controle de riscos e eventos adversos que afetam a segurança, a saúde humana, a integridade profissional, o meio ambiente e a imagem institucional (Brasil, 2013).

Incidente: evento ou circunstância que poderia ter resultado, ou resultou, em dano desnecessário à saúde (Brasil, 2013).

Parte interessada: pessoa ou organização que pode afetar, ser afetada, ou perceber-se afetada por uma decisão ou atividade (ABNT ISO GUIA 73:2009).

Monitoramento: verificação, supervisão, observação crítica ou identificação da situação, executadas de forma contínua, a fim de identificar mudanças no nível de desempenho requerido ou esperado (ABNT ISO GUIA 73:2009).

Perigo: fonte de potencial dano (ABNT ISO GUIA 73:2009) (ISO/IEC Guide 51:1999).

Plano de gerenciamento: documento que aponta e descreve os critérios estabelecidos pelo 
estabelecimento de saúde para a execução das etapas do gerenciamento das diferentes tecnologias em saúde submetidas ao controle e fiscalização sanitária abrangidas pela RDC $\mathrm{n}^{\mathrm{o}}$ 2, de 2010, desde o planejamento e entrada no estabelecimento de saúde, até sua utilização no serviço de saúde e descarte (Brasil, 2010).

Plano de gestão de riscos: esquema dentro da estrutura da gestão de riscos, que especifica a abordagem, os componentes de gestão e os recursos a serem aplicados para gerenciar riscos (ABNT ISO GUIA 73:2009).

Plano de segurança do paciente em serviços de saúde: documento que aponta situações de risco e descreve as estratégias e ações definidas pelo serviço de saúde para a gestão de risco visando a prevenção e a mitigação dos incidentes, desde a admissão até a transferência, a alta ou o óbito do paciente no serviço de saúde (Brasil, 2013).

Probabilidade (likelihood) [1]: chance de algo acontecer (ABNT ISO GUIA 73:2009).

Probabilidade [2]: medida da chance de ocorrência expressa como um número entre 0 e 1 , onde 0 é a impossibilidade e 1 é a certeza absoluta (ABNT ISO GUIA 73:2009).

Produto para saúde [1]: é aquele enquadrado como produto médico ou produto para diagnóstico de uso in vitro (Brasil, 2010a).

Produto para a saúde [2]: qualquer instrumento, aparelho, implemento, máquina, produto, implante, reagente ou calibrador in vitro, software, material, ou outro artigo similar ou relacionado, destinado pelo fabricante a ser utilizado, sozinho ou em combinação, em seres humanos, para um ou mais dos seguintes propósitos específicos:

- diagnosticar, prevenir, monitorar, tartar ou aliviar uma doença;

- diagnosticar, monitorar, tartar aliviar ou compensar lesões;

- investigar, substituir, modificar ou suportar a anatomia ou um processo fisiológico;

- suportar ou sustentar a vida;

- controlar a concepção;

- desinfetar produtos para a saúde;

- fornecer informação para propósitos medicos por meio de espécimes in vitro retirados do corpo humano, e que não alcance sua ação destinada primária no corpo humano por meios farmacológicos, imunológicos ou metabólicos, mas que possa ter seu funcionamento assistido por tais meios (ABNT NBR ISO 14971:2009).

Produto para a saúde [3]: qualquer instrumento, aparelho, utensílio, material ou outro artigo, quer seja usado sozinho ou em combinação com outro(s), incluindo o software necessário para sua aplicação apropriada, produzido pelo fabricante com o intuito de ser utilizado em seres humanos com o propósito de promover:

- diagnóstico, prevenção, monitoramento, tratamento ou paliativo de doença;

- diagnóstico, monitoramento, tratamento, paliativo ou compensação para lesão ou deficiência;

- pesquisa, substituição ou modificação da anatomia de um processo fisiológico; 
- controle contraceptivo;

e que não atinja a sua principal ação pretendida no corpo humano por meio farmacológico, imunológico, ou metabólico, mas que possa ser auxiliado em sua função por tais meios (ABNT NBR 14155-1:2004a).

Rastreabilidade: capacidade de traçar o histórico, a aplicação ou a localização de um item por meio de informações previamente registradas (Brasil, 2010).

Risco [1]: efeito da incerteza nos objetivos (ABNT ISO GUIA 73:2009).

Risco [2]: combinação da probabilidade de ocorrência de um dano e a severidade de tal dano (ABNT NBR ISO 14971:2009).

Serviço de saúde: estabelecimento de saúde destinado a prestar assistência à população na prevenção de doenças, no tratamento, recuperação e na reabilitação de pacientes (Brasil, 2011b).

Tecnologia em saúde: conjunto de equipamentos, medicamentos, insumos e procedimentos utilizados na atenção à saúde, bem como os processos de trabalho, a infraestrutura e a organização do serviço de saúde (Brasil, 2013). 


\section{APÊNDICE A - QUESTIONÁRIO}

\section{Organização}

1.1 O serviço de saúde estabeleceu e implementou em sua unidade um Plano de Gerenciamento de Tecnologias em Saúde, tal como determinado pela RDC 2, de 2010 da ANVISA?

1.2 O serviço de saúde estabeleceu e implementou em sua unidade um Plano de Gerenciamento de Equipamentos, tal como determinado pela ABNT NBR 15943/2011?

1.3 Como são previstos e mantidos os recursos necessários para o cumprimento do Plano de Gerenciamento de Tecnologias em Saúde / Plano de Gerenciamento de Equipamentos?

1.4 A organização possui uma sistemática de manutenção preventiva e corretiva das instalações e equipamentos documentada?

1.5 O serviço de saúde: (a) prevê e provê os recursos necessários ao cumprimento das disposições do Plano de Gerenciamento de Tecnologias em Saúde / Plano de Gerenciamento de Equipamentos; (b) assegura recursos humanos e materiais prontamente disponíveis para a realização das atividades descritas nos procedimentos de inspeção e manutenção, equipamentos de proteção exigidos em legislação especifica voltada à segurança e saúde do trabalhador, entre outros?

1.6 Os serviços de apoio técnico, logístico e gerenciamento de equipamentos, quando terceirizados pelos serviços de saúde, constam em contrato formal de prestação de serviços?

\section{Infraestrutura}

2.1 A organização possui em sua infraestrutura física uma unidade para a realização dos procedimentos de gerenciamento de equipamentos?

2.2 Se sim, a unidade está dimensionada e compatível com as atividades desenvolvidas, conforme os requisitos contidos nas normas ABNT NBR 15943/2011 e RCD 2, de 2010 da ANVISA?

2.3 As áreas destinadas à intervenção técnica são mantidas em bom estado de conservação, higiene e limpeza?

2.4 As áreas destinadas à intervenção técnica possuem instalações elétricas, iluminação e 
sistemas de climatização necessários à conservação dos equipamentos para saúde e às atividades desenvolvidas, de acordo com a recomendação do fabricante e demais regulamentações pertinentes?

2.5 As áreas destinadas à intervenção técnica estão protegidas contra a entrada de insetos, roedores e outros animais?

\section{Gestão de pessoal}

3.1 As atividades de gerenciamento de equipamentos são de responsabilidade de profissional de nível superior, com registro no respectivo conselho de classe, de acordo com as competências profissionais definidas na legislação vigente, com conhecimento comprovado na área?

3.2 As atribuições e responsabilidades profissionais estão formalmente descritas, divulgadas e compreendidas pelos envolvidos nas atividades de gerenciamento de equipamentos?

3.3 Todos os profissionais envolvidos nas atividades de gestão dos equipamentos recebem educação permanente, em conformidade com as atividades desenvolvidas, com registro de sua realização e da participação destes profissionais?

3.4 Todos os profissionais são orientados quanto às práticas de higiene pessoal e ao uso de equipamento de proteção individual (EPI) e equipamento de proteção coletiva (EPC)?

3.5 Todo profissional utiliza EPI e EPC compatíveis com as atividades por ele desenvolvidas, em conformidade com as normas regulamentadoras do órgão governamental competente?

\section{Documentação}

4.1 As atividades descritas no Plano de Gerenciamento de Tecnologias em Saúde / Plano de Gerenciamento de Equipamentos têm seus procedimentos operacionais descritos, aprovados pelo profissional designado e disponíveis aos envolvidos na realização das atividades?

4.2 Os procedimentos operacionais estão datados, assinados e atualizados?

4.3 O serviço de saúde estabelece e registra os métodos que garantam a utilização dos procedimentos operacionais?

4.4 O serviço de saúde dispõe de mecanismos que permitam gerar, armazenar e 
disponibilizar informações técnicas e gerenciais acerca dos equipamentos, bem como sobre procedimentos utilizados pelo serviço de saúde?

4.5 O serviço de saúde possui histórico de incidentes e falhas dos equipamentos?

4.6 O serviço de saúde estabelece e mantém documento escrito para controle dos procedimentos operacionais para assegurar que estes satisfaçam os requisitos do Plano de Gerenciamento de Tecnologias em Saúde / Plano de Gerenciamento de Equipamentos e estejam corretos e adequados para o uso pretendido?

4.7 O serviço de saúde mantém registro de alteração em procedimentos operacionais, incluindo sua descrição, análise crítica, assinatura do responsável, data de aprovação e data de vigência das alterações?

4.8 O serviço de saúde tem as atividades do gerenciamento descritas, registradas, analisadas, datadas e assinadas pelo executor?

\subsection{O Plano de Gerenciamento de Tecnologias em Saúde / Plano de Gerenciamento}

de Equipamentos permite a rastreabilidade dos equipamentos desde sua incorporação ao serviço de saúde até seu descarte final, incluindo o uso?

4.10 A documentação de um equipamento inclui os seus documentos acompanhantes (manual, orientações do fabricante etc.)?

\section{Requisitos específicos}

\subsection{Planejamento e seleção}

5.1.1 Há um planejamento para aquisição, considerando a demanda, a infraestrutura física ou tempo necessário para sua adequação e os recursos e materiais necessários à utilização do equipamento?

5.1.2 O serviço de saúde estabelece um fluxo para incorporação tecnológica, considerando:

a) critérios para seleção de equipamentos;

b) regularização dos equipamentos e dos seus fornecedores junto à autoridade sanitária competente.

5.1.3 O planejamento e a seleção são documentados e atendem aos procedimentos escritos?

\subsection{Aquisição}

5.2.1 O serviço de saúde estabelece, documenta e implementa critérios para qualificação 
de fornecedores de equipamentos e de serviços?

5.2.2 Os equipamentos, seus fornecedores e os fornecedores de serviço estão regularizados junto ao órgão sanitário competente e aos conselhos de classe, quando aplicável?

5.2.3 A importação de equipamentos diretamente pelo serviço de saúde segue a legislação sanitária vigente?

5.2.4 A aquisição é documentada e atende aos procedimentos escritos?

\subsection{Recebimento, verificação e aceitação}

5.3.1 O serviço de saúde estabelece critérios para receber equipamentos acompanhados de:

- $\quad$ especificações técnicas do equipamento;

- comprovação da regularização do equipamento no órgão sanitário competente;

- $\quad$ número de série;

- documento fiscal, e

- documentos acompanhantes.

5.3.2 Quais as fases de recebimento do equipamento no serviço de saúde (chegada do equipamento $=>$ emissão do laudo de ensaio de aceitação)?

5.3.3 O serviço de saúde desenvolveu e mantém um procedimento que assegure que todos os equipamentos sejam avaliados antes do seu primeiro uso, por meio de ensaios de aceitação?

5.3.4 A empresa fornecedora do equipamento participa da realização desses ensaios?

5.3.5 Os ensaios de aceitação seguem atividades estabelecidas entre o fornecedor e o serviço de saúde, com base nas normas técnicas aplicáveis ao equipamento, incluindo atividades que garantam a segurança e o desempenho essencial do equipamento? Esta atividade é documentada?

5.3.4 O serviço de saúde estabeleceu um acordo formal com o fornecedor do equipamento para execução do ensaio de aceitação? Terceirizou a realização do ensaio de aceitação?

5.3.5 Caso o serviço de saúde prefira não utilizar o fornecedor como executor do ensaio ou não aceite sua participação durante a execução, este (o serviço de saúde) assume a responsabilidade sobre o ensaio de aceitação?

5.3.6 Os seguintes procedimentos/documentos compõem o ensaio de aceitação: (a) parecer técnico que evidencie a segurança e o desempenho essencial do equipamento e (b) 
comissionamento da infraestrutura, quando necessário ao funcionamento seguro do equipamento?

5.3.7 São estabelecidos e implementados procedimentos para prevenir o uso de equipamentos que não tenham sido ensaiados e aprovados no recebimento?

5.3.8 Os números de série do equipamento e de seus acessórios são discriminados no documento fiscal, guia de remessa ou outro documento equivalente, e são conferidos no momento do recebimento?

5.3.9 As não conformidades implicam não aceitação do equipamento pelo serviço de saúde? São registradas? São notificadas à autoridade sanitária competente?

5.3.10 O serviço de saúde desenvolveu e implementou procedimentos que garantam a comunicação entre o agente de serviços, outros departamentos e a quem o serviço de saúde decida informar sobre o andamento dos ensaios de aceitação? Ao desenvolver tais procedimentos, o serviço de saúde considera a notificação dos departamentos: (a) que utiliza o equipamento; (b) responsável pela aprovação do pagamento do equipamento; (c) responsável por gerenciar patrimônio; e (d) responsável pelo treinamento de operadores do equipamento?

\subsection{Procedimento para ensaios de aceitação do equipamento}

5.4.1 O serviço de saúde desenvolveu e implementou procedimentos para ensaio de aceitação de cada equipamento que indiquem: (a) as atividades que um agente de serviços realiza durante a inspeção do equipamento; (b) os requisitos de ensaio de aceitação do equipamento determinados pelo seu fabricante, quando informados; (c) os responsáveis pela sua execução; e (d) a documentação usada para registrar todas as informações referentes aos ensaios de aceitação do equipamento?

\subsection{Inventário}

5.5.1 O serviço de saúde desenvolveu e mantém o inventario dos seus equipamentos, independentemente do meio de armazenamento dos dados do inventário?

5.5.2 O serviço de saúde tem capacidade de reproduzir a listagem impressa quando necessário?

5.5.3 Toda documentação referente ao inventário garante sua rastreabilidade?

\subsubsection{Lista de inventário de equipamento}


5.5.1.1 Estão listados no inventário do serviço de saúde os equipamentos: (a) de propriedade do serviço de saúde, e (b) cedidos de forma exclusiva ao serviço de saúde por contratos e convênios legalmente reconhecidos?

5.5.1.2 Para equipamentos não incluídos nessa seção, o serviço de saúde estabelece uma politica documentada para utilização desses equipamentos, de forma a garantir a rastreabilidade e segurança do equipamento, além das responsabilidades das partes envolvidas? O serviço de saúde mantém o registro do uso destes equipamentos?

\subsubsection{Informações a serem incluídas no inventário}

5.5.2.1 O serviço de saúde realiza inventario contendo os dados cadastrais de cada equipamento, com as seguintes informações: (a) nome técnico; (b) nome e modelo comercial; (c) fabricante; (d) número de série; (e) código de identificação individual criado pelo serviço de saúde; (f) partes e acessórios; (g) data (dia/mês/ano) de aceitação do equipamento pelo serviço de saúde; (h) data (dia/mês/ano) em que o equipamento entrou em funcionamento e data de desativação; e (i) dados de regularização do equipamento junto ao órgão sanitário competente?

\subsubsection{Atualização do inventário}

5.5.3.1 O inventário está atualizado a cada nova aquisição ou desativação do equipamento no serviço de saúde?

\subsubsection{Auditoria}

5.5.4.1 O inventário é auditado periodicamente, com periodicidade estabelecida formalmente pelo serviço de saúde? Os procedimentos de auditoria verificam a exatidão da informação registrada no inventário, assim como a inclusão de todos os equipamentos utilizados no serviço de saúde que atendam aos critérios de inclusão?

5.5.4.2 O serviço de saúde estabelece e documenta padrões para assegurar a exatidão dos dados do inventário? Caso os padrões não tenham sido atendidos, o serviço de saúde estabelece e valida um plano de amostragem para realizar a auditoria de seu inventário, em conformidade com normas técnicas em vigor aplicáveis?

5.5.4.3 Outras técnicas estatísticas são utilizadas? Estão formalizadas por escrito e baseadas em lógica estatística válida? O serviço de saúde estabelece e mantém procedimentos para assegurar que os métodos de amostragem sejam adequados ao uso pretendido e revisados regularmente? 
5.5.4.4 O serviço de saúde mantém profissional qualificado e designado para realizar a revisão e propor técnicas estatísticas adequadas?

\subsection{Instalação}

5.6.1 O serviço de saúde realiza a instalação dos equipamentos para a saúde e de infraestrutura em conformidade com a normatização aplicável e com as recomendações do fabricante?

\subsection{Registro histórico do equipamento}

5.7.1 O serviço de saúde deve manter um registro histórico de cada equipamento, contendo, além das informações constantes no inventário: (a) a identificação da unidade no serviço de saúde onde está alocado o equipamento, incluindo suas informações de transferência, quando houver; (b) profissional designado pelo serviço de saúde responsável pelo uso do equipamento em cada unidade; (c) histórico de falhas do equipamento; (d) histórico documentado dos problemas e incidentes relacionados a eventos adversos causados, ou potencialmente causados, por falhas do equipamento ${ }^{7}$; (e) documentação de intervenções técnicas no equipamento; e (f) Outras informações que o serviço de saúde julgue necessárias são incluídas no registro histórico do equipamento?

\subsection{Arquivo de registros}

5.8.1 O serviço de saúde arquiva os registros históricos dos equipamentos e indica formalmente o responsável pelo seu gerenciamento? O registro histórico é arquivado pelo tempo que o equipamento estiver em utilização pelo serviço de saúde, acrescido pelo menos de dois anos?

\subsection{Treinamento}

\subsubsection{Responsabilidade do treinamento}

5.9.1.1 O prestador de serviços provê o treinamento permanente necessário para garantir que cada agente de serviços esteja apto a realizar as suas atividades?

5.9.1.2 O conteúdo do treinamento deve incluir capacitação em: (a) normas de segurança previstas em atos legais e normativos; (b) novos equipamentos e ferramentas; e (c) novos processos de trabalho.

\subsubsection{Documentação sobre o treinamento}

7 Deve existir evidência da ação tomada pelo serviço de saúde e da notificação ao órgão sanitário competente e fornecedor, quando pertinente. 
5.9.2.1 O serviço de saúde documenta: (a) conteúdo programático do treinamento; (b) critérios da avaliação das necessidades desse treinamento; (c) participação e avaliação do treinado; e (d) avalição da eficácia do treinamento.

\subsection{Armazenamento}

5.10.1 O armazenamento segue os procedimentos escritos e as orientações estabelecidas no Plano de Gerenciamento de Tecnologias em Saúde / Plano de Gerenciamento de Equipamentos?

5.10.2 Os equipamentos são armazenados conforme especificação do fornecedor?

5.10.3 Quando as especificações do fornecedor exigirem controle ambiental contínuo, existem registros que comprovem o atendimento a estas exigências?

5.10.4 São estabelecidos e implementados critérios para impedir o uso de equipamentos que ainda não tenham sido aprovados no recebimento, estejam sob manutenção, impedidos de uso, indicados para descarte ou devolução, devendo estar identificados quando à sua situação e destino, além de devidamente segregados?

5.10.5 Os equipamentos são armazenados isoladamente de produtos e substâncias que possam afetar a sua identidade, integridade, segurança e desempenho, tais como: produtos radioativos, substancias químicas voláteis, inflamáveis, explosivas, altamente reativas, toxicas ou corrosivas?

5.10.6 O armazenamento é feito em local específico, não podendo ocorrer em área de circulação, mesmo que temporariamente?

5.10.7 O armazenamento de fontes radioativas ou de equipamentos que possuam fontes radioativas incorporadas está de acordo com o plano de proteção radiológica aprovado para o serviço de saúde, conforme legislação vigente?

\subsection{Transferência interna de equipamento}

5.11.1 O serviço de saúde possui procedimentos escritos e registro documentados para transferência de equipamento?

5.11.2 O processo de transferência de equipamento é feito de forma a manter a integridade, segurança, rastreabilidade, desempenho e adequada utilização deste equipamento?

5.11.3 No processo de transferência é feita a atualização do registro histórico do 
equipamento, de forma a contemplar a realocação do equipamento, bem como o respectivo responsável por ele? O histórico da transferência do equipamento é computado no registro histórico do equipamento, indicando o período de tempo, informando data (dia/mês/ano) e entrada e saída em que o equipamento esteve alocado em cada unidade do serviço?

\subsection{Uso}

5.12.1 O serviço de saúde estabeleceu e implementou procedimentos para garantir a rastreabilidade do equipamento e a segurança do paciente no seu atendimento e do operador?

5.12.2 O equipamento somente é utilizado por profissional comprovadamente treinado?

5.12.3 O equipamento está em condições adequadas de segurança?

5.12.4 Para uso de equipamento emissor de radiações ionizantes, são observados ainda os requisitos de proteção radiológica contidos em legislação específica vigente?

\subsection{Intervenção técnica}

5.13.a O serviço de saúde: (a) estabeleceu e implementou procedimentos para assegurar a rastreabilidade metrológica do equipamento; (b) desenvolveu e implementou procedimentos para inserção, ensaio, manutenção, ajuste e calibração no equipamento?

5.13.b As intervenções técnicas: (a) são documentadas no registro histórico do equipamento, indicando inclusive o nome do executor; (b) são executados somente por profissional comprovadamente treinado?

5.13.c Em caso de terceirização de qualquer intervenção técnica, há acordo formal entre as partes? O serviço de saúde dispõe de todas as informações de intervenções técnicas realizadas pelo terceiro para alimentar registro histórico do equipamento?

\subsubsection{Procedimento para manutenção corretiva (MC)}

5.13.1.1 O serviço de saúde desenvolveu e implementou procedimentos de MC para cada equipamento que indique: (a) o fluxo para realização da $\mathrm{MC}$, desde a sua solicitação até o seu encerramento; (b) as ações necessárias para recolocar o equipamento em condições de uso de acordo com as especificações; (c) os responsáveis pela sua execução; (d) a documentação usada para registrar as informações referentes à $\mathrm{MC}$ do equipamento?

5.13.1.2 A documentação da $\mathrm{MC}$ faz parte do registro histórico do equipamento?

\subsubsection{Procedimentos para prevenção preventiva (MP)}


5.13.2.1 O serviço de saúde desenvolveu e implementou procedimentos de MP para cada equipamento que indique: (a) as ações necessárias para verificar se o equipamento está em condições de uso e de acordo com suas especificações após realização da $\mathrm{MP}^{8}$; (b) periodicidade destas ações ${ }^{9}$; (c) os responsáveis pelo sua execução; (d) a avaliação da efetividade do serviço realizado; (e) a documentação usada para registrar todas as informações referentes à MP do equipamento?

5.13.2.2 A documentação da MP do equipamento faz parte do registro histórico do equipamento?

\subsubsection{Critérios de análise de risco para priorização da MP}

5.13.3.1 O programa de MP leva em consideração: (a) a função do equipamento, bem como se é usado para suporte à vida, terapia, diagnóstico, monitorização ou apoio; (b) os riscos associados com o equipamento tanto em seu uso normal como o possível uso impróprio; (c) os requisitos de manutenção do equipamento, de acordo com definição do fabricante, quando fornecidos; (d) o histórico de incidentes e falhas com o equipamento, tanto nas dependências dos serviços de saúde quanto em outras fontes externas disponíveis?

\subsection{Desativação}

5.14.1 O serviço de saúde estabeleceu e documentou critérios para desativação dos equipamentos para a saúde e de infraestrutura?

5.14.2 Ao desativar um equipamento, o estabelecimento de saúde gera um laudo de desativação para cada equipamento para a saúde e de infraestrutura? O laudo contempla os seguintes dados: (a) dados do equipamento; (b) data de desativação; (c) motivo da desativação; e (f) responsável pela desativação?

5.14.3 Os equipamentos para saúde e de infraestrutura desativados devem são segregados e devidamente identificados e documentados quanto à sua condição e destino?

\subsection{Descarte}

Não são considerados apenas os parâmetros para ensaios de corrente de fuga e de resistência de atendimento, quando a intervenção realizada assim os requererem. Todos os requisitos para ensaio de desempenho e manutenção preventiva devem ser considerados quando procedimentos se inspeção programada forem desenvolvidos.

9 A periodicidade é fundamentada nas necessidades de cada serviço de saúde, no acompanhamento dos registros históricos dos seus equipamentos e na periodicidade determinada pelo fabricante do equipamento. 
5.15.1 O serviço de saúde implantou um plano de gerenciamento de resíduos de serviços de saúde (PGRSS), atendendo aos requisitos da legislação específica vigente?

\subsection{Evento adverso relacionado ao equipamento}

5.16.1 O serviço de saúde mantém registro dos eventos adversos relacionados ao equipamento?

5.16.2 Todas as etapas do gerenciamento de equipamento contam com informações necessárias para uma investigação de possível evento adverso, para notificação ao Sistema Nacional de Vigilância Sanitária e comunicação ao fabricante?

5.16.3 A avaliação de evento adverso atende a procedimentos escritos e é registrada?

5.17 Avaliação do Plano de Gerenciamento de Tecnologias em Saúde / Plano de Gerenciamento de Equipamentos

5.17.1 O serviço de saúde desenvolveu e implementou um processo de melhoria de desempenho para: (a) avaliar o desempenho anual do Plano de Gerenciamento de Tecnologias em Saúde / Plano de Gerenciamento de Equipamentos; (b) planejar e executar qualquer alteração necessária que seja das informações obtidas desta avaliação?

5.17.2 O serviço de saúde elabora relatórios de indicadores que permitam avaliar a conformidade com os objetivos do Plano de Gerenciamento de Tecnologias em Saúde / Plano de Gerenciamento de Equipamentos? 


\section{APÊNDICE B - IDENTIFICAR RISCOS}

Conjunto de questões a serem utilizadas para identificar características do produto para a saúde que poderiam gerar impactos sobre a segurança (ABNT 2009, pp. 26-32)

1 Qual é a utilização do produto para a saúde e como ele deve ser utilizado?

2 O produto para a saúde é destinado a ser implantado?

3 O produto para a saúde é destinado a entrar em contato com o paciente ou outras pessoas?

4 Que materiais e/ou componentes estão incorporados ao produto para a saúde ou são utilizados em conjunto, ou em contato com ele?

5 Energia é fornecida para e/ou extraído do paciente?

6 Substâncias são fornecidas para e/ou extraídas do paciente?

7 Materiais biológicos são processados pelo produto para a saúde para reutilização subsequente, transfusão ou implantação?

8 O produto para a saúde é fornecido estéril ou destinado a ser esterilizado pelo usuário, ou são aplicáveis outros controles microbiológicos?

9 O produto para a saúde é destinado a ser limpo e desinfetado rotineiramente pelo usuário?

10 O produto para a saúde é destinado a modificar o ambiente do paciente?

11 Medições são realizadas?

12 O produto para a saúde é interpretativo?

13 O produto para a saúde é destinado a ser utilizado em conjunto com medicamentos ou outras tecnologias médicas?

14 Há saídas indesejáveis de energia ou substâncias?

15 O produto para a saúde é suscetível a influências ambientais?

16 O produto para a saúde influencia o ambiente?

17 Há algum acessório ou artigo de consumo essencial associado ao produto para a saúde?

18 É necessária a manutenção ou calibração? 
19 O produto para a saúde contém software?

20 O produto para a saúde possui prazo de validade restrito?

21 Há quaisquer efeitos retardados e/ou de uso a longo prazo?

22 A quais forças mecânicas estará sujeito o produto para a saúde?

23 O que determina a vida útil do produto para a saúde?

24 O produto para a saúde é destinado a uso único?

25 É necessário tomar medidas especiais de segurança quanto ao descarte ou desativação do produto para a saúde?

26 A instalação ou utilização do produto para a saúde requer treinamento especial ou habilidades especiais?

27 Como a informação para a segurança será fornecida?

28 Haverá necessidade de estabelecer ou introduzir novos processos de produção?

29 A aplicação bem-sucedida do produto para a saúde depende criticamente de fatores humanos, tais como a interface com o usuário?

29.1 As características do projeto de interface com o usuário podem contribuir para erros de utilização?

29.2 O produto para a saúde será utilizado em um ambiente onde distrações podem causar erros de utilização?

29.3 O produto para a saúde possui partes ou acessórios conectados a ele?

29.4 O produto para a saúde possui uma interface de controle?

29.5 O produto para a saúde exibe informação?

29.6 O produto para a saúde é controlado por um menu?

29.7 O produto para a saúde será utilizado por pessoas com necessidades especiais?

29.8 A interface do usuário pode ser utilizada para iniciar ações do usuário?

30 O produto para a saúde utiliza um sistema de alarme?

31 De quais maneiras o produto para a saúde pode ser deliberadamente mal utilizado?

32 O produto para a saúde guarda dados críticos ao cuidado do paciente? 
$33 \mathrm{O}$ produto médico é projetado para ser móvel ou portátil?

$34 \mathrm{O}$ uso do produto médico depende de desempenho essencial? 


\section{APÊNDICE C - PUBLICAÇÕES}

\section{a) Publicações realizadas em eventos}

ALVES, Cleber S.; GOMES, Marília M. F.; BRASIL, Lourdes M. Disponibilidade de mamógrafos no Brasil: desempenho na produção de exames de mamografia de rastreamento. In: CONGRESSO BRASILEIRO DE ENGENHARIA BIOMÉDICA, XXIV., 2014, Uberlândia. Anais... . Uberlândia: Sbeb, 2014. p. 361-364. (Apresentação oral em congresso).

ALVES, CS; BRASIL, LM. Pan American Health Care Exchanges (PAHCE 2014). Health Technology Management: Challenges for the Biomedical Engineers. Brasília, DF: 2014. (Apresentação oral em congresso).

C.S. Alves, M.M.F. Gomes, L.M. Brasil. Project Management for Clinical Engineering Considerations in the evaluation and acquisition of medical equipment for health services in Brazil.World Congress on Medical Physics \& Biomedical Engineering (Apresentação de poster em congresso).

b) Capítulo de livro publicado

ALVES, CS; GOMES, MMF; BRASIL, LM. Mammography availability in Brazil. Mammography (ISBN 978-953-51-4178-5). Book edited by: Dr. Fabiano Fernandes Instituto Federal de Brasília - Brazil; Profa. Dra. Lourdes M. Brasil - Post-Graduation Program in Biomedical Engineering - University of Brasília at Gama - Brasilia - Brazil; Dr. Renato V. Guadagnin - MS Program in Information Technology and Knowledge Management - Catholic University of Brasília - Brasília - Brazil (Capítulo de livro publicado).

Estudo de caso realizado no Hospital das Forças Armadas, sob autorização da Direção do Hospital.

c) Artigo submetido para publicação em periódico

C.S. Alves, L.B. Gomide, M.M.F. Gomes, L.M. Brasil. Software Risk in Programmable Electrical Medical Systems: Instructions for use of Mammography X-Ray Equipment. 


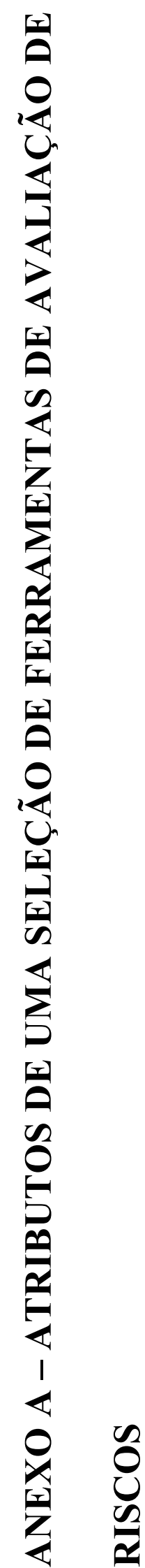

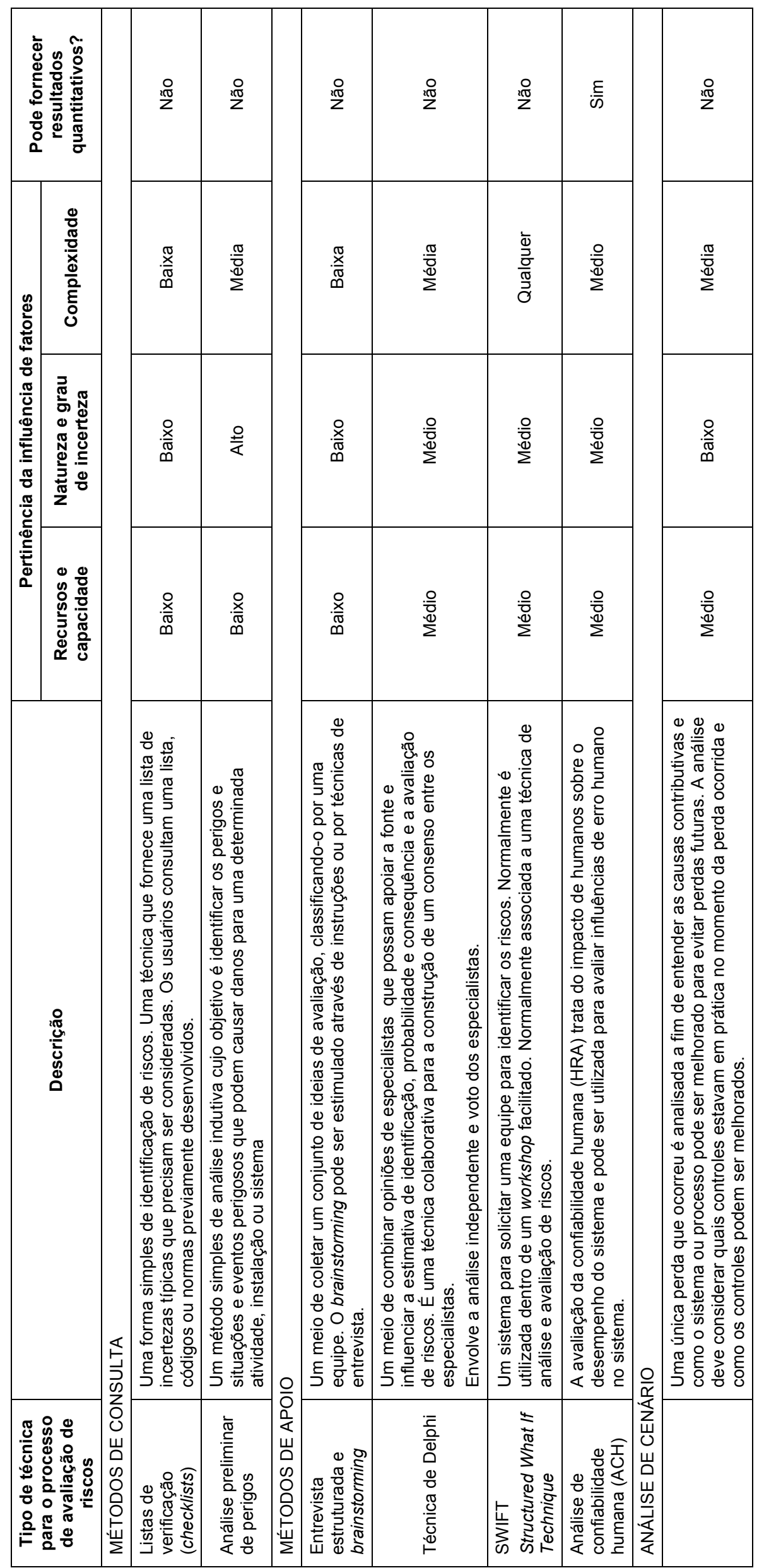




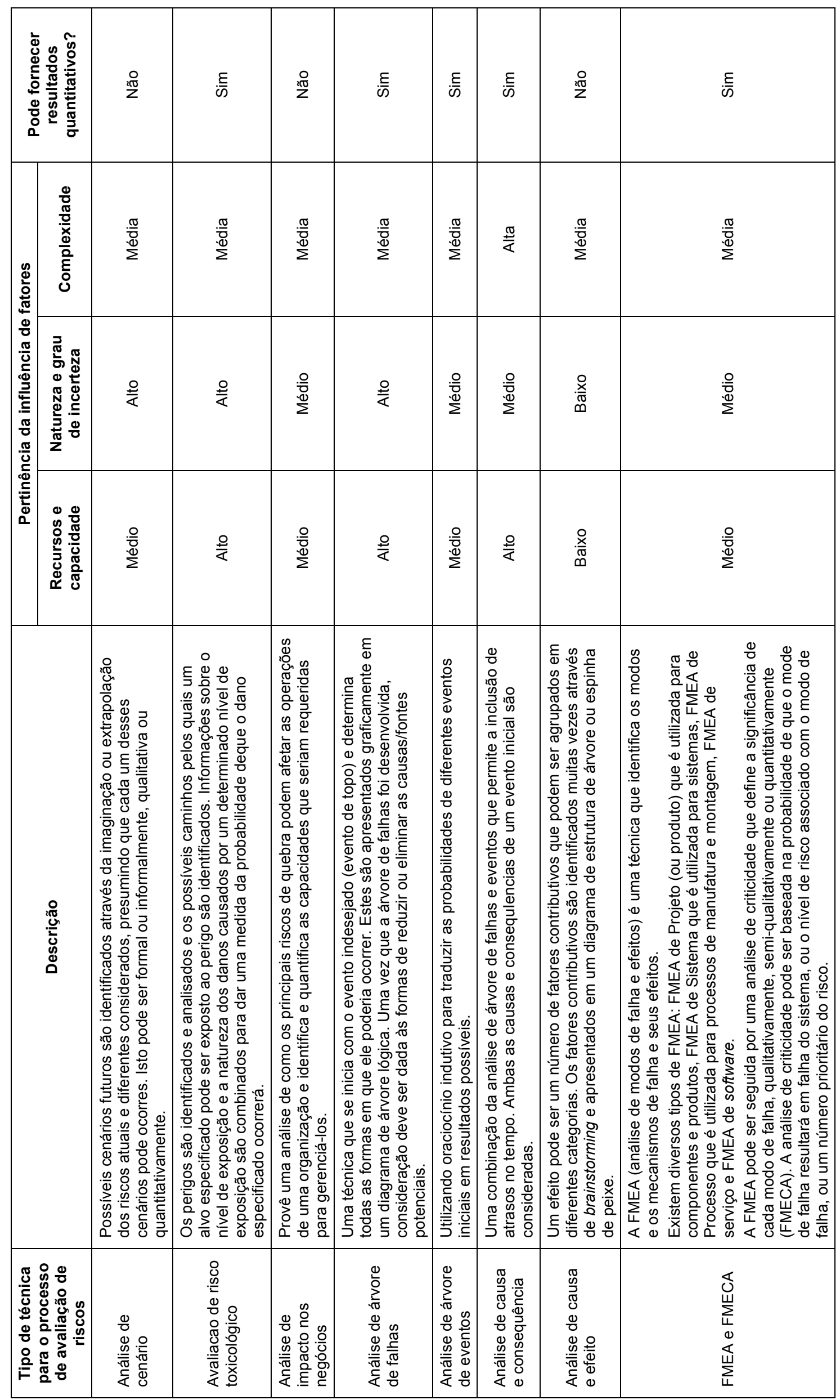




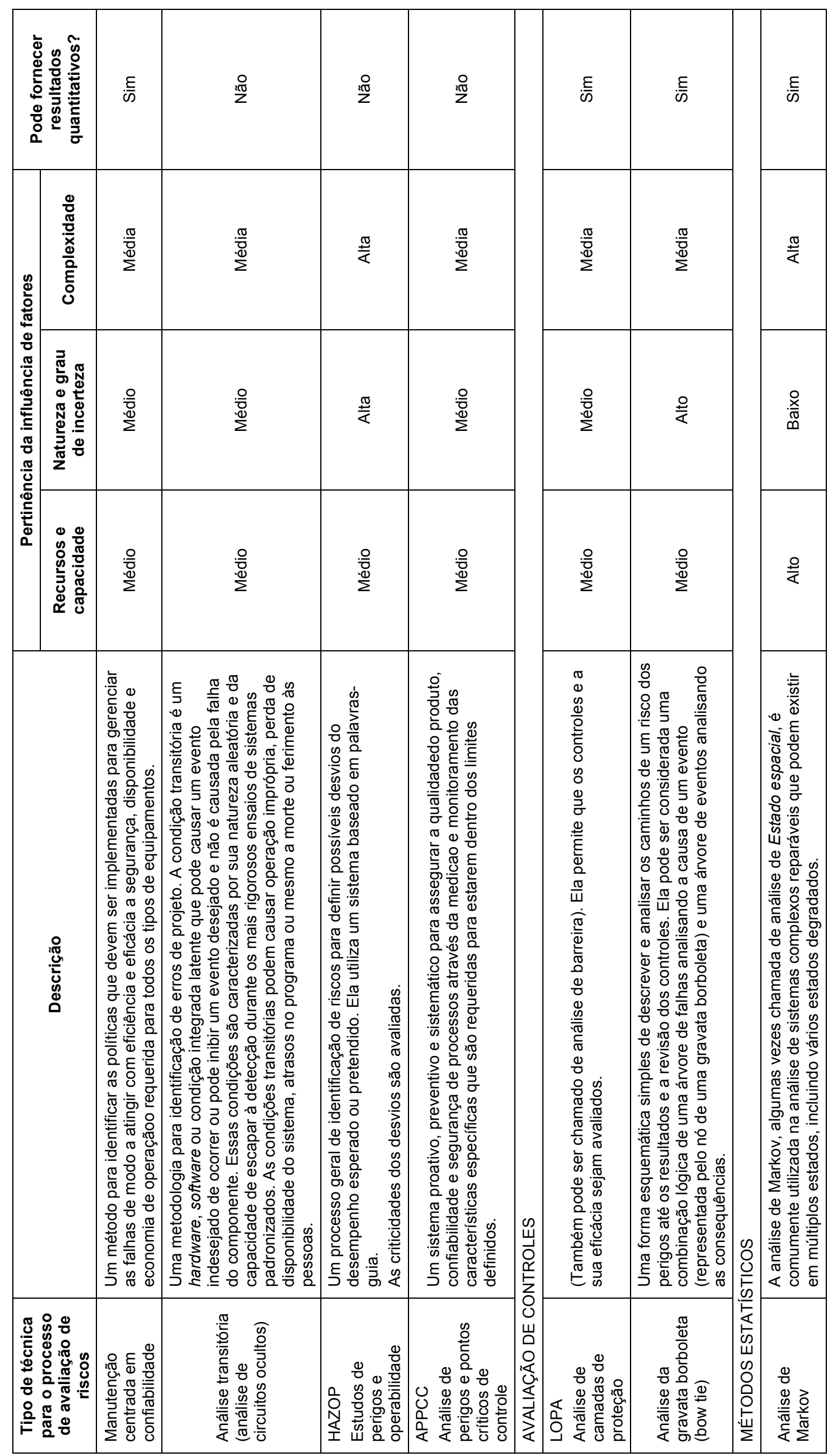




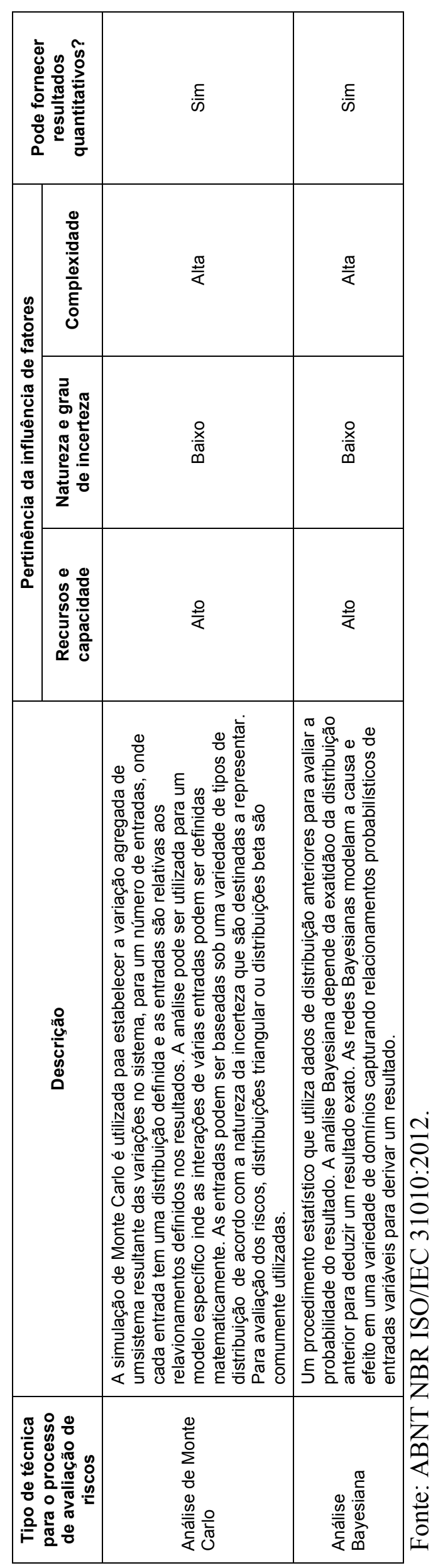




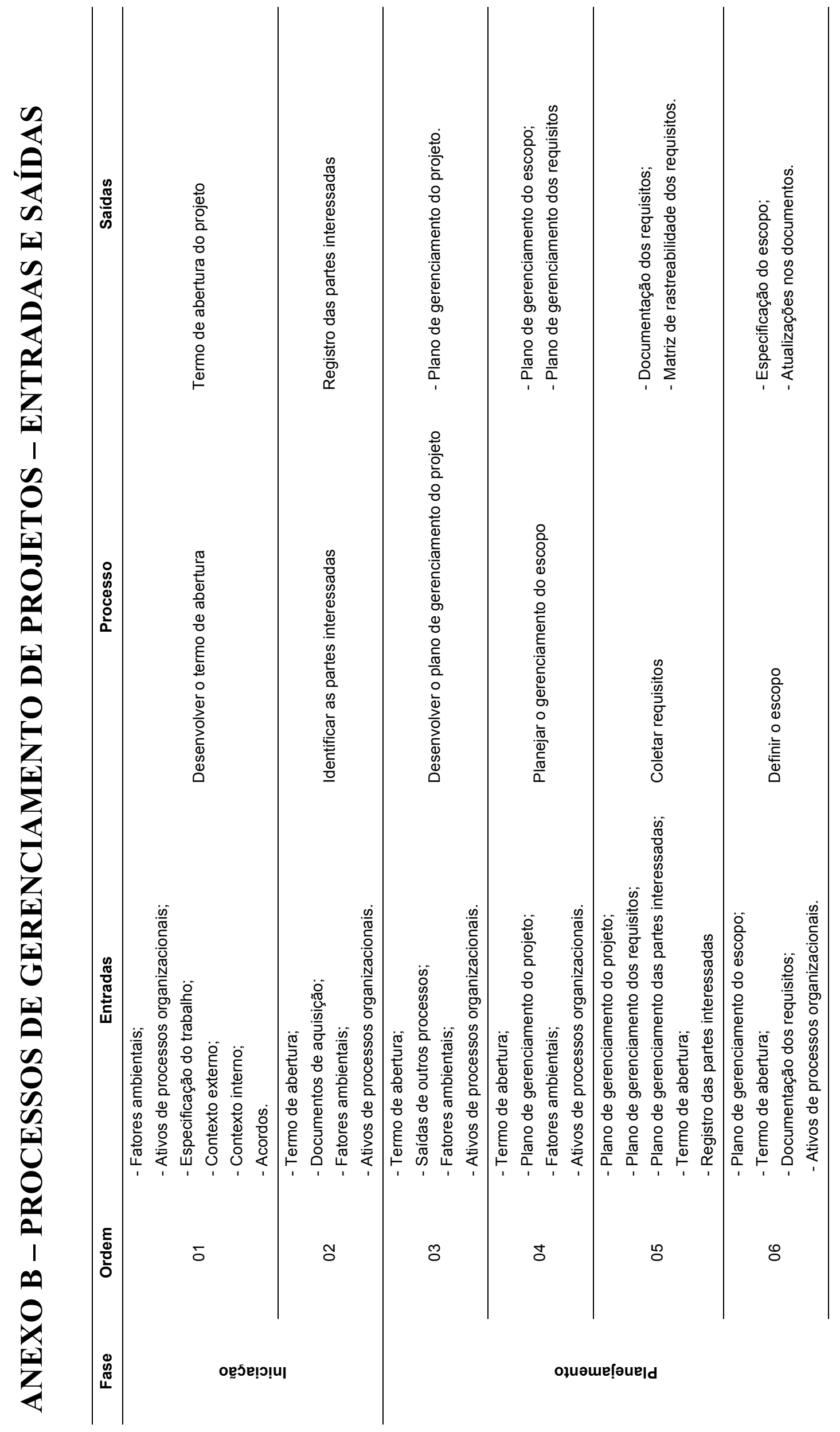




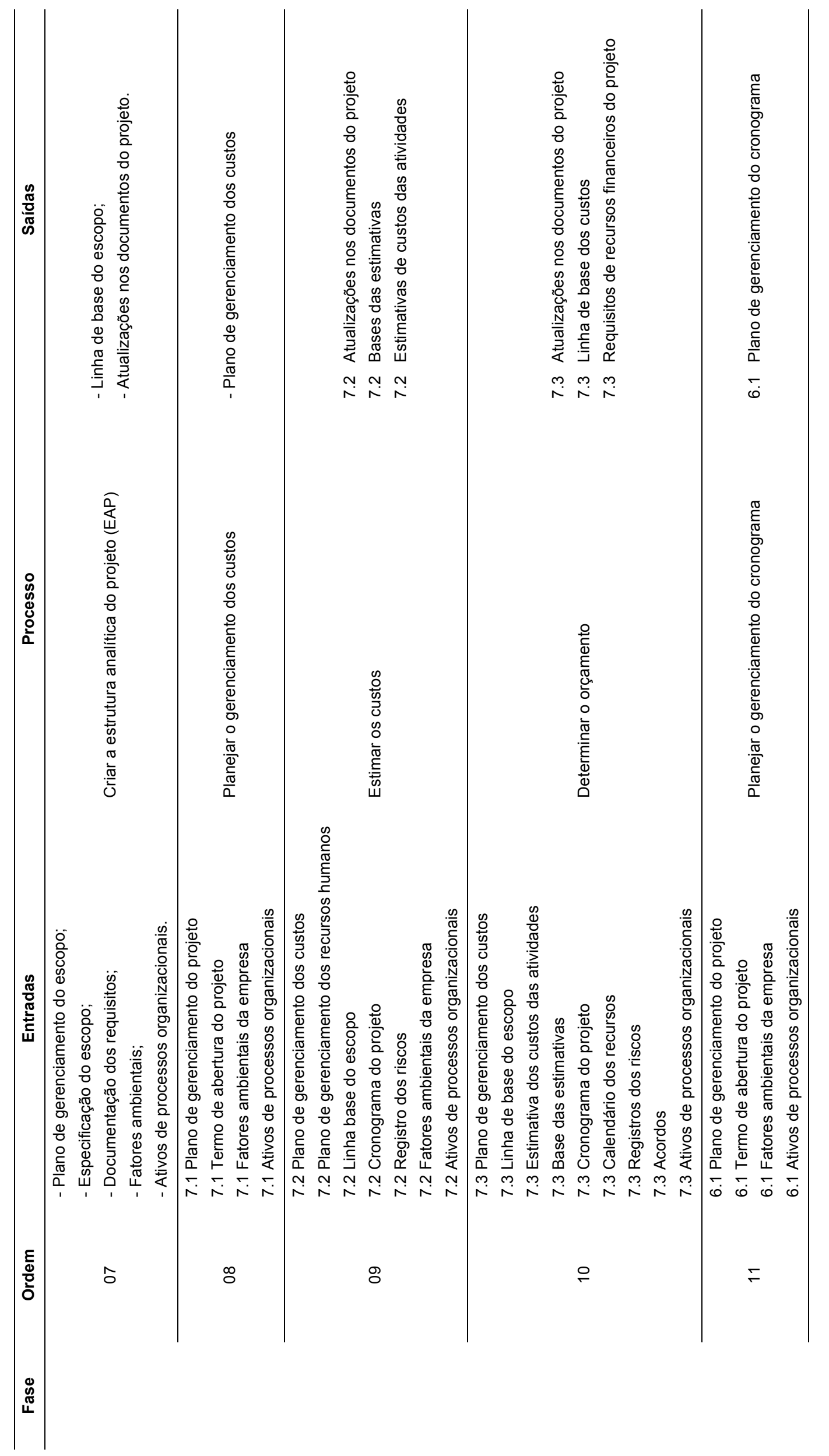




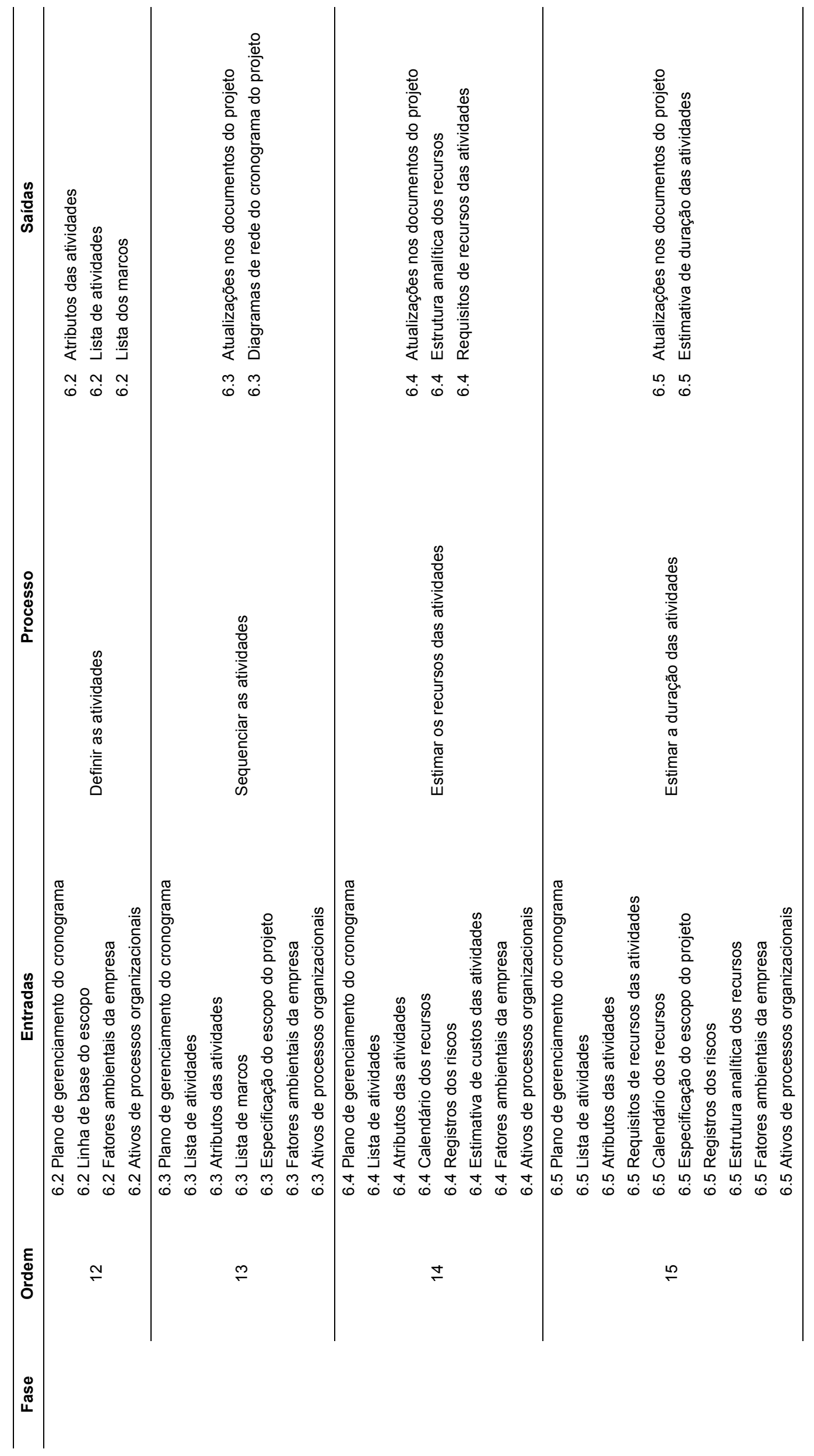




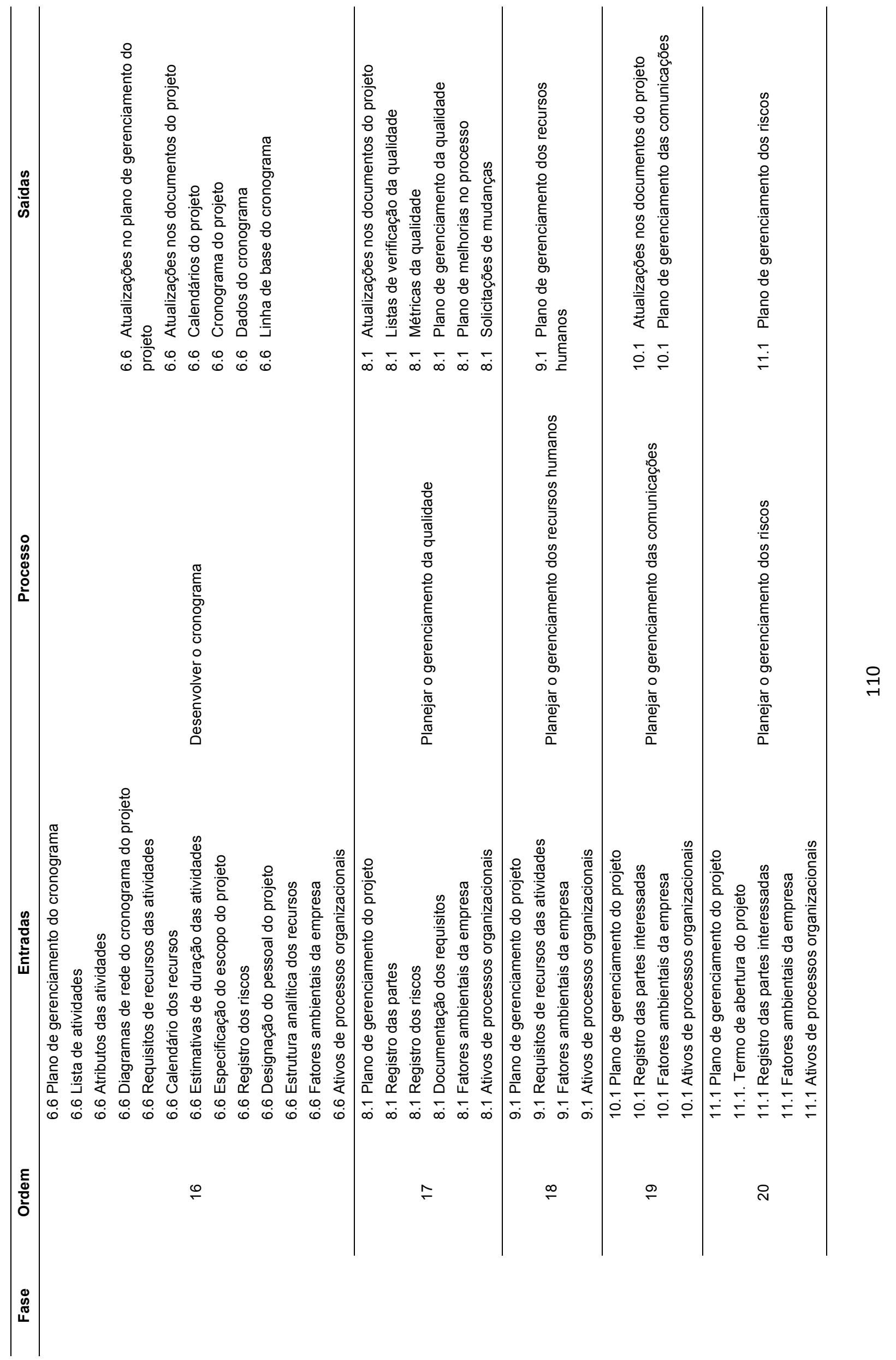




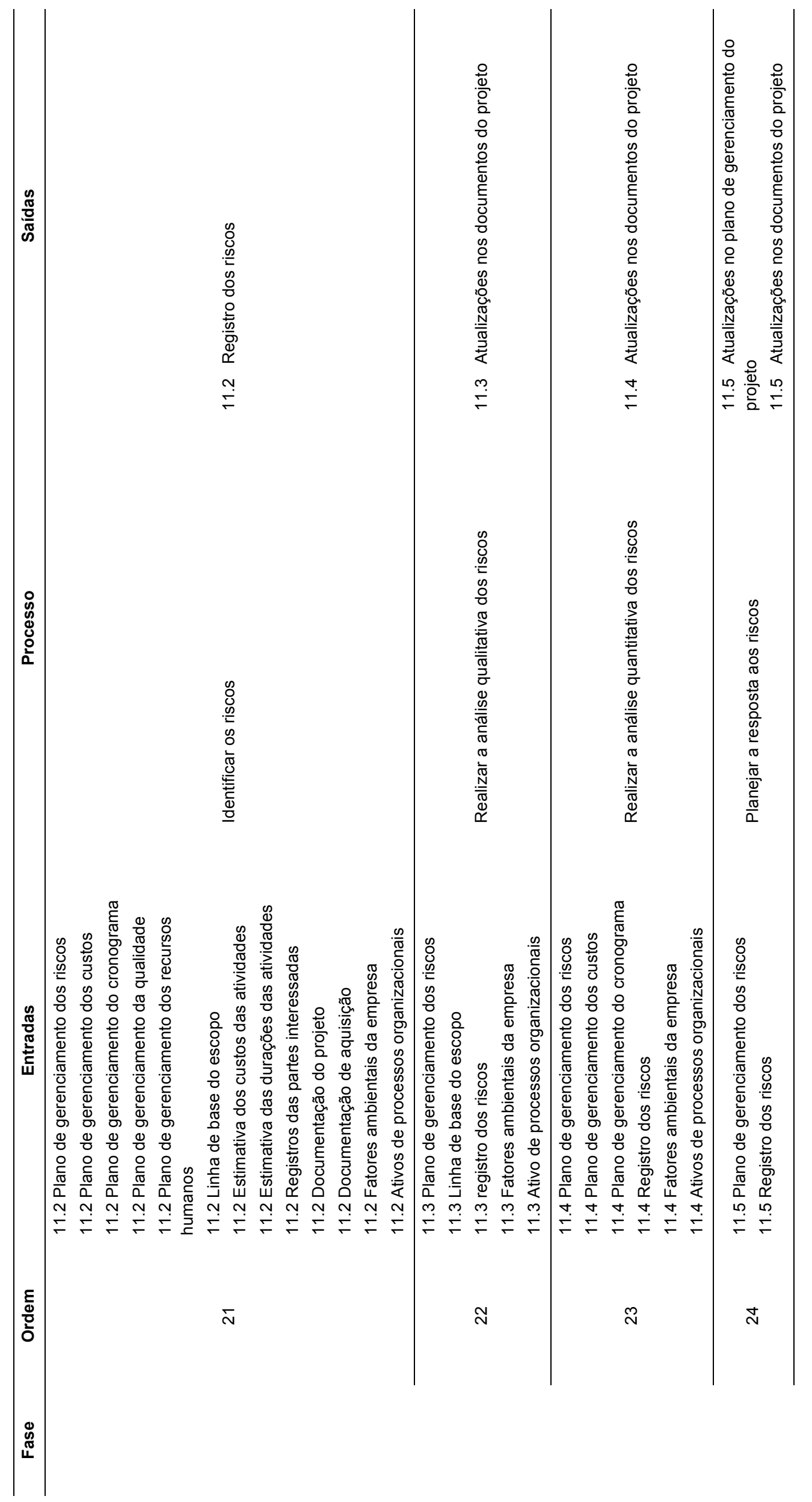




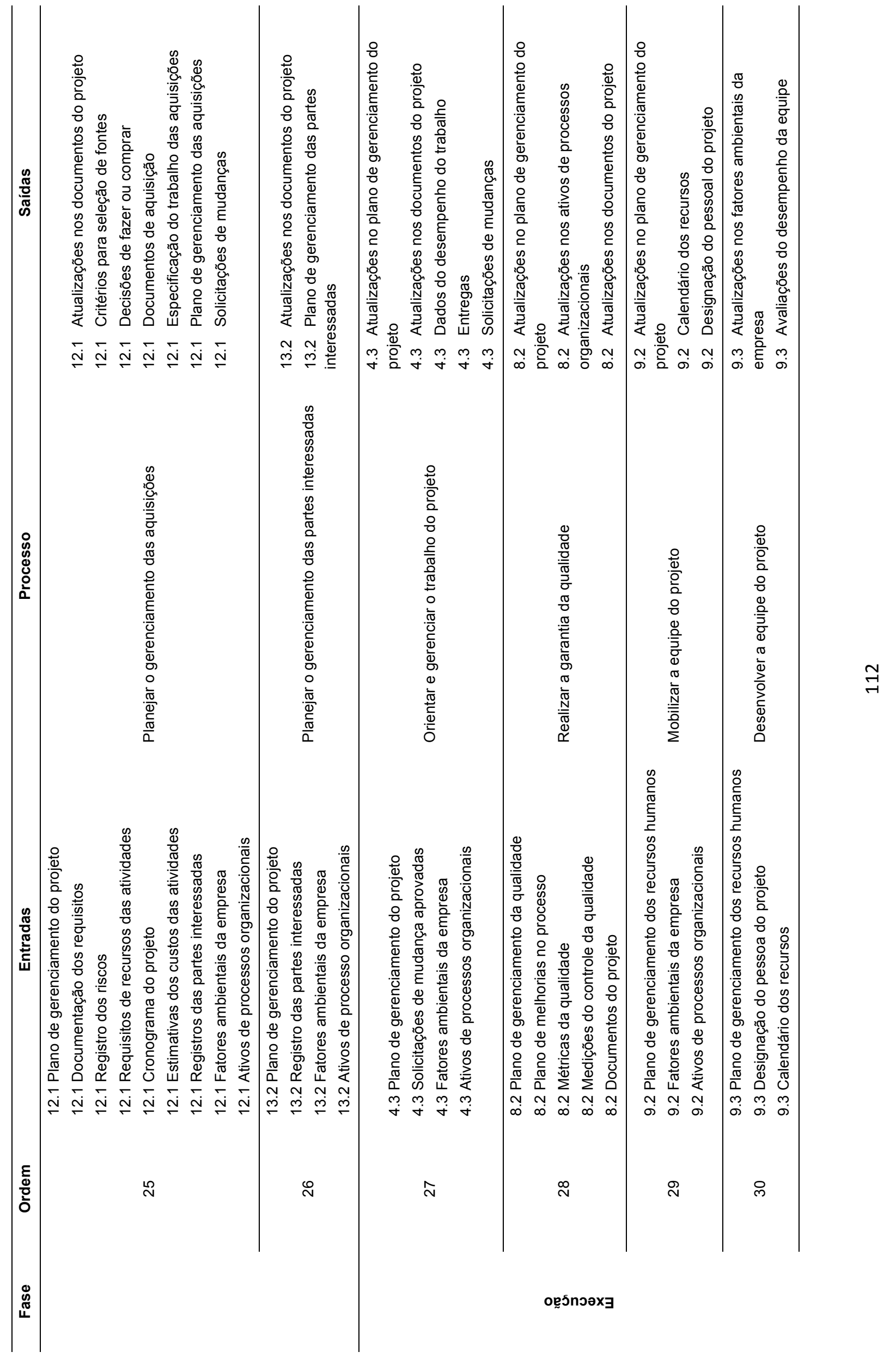




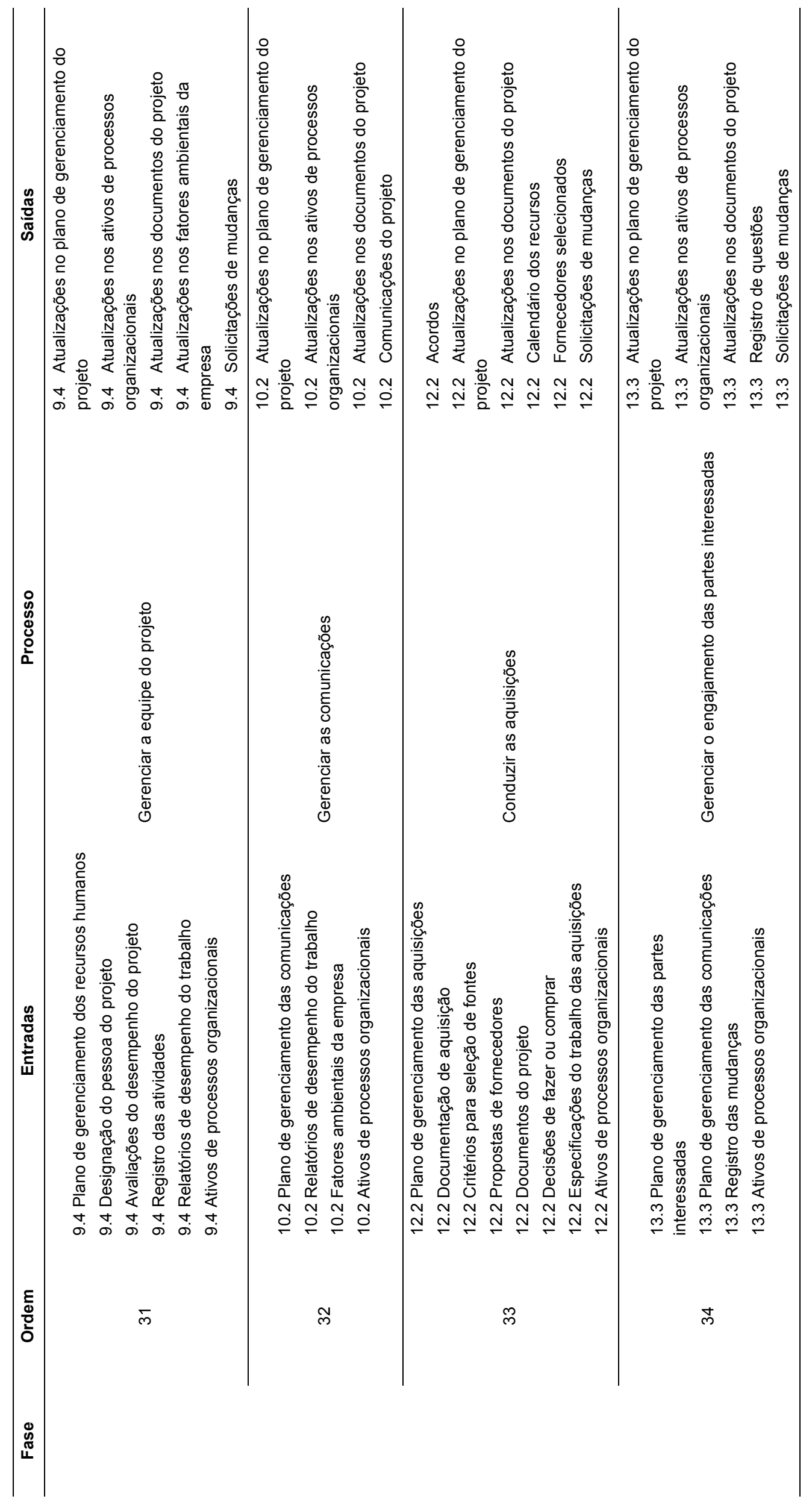




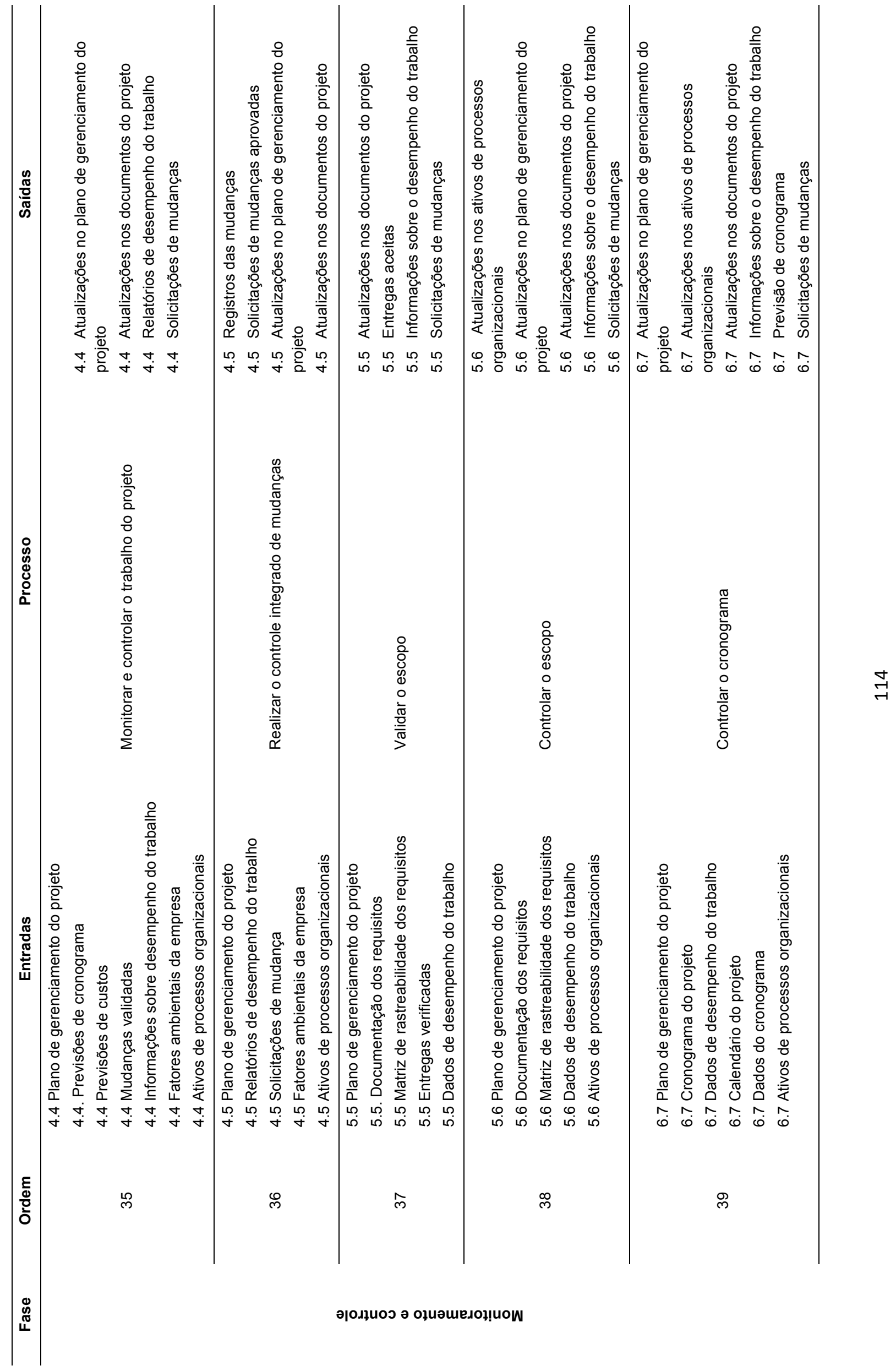




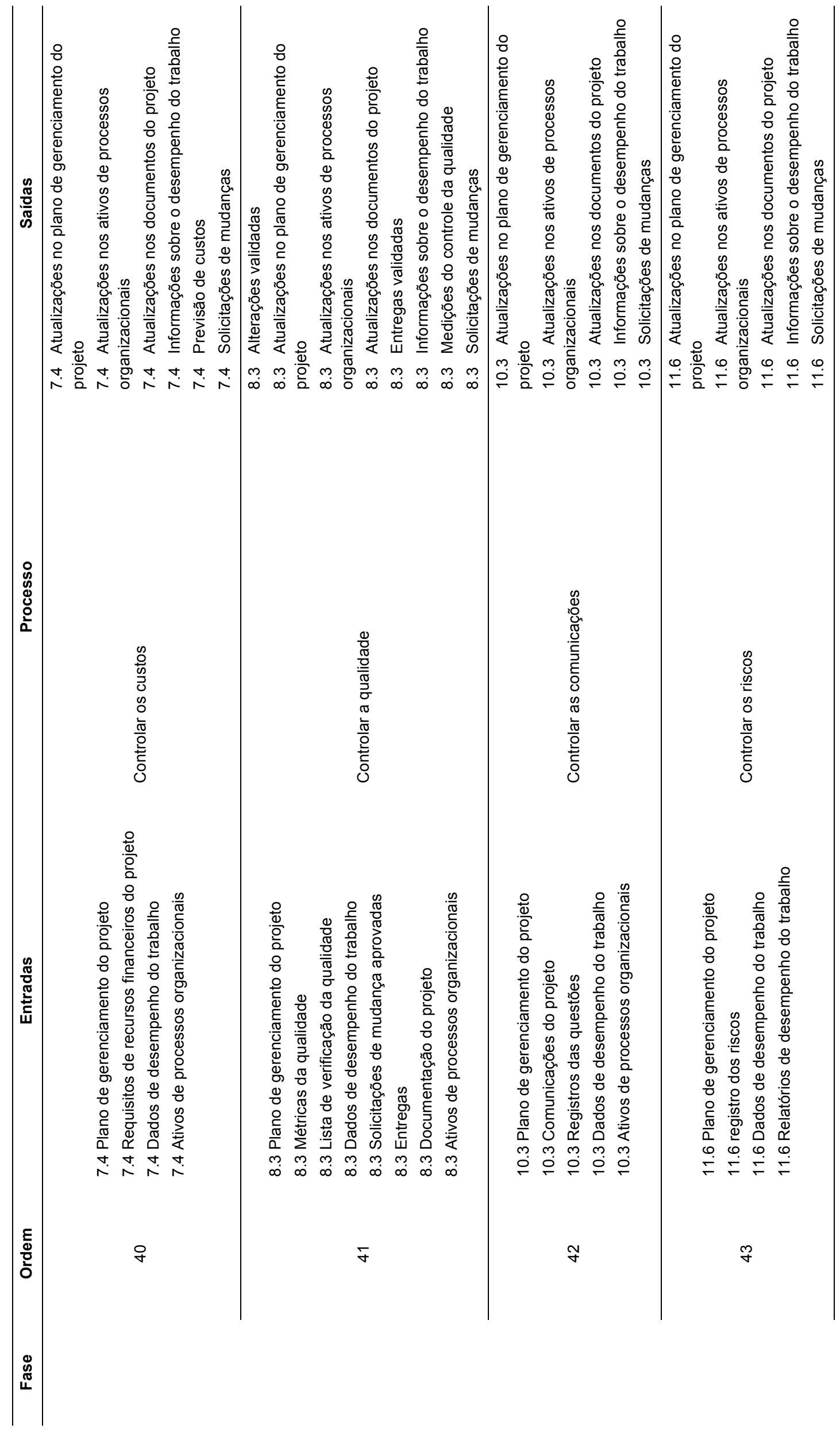




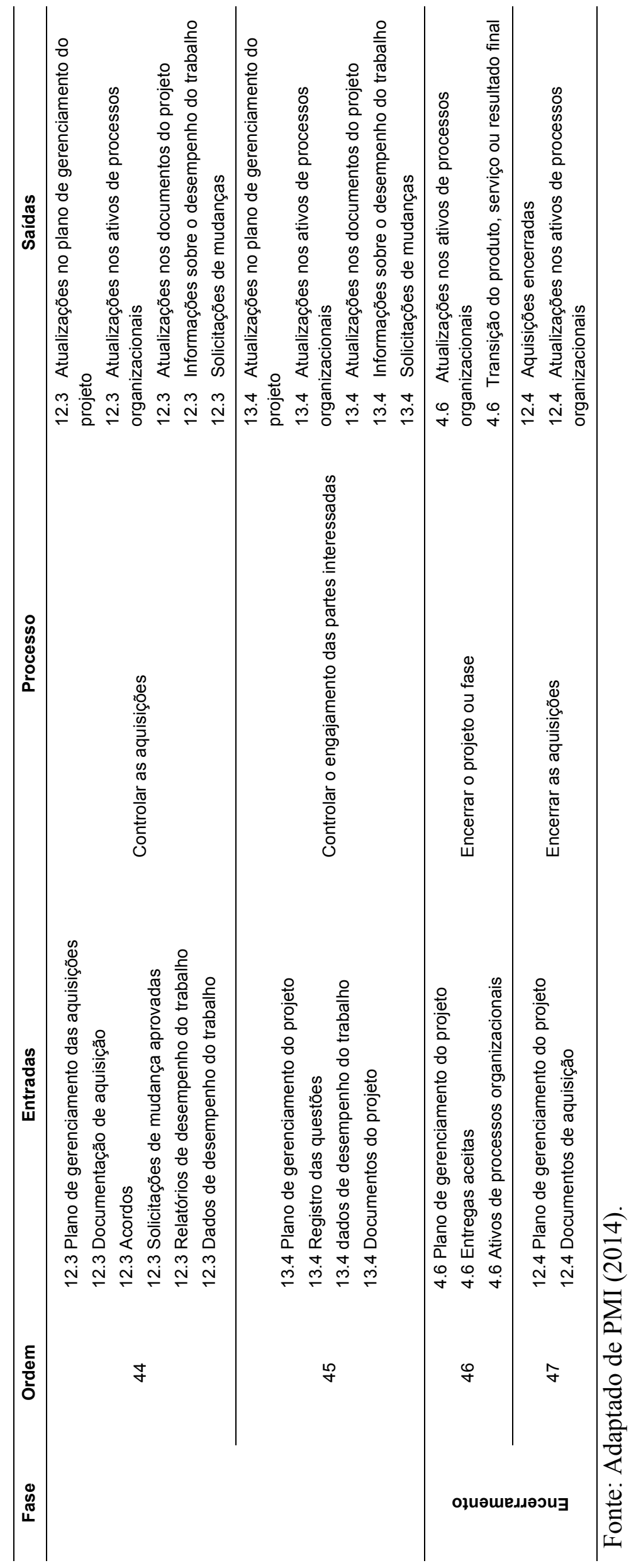

